\title{
Transgenic fluorescent zebrafish lines that have revolutionized biomedical research
}

\author{
Chong Pyo Choe ${ }^{1,2+}$, Seok-Yong Choi ${ }^{3 \dagger}$, Yun Kee ${ }^{4 *}{ }^{*}$, Min Jung Kim ${ }^{5 \dagger}$, Seok-Hyung Kim ${ }^{6 \dagger}$, Yoonsung Lee ${ }^{7 \dagger}$, \\ Hae-Chul Park ${ }^{8+}$ and Hyunju Ro ${ }^{9 \dagger}$
}

\begin{abstract}
Since its debut in the biomedical research fields in 1981, zebrafish have been used as a vertebrate model organism in more than 40,000 biomedical research studies. Especially useful are zebrafish lines expressing fluorescent proteins in a molecule, intracellular organelle, cell or tissue specific manner because they allow the visualization and tracking of molecules, intracellular organelles, cells or tissues of interest in real time and in vivo. In this review, we summarize representative transgenic fluorescent zebrafish lines that have revolutionized biomedical research on signal transduction, the craniofacial skeletal system, the hematopoietic system, the nervous system, the urogenital system, the digestive system and intracellular organelles.
\end{abstract}

Keywords: Zebrafish, Transgenic, Fluorescent, Signal, Skeletal, Hematopoietic, Nervous, Urogenital, Digestive, Organelle

\section{Background}

Zebrafish (Danio rerio or Brachydanio rerio) are freshwater fish native to South Asia and were first described scientifically in 1822 by the Scottish physician Francis Hamilton in the monograph entitled An account of the fishes found in the river Ganges and its branches, an ichthyological masterpiece [1]. In this monograph, he referred to the zebrafish as "this beautiful fish I found in the Kosi river, where it grows to about two inches in length (Fig. 1).' The genus name 'Danio' came from the Bengali word 'Dhani', which means rice or rice paddy. One and a half century later, zebrafish made its debut in the biomedical research fields with a George Streisinger's milestone paper entitled Production of clones of homozygous diploid zebra fish (Brachydanio rerio) [2]. In 1988,

\footnotetext{
*Correspondence: yunkee@kangwon.ac.kr

${ }^{\dagger}$ Chong Pyo Choe, Seok-Yong Choi, Yun Kee, Min Jung Kim, Seok-

Hyung Kim, Yoonsung Lee, Hae-Chul Park and Hyunju Ro have equally contributed to this work

${ }^{4}$ Division of Biomedical Convergence, College of Biomedical Science, Kangwon National University, Chuncheon 24341, Republic of Korea

Full list of author information is available at the end of the article
}

the Westerfield group first reported that foreign DNA fragments (5.2-kb linearized plasmid) could be integrated into the zebrafish genome and transmitted through the germline [3]. In 1997, the Lin group reported the creation of a transgenic zebrafish line expressing green fluorescent protein (GFP) in a cell-specific manner. They microinjected into one-cell stage zebrafish embryos promoter sequences of GATA-1, an erythroid-specific transcription factor, fused to GFP, and confirmed expression of GFP in the GATA-1 ${ }^{+}$cells in F1 and F2 zebrafish [4]. Since then, numerous transgenic zebrafish lines expressing fluorescent proteins in a molecule, intracellular organelle, cell or tissue specific manner (referred to as transgenic fluorescent zebrafish lines hereafter) have been generated. As zebrafish embryos are small and transparent, molecules, intracellular organelles, cells or tissues of interest in the transgenic fluorescent zebrafish lines can be easily visualized and tracked in real time and in vivo. As such, they have revolutionized biomedical research on cell biology, developmental biology, genetics, toxicology, human disease pathobiology and drug development. As of April 29, 


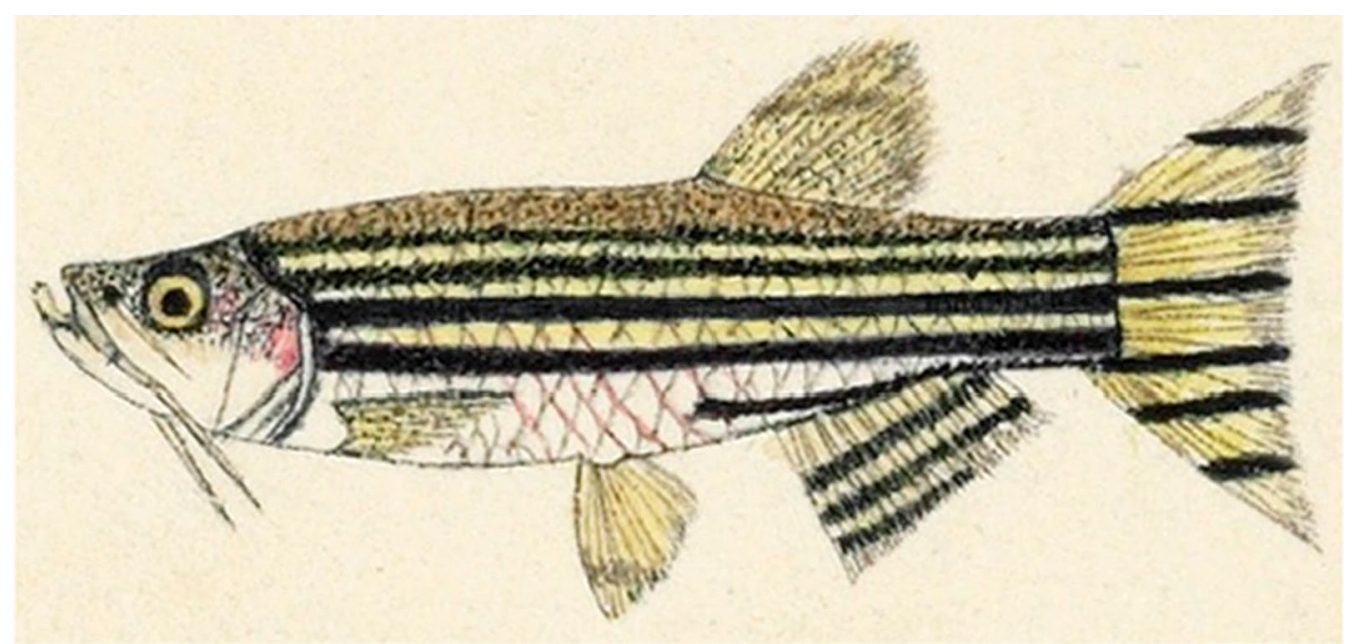

Fig. 1 Illustration of zebrafish drawn by Francis Hamilton. Credit: @The Trustees of the Natural History Museum, London, United Kingdom

2021, the Zebrafish Information Network (ZFIN) [5] displays 8960 transgenic zebrafish lines expressing GFP.

In this review, we summarize the representative transgenic fluorescent zebrafish lines that have been extensively used in biomedical research as well as some of their primary applications.

\section{Main text}

\section{Signal transduction}

Early embryonic zebrafish development is tightly regulated by various signaling cascades that should be sequentially activated in restricted domains and time windows $[6,7]$. The default state of the fertilized embryos is the ventral fate, determined by the expression of maternal genes related to Transforming growth factor beta (TGF$\beta)$ including radar, bone morphogenetic protein 2 (bmp2), bmp4 and bmp7 [7-9]. Ventral tissue specification during early embryonic development is abruptly interrupted at the onset of maternal-zygotic transition stage by the expression of various BMP antagonists such as bozozok, noggin and chordin. The expression of these genes is triggered by the canonical Wnt (Wnt/ $\beta$-catenin) and Fibroblast growth factor (FGF) signaling, and is restricted to putative organizer regions $[7,10]$. Formation of these organizer regions is a prerequisite for the subsequent anterior-posterior (AP) body axis specification. The AP patterning is a complex process triggered by maternal Wnt $/ \beta$-catenin signaling whose activity is required for the induction of Nodal, another TGF- $\beta$ related signaling, whereby FGF expression is stimulated in both organizer and blastoderm margin [6, 7]. Ectopically expressed Nodal results in severe embryonic dorsalization as it antagonizes BMP signaling, while the depletion of Nodal disrupts mesendoderm specification, leaving ectoderm unaffected [6, 7]. These signaling pathways also play critical roles in later embryonic development, especially in left-right patterning and in organogenesis.

Various transgenic zebrafish lines have been generated to study the aforementioned signaling pathways as well as the consequences of their hypo- or hyper-activation. To study the role of BMP signaling, Pyati et al. generated a transgenic zebrafish line integrating into its genome a dominant negative BMP receptor fused to GFP under the control of heat shock promoter [ $\mathrm{Tg}$ (hsp70l:dnBmprGFP)] (Table 1). With this transgenic line, they were able to delineate the roles of BMP signaling before and after mid-gastrulation by exposing the line to heat shock at different developmental stages [11]. To visualize BMP signaling in live embryos, several transgenic lines have been generated expressing various fluorescent proteins under the control of BMP responsive element adopted from mouse inhibitor of differentiation-1 enhancer: $T g$ (hsp70l:dnBmpr-GFP), $\quad T g(B m p R E-A A V m l p: E G F P)$, $T g(B R E-A A V m l p: d 2 G F P)$ and $T g(B R E-A A V m l p: d m K O 2)$ [12-15]. EGFP indicates enhanced GFP. To track Nodal activity, Dubrelle et al. measured the nuclear accumulation of Smad2, the hallmark of Nodal signaling activation. To accurately quantify the nucleo-cytoplasmic ratio of Smad2, they generated a transgenic zebrafish line expressing GFP-Smad2 ubiquitously, and then observed the graded nuclear accumulation of GFP-Smad2 along the diffused Nodal gradient from vegetal to animal axis during blastula stage [16].

Several lines are available to study Wnt/ $\beta$-catenin signaling in live embryos. In the $T g$ (top:GFP) transgenic line, the fluorescent reporter is under the control of TOPFlash comprising four consensus TCF/LEF binding elements juxtaposed to a $c$-fos minimal promoter $[17,18]$. 
Table 1 Transgenic reporter zebrafish lines targeting signal transduction pathways

\begin{tabular}{|c|c|c|c|c|c|}
\hline Construct name & Construct ID & Transgenic name & Transgenic ID & Target & References \\
\hline $\begin{array}{l}\text { Tg(hsp70l:dnXla.Bmpria- } \\
\text { GFP) }\end{array}$ & $\begin{array}{l}\text { ZDB-TGCON- } \\
\text { STRCT-070117-43 }\end{array}$ & $T g(h s p 701: d n B m p r-G F P)^{w 30}$ & ZDB-ALT-050503-2 & BMP signaling & [11] \\
\hline$T g(B M P R E: M R F P)$ & $\begin{array}{l}\text { ZDB-TGCON- } \\
\text { STRCT-110705-4 }\end{array}$ & $\operatorname{Tg}(B m p R E: m R F P)^{c j 100}$ & ZDB-ALT-110705-4 & BMP signaling & {$[13,14]$} \\
\hline Tg(BMPRE-AAV.Mlp:EGFP) & $\begin{array}{l}\text { ZDB-TGCON- } \\
\text { STRCT-110308-1 }\end{array}$ & $\begin{array}{l}\operatorname{Tg}(B m p R E- \\
\text { AAVm/p:EGFP) }\end{array}$ & ZDB-ALT-110308-1 & BMP signaling & [15] \\
\hline $\operatorname{Tg}(B R E-A A V m / p: d 2 G F P)$ & $\begin{array}{l}\text { ZDB-TGCON- } \\
\text { STRCT-110310-1 }\end{array}$ & $\operatorname{Tg}(B R E-A A V m / p: d 2 G F P)^{m w 30}$ & ZDB-ALT-110310-1 & BMP signaling & {$[15]$} \\
\hline $\operatorname{Tg}(B R E-A A V m / p: d m K O 2)$ & $\begin{array}{l}\text { ZDB-TGCON- } \\
\text { STRCT-110310-2 }\end{array}$ & $\operatorname{Tg}(B R E-A A V m / p: d m K O 2)^{m w 40}$ & ZDB-ALT-110310-2 & BMP signaling & {$[15]$} \\
\hline Tg(top:GFP) & $\begin{array}{l}\text { ZDB-TGCON- } \\
\text { STRCT-070117-137 }\end{array}$ & $\operatorname{Tg}(T O P: G F P)^{w 25}$ & ZDB-ALT-020621-4 & Wnt signaling & {$[17,18]$} \\
\hline Tg(7xTCF-XIa.Sia:GFP) & $\begin{array}{l}\text { ZDB-TGCON- } \\
\text { STRCT-110113-1 }\end{array}$ & Tg(7xTCF-Xla.Siam:GFP)ia4 & ZDB-ALT-110113-1 & Wnt signaling & [19] \\
\hline $\begin{array}{l}\text { Tg(7xTCF-XIa.Sia:NLS- } \\
\text { mCherry) }\end{array}$ & $\begin{array}{l}\text { ZDB-TGCON- } \\
\text { STRCT-110113-2 }\end{array}$ & $\begin{array}{l}\text { Tg(7xTCF-Xla. } \\
\text { Siam:nlsmCherry) }\end{array}$ & ZDB-ALT-110113-2 & Wnt signaling & [19] \\
\hline $\operatorname{Tg}(k d r l: E G F P)$ & $\begin{array}{l}\text { ZDB-TGCON- } \\
\text { STRCT-070117-47 }\end{array}$ & $\operatorname{Tg}(k d r: E G F P)^{s 843}$ & ZDB-GENO-050916-7 & Vascular endothelial cells & [19] \\
\hline $\operatorname{Tg}(T i e 2: E G F P)$ & $\begin{array}{l}\text { ZDB-TGCON- } \\
\text { STRCT-070117-80 }\end{array}$ & $\operatorname{Tg}(T i e 2: E G F P)^{5849}$ & ZDB-ALT-050916-12 & Vascular endothelial cells & [19] \\
\hline $\operatorname{Tg}(m y \mid 7: E G F P)$ & $\begin{array}{l}\text { ZDB-TGCON- } \\
\text { STRCT-070117-164 }\end{array}$ & $\operatorname{Tg}(m y \mid 7: E G F P)^{\text {twu34 }}$ & ZDB-ALT-050809-20 & Heart muscle & [19] \\
\hline $\operatorname{Tg}($ sox 10:mRFP) & $\begin{array}{l}\text { ZDB-TGCON- } \\
\text { STRCT-080321-2 }\end{array}$ & $\operatorname{Tg}($ sox 10:mRFP) viv234 & ZDB-ALT-080321-3 & $\begin{array}{l}\text { Olfactory bulb, iridophore, } \\
\text { glial cells, neural crest and } \\
\text { nervous system }\end{array}$ & [19] \\
\hline Tg(hsp70l:dkk1b-GFP) & $\begin{array}{l}\text { ZDB-TGCON- } \\
\text { STRCT-070403-1 }\end{array}$ & $\operatorname{Tg}(h s p 70 l: d k k 1-G F P)^{w 32}$ & ZDB-ALT-070403-1 & Dkk1b & [19] \\
\hline Tg(hsp70l:wnt8a-GFP) & $\begin{array}{l}\text { ZDB-TGCON- } \\
\text { STRCT-070403-3 }\end{array}$ & $\operatorname{Tg}(h s p 70: w n t 8 a-G F P)^{w 34}$ & ZDB-ALT-070403-3 & Wnt8a & [19] \\
\hline $\operatorname{Tg}(f l i 1: E G F P)$ & $\begin{array}{l}\text { ZDB-TGCON- } \\
\text { STRCT-070117-94 }\end{array}$ & $\operatorname{Tg}(f l i 1: E G F P)^{y 1}$ & ZDB-ALT-011017-8 & $\begin{array}{l}\text { Pharyngeal arch, endothe- } \\
\text { lial cells and skeletogenic } \\
\text { precursors }\end{array}$ & {$[19,20,23]$} \\
\hline $\operatorname{Tg}$ (dusp6:d2EGFP) & $\begin{array}{l}\text { ZDB-TGCON- } \\
\text { STRCT-071017-3 }\end{array}$ & $\operatorname{Tg}(d u s p 6: d 2 E G F P)^{p t 6}$ & ZDB-ALT-071017-3 & FGF signaling & [20] \\
\hline Tg(hsp70l:dnfgfr 1a-EGFP) & $\begin{array}{l}\text { ZDB-TGCON- } \\
\text { STRCT-070117-101 }\end{array}$ & $T g$ (hsp70l:dnfgfr1-EGFP) ${ }^{p d 1}$ & ZDB-ALT-060322-2 & FGF signaling & {$[21,22]$} \\
\hline Tg(fabp10a:dnfgfr1-EGFP) & $\begin{array}{l}\text { ZDB-TGCON- } \\
\text { STRCT-131120-6 }\end{array}$ & $\begin{array}{l}\text { Tg(fabp 10a:dnfgfr1- } \\
\text { EGFP) }\end{array}$ & ZDB-ALT-131120-24 & $\begin{array}{l}\text { FGF signaling specifically } \\
\text { in liver }\end{array}$ & [22] \\
\hline
\end{tabular}

Also developed are transgenic fluorescent zebrafish lines in which GFP or nuclear mCherry is driven by the enhancer region of minimal promoter of Xenopus gene siamois with seven tandem repeats of the TCF/LEF binding elements: $\operatorname{Tg}(7 x T C F-X l a . S i a m: G F P), \operatorname{Tg}(7 x T C F-$ Xla.Siam:nlsmCherry), $\operatorname{Tg}(k d r: E G F P), \quad T g(T i e 2: E G F P)$, Tg(myl7:EGFP), Tg(sox10:mRFP), Tg(hsp70l:dkk1-GFP), $\operatorname{Tg}$ (hsp70:wnt8a-GFP) and Tg(fli1:EGFP) [19]. With these reporter lines, Moro et al. identified zebrafish tissues sensitive to canonical Wnt stimuli including the hypothalamus, the gill arches and rakers, the olfactory bulb and the cloacal aperture. In contrast to the canonical Wnt signaling, transgenic zebrafish lines have not been used to study non-canonical Wnt signaling, to the best of our knowledge. Therefore, it would be challenging to explore zebrafish planar cell polarity governed by the non-canonical Wnt signaling in real time and in vivo.

As the endogenous expression of dual specificity phosphatase 6 (dusp6, also called $M k p 3$ ) is directly controlled by FGF signaling throughout zebrafish development, Molina et al. introduced destabilized EGFP under the control of the isolated $d u s p 6$ promoter. The resulting $\operatorname{Tg}($ dusp6:EGFP) is highly sensitive to FGF signaling and allows for the visualization of FGF responsive tissues [20]. Moreover, as $\operatorname{Tg}(d u s p 6: E G F P)$ is easily sensitized by specific FGF signaling chemical antagonists, this reporter embryos are very useful to identify compounds that alter FGF signaling. On the other hand, to suppress 
FGF signaling in developing embryos, dominant negative FGF receptor ( $d n-f g f r 1)$ was exploited for the transgenesis. Initially, Hsp70 promoter was adopted to generate $T g$ (hsp70l:dnfgfr1-EGFP) zebrafish that can be activated by moderate heat stimuli [21]. Later on, Tsai et al. generated transgenic zebrafish in which $d n-f g f r 1$ is expressed specifically in the liver using a hepatocyte specific promoter, a liver fatty acid binding protein (lfabp) promoter. This adult Tg(fabp10a:dnfgfr1-EGFP) manifested liver pathology such as hepatic steatosis and cholestasis, suggesting that the maintenance of hepatic FGF signaling is required for lipid homeostasis [22].

\section{The craniofacial skeletal system Introduction}

Formation of the craniofacial skeleton is an intricate process that requires a series of developmental events mediated by cells derived from the neural crest (NC), endoderm, mesoderm, and ectoderm. The craniofacial skeleton is largely derived from cranial neural crest $(\mathrm{CNC})$ cells that populate the pharyngeal arches [24, 25]. From there, CNC cells become skeletogenic precursors called ectomesenchyme and then chondrocytes and osteoblasts that will subsequently form facial cartilages and bones, respectively [24-26]. While the $\mathrm{CNC}$ is an important transient cell population for the development of craniofacial skeleton, the pharyngeal endoderm, mesoderm, and ectoderm are required for the $\mathrm{CNC}$ to form the craniofacial skeleton. During embryogenesis, the head ectoderm forms a series of infoldings, termed clefts, and the pharyngeal endoderm develops a series of outpocketings, termed pouches $[27,28]$. The endodermal pouches, together with the ectodermal clefts, segment the pharyngeal arches and have important signaling functions in the survival and differentiation of CNC cells during craniofacial skeleton development [27, 29]. While the head mesoderm of the pharyngeal arches is primarily of myogenic origin, it also contributes to craniofacial skeleton development by establishing and patterning the pharyngeal endoderm [27, 30]. Thus, to better understand craniofacial skeleton development, essentially required is the unprecedented ability to track and manipulate cells derived from the $\mathrm{NC}$, endoderm, mesoderm and ectoderm in vivo. To this end, several transgenic fluorescent zebrafish lines have been generated (Table 2) and widely used for research on craniofacial development.

\section{Ectomesenchyme transgenic lines}

The Fli1 transcription factor marks endothelial cells as well as CNC-derived skeletogenic precursors [31, 32]. Although the $T g(f l i 1: E G F P)$ transgenic line was originally generated to visualize endothelial cells [23], it has been widely used to image $\mathrm{CNC}$ cells within the pharyngeal arches. Lawson and Weinstein identified fragments containing the $5^{\prime}$ end of the fli1 gene by screening a P1-derived artificial chromosome (PAC) library, and subcloned a 15-kb PAC DNA fragment into the pGEM3zf plasmid. EGFP was placed immediately upstream of the fli1 start codon, resulting in the $T g(f l i 1: E G F P)$ transgenic construct, which was linearized with NotI and then injected into one-cell stage embryos to generate $T g(f l i 1: E G F P)$ zebrafish. This transgenic zebrafish labels the endothelial cells as well as CNC cells. During craniofacial skeleton development, this line expresses EGFP in post-migratory CNC cells in the pharyngeal arches. To understand the early stage of craniofacial skeleton formation, this line, along with the $T g$ (sox10:EGFP) line that expresses EGFP in NC including the $\mathrm{CNC}$, has been used to visualize the skeletogenic precursors. For example, this line was adopted to study the roles of the variant histone H3.3, BMPs and inhibitor of DNA binding 2a (Id2a) in ectomesenchyme potential of the CNC [33, 34] as well as to correlate defects in pharyngeal pouches with later defects in the condensation of CNC cells to form the craniofacial skeleton $[27,35]$.

\section{Cartilage and bone transgenic lines}

In addition to the transgenic reporters marking the $\mathrm{CNC}$ and skeletogenic precursors, a number of transgenic lines have been developed to image different cell types within the differentiated skeleton in vivo. These include $\operatorname{Tg}(s p 7: E G F P), \quad \operatorname{Tg}$ (RUNX2:EGFP) and $T g$ (osteocalcin:EGFP) for osteoblasts, and $\mathrm{Tg}$ (col2ala:EGFP) and $\mathrm{Tg}$ (sox9a:EGFP) for chondrocytes. Sp7 (Osterix) and RUNX2 are expressed in committed osteoblast progenitors, and Osteocalcin (Bone $\gamma$-carboxyglutamate protein [Bglap]) in late osteoblasts [36].

Sp7 is a transcription factor that is expressed in osteoblasts but not chondrocytes, making it an excellent marker of osteoblasts [37]. Although a 4.1-kb upstream regulatory region of the medaka $s p 7$ gene was used to drive mCherry or nuclear GFP expression in zebrafish [38], this transgenic line did not completely recapitulate expression pattern of endogenous zebrafish $s p 7$ [39, 40]. To overcome this discrepancy, the Kimmel group wished to generate the transgenic $s p 7$ reporter using a regulatory region of the zebrafish $s p 7$ [39]. Since the regulatory elements necessary for zebrafish $s p 7$ expression were not known, they used bacterial artificial chromosome (BAC) mediated transgenesis to drive EGFP expression under the control of the sequences upstream of $s p 7$. Using an E. coli recombination machinery, they inserted a DNA fragment containing EGFP and a kanamycin resistant cassette into the start codon of the $s p 7$ coding sequence 
Table 2 Transgenic reporter zebrafish lines targeting the craniofacial-skeletal system

\begin{tabular}{|c|c|c|c|c|c|}
\hline Construct name & Construct ID & Transgenic name & Transgenic ID & Target & References \\
\hline $\operatorname{Tg}(f i 1: E G F P)$ & $\begin{array}{l}\text { ZDB-TGCON- } \\
\text { STRCT-070117-94 }\end{array}$ & $\operatorname{Tg}(f l i 1: E G F P)^{y 1}$ & ZDB-ALT-011017-8 & $\begin{array}{l}\text { Pharyngeal arch, endothe- } \\
\text { lial cells and skeletogenic } \\
\text { precursors }\end{array}$ & [23] \\
\hline $\begin{array}{l}\text { Tg(sox10:GAL4-VP16-IRES- } \\
\text { EGFP) }\end{array}$ & $\begin{array}{l}\text { ZDB-TGCON- } \\
\text { STRCT-120523-1 }\end{array}$ & $\begin{array}{l}\text { Tg(sox10:GAL4-VP16-IRES- } \\
\text { EGFP) }\end{array}$ & ZDB-ALT-120523-1 & NCs and CNS & [34] \\
\hline $\operatorname{Tg}(s p 7: E G F P)$ & $\begin{array}{l}\text { ZDB-TGCON- } \\
\text { STRCT-100402-2 }\end{array}$ & $\operatorname{Tg}(s p 7: E G F P)^{b 1212}$ & ZDB-ALT-100402-1 & Osteoblasts & [41] \\
\hline $\begin{array}{l}\text { Tg(Hsa.RUNX2-Mmu. } \\
\text { Fos:EGFP) }\end{array}$ & $\begin{array}{l}\text { ZDB-TGCON- } \\
\text { STRCT-120209-6 }\end{array}$ & $\begin{array}{l}\operatorname{Tg}(\mathrm{Hsa} \cdot R \cup N X 2-M m u \\
\text { Fos:EGFP) }\end{array}$ & ZDB-ALT-120209-60 & Osteoblasts & {$[46-49]$} \\
\hline Tg1(Ola.Bglap:EGFP) & $\begin{array}{l}\text { ZDB-TGCON- } \\
\text { STRCT-110713-1 }\end{array}$ & $\operatorname{Tg1} 1(O / a . B g l a p: E G F P)^{h u 4008}$ & ZDB-ALT-1 10713-1 & Late osteoblasts & {$[36,42,46,47]$} \\
\hline $\operatorname{Tg}(r r . c o l 2 a 1 a .2: E G F P)$ & $\begin{array}{l}\text { ZDB-TGCON- } \\
\text { STRCT-111205-2 }\end{array}$ & $\operatorname{Tg}(r r . c o l 2 a 1 a .2: E G F P)^{n u 13}$ & ZDB-ALT-111205-4 & Chondrocytes & [54] \\
\hline $\operatorname{Tg}(-1.7 \mathrm{col} 2 \mathrm{a} 1 \mathrm{a} a \mathrm{EGFP}-\mathrm{CAAX})$ & $\begin{array}{l}\text { ZDB-TGCON- } \\
\text { STRCT-111205-1 }\end{array}$ & $\begin{array}{l}\operatorname{Tg}(-1.7 \mathrm{Ccol} 2 \mathrm{a} \text { 1a:EGFP- } \\
\text { CAAX) }\end{array}$ & ZDB-ALT-111205-1 & Chondrocytes & {$[57]$} \\
\hline $\operatorname{Tg}(f \circ x p 2 . A: E G F P)$ & $\begin{array}{l}\text { ZDB-TGCON- } \\
\text { STRCT-100412-4 }\end{array}$ & $\operatorname{Tg}(f \circ x p 2 . A: E G F P)^{z c 42}$ & ZDB-ALT-100412-5 & Chondrocytes & {$[60,61]$} \\
\hline $\operatorname{Tg}(f \circ x p 2 . A: E G F P)$ & $\begin{array}{l}\text { ZDB-TGCON- } \\
\text { STRCT-100412-4 }\end{array}$ & $\operatorname{Tg}(f \circ x p 2 . A: E G F P)^{2 c 81}$ & ZDB-ALT-111214-1 & Chondrocytes & {$[62-64]$} \\
\hline Tg(her5PAC:EGFP) & $\begin{array}{l}\text { ZDB-TGCON- } \\
\text { STRCT-070117-155 }\end{array}$ & $\operatorname{Tg}(\text { her5PAC:EGFP) })^{\text {ne1939 }}$ & ZDB-ALT-050919-8 & $\begin{array}{l}\text { Mid-hindbrain, pharyngeal } \\
\text { endoderm and pouch }\end{array}$ & {$[65]$} \\
\hline $\operatorname{Tg}(-3.4$ her5:EGFP) & $\begin{array}{l}\text { ZDB-TGCON- } \\
\text { STRCT-070117-9 }\end{array}$ & $\operatorname{Tg}(-3.4 \text { her5:EGFP) })^{\text {ne1911 }}$ & ZDB-ALT-050919-4 & $\begin{array}{l}\text { Mid-hindbrain and phar- } \\
\text { yngeal endoderm }\end{array}$ & {$[65]$} \\
\hline $\operatorname{Tg}(50 \times 17: G F P)$ & $\begin{array}{l}\text { ZDB-TGCON- } \\
\text { STRCT-070117-57 }\end{array}$ & $\operatorname{Tg}(50 \times 17: G F P)^{5870}$ & ZDB-ALT-061228-2 & Pharyngeal endoderm & {$[74-77]$} \\
\hline $\begin{array}{l}\text { Tg(nkx2.3:GAL4- } \\
\text { VP16,myl7:EGFP) }\end{array}$ & $\begin{array}{l}\text { ZDB-TGCON- } \\
\text { STRCT-130610-1 }\end{array}$ & $\begin{array}{l}\operatorname{Tg}(n k \times 2.3: G A L 4- \\
\text { VP16,myl7:EGFP) }\end{array}$ & ZDB-ALT-130610-2 & Pharyngeal pouch & {$[67]$} \\
\hline $\begin{array}{l}\text { Tg(UAS:CFP-ECO. } \\
\text { NfsB, myI7:EGFP) }\end{array}$ & $\begin{array}{l}\text { ZDB-TGCON- } \\
\text { STRCT-130610-7 }\end{array}$ & $\begin{array}{l}\mathrm{Tg}(\text { UAS:CFP-ECO. } \\
\text { NfsB, myl7:EGFP) }\end{array}$ & ZDB-ALT-130610-8 & Gal4/UAS system & {$[67]$} \\
\hline $\operatorname{Tg}(n k \times 2.3: E G F P-d v / 2)$ & $\begin{array}{l}\text { ZDB-TGCON- } \\
\text { STRCT-130610-3 }\end{array}$ & $\operatorname{Tg}(n k \times 2.3: E G F P-d v / 2)^{e l 303}$ & ZDB-ALT-130610-4 & Pharyngeal pouch & {$[67]$} \\
\hline $\operatorname{Tg}(n k \times 2.3: a l c a m a-E G F P)$ & $\begin{array}{l}\text { ZDB-TGCON- } \\
\text { STRCT-130610-4 }\end{array}$ & $\operatorname{Tg}(n k \times 2.3: \text { alcama-EGFP) })^{e / 304}$ & ZDB-ALT-130610-5 & Pharyngeal pouch & {$[67]$} \\
\hline $\operatorname{Tg}(n k \times 2.5: E G F P)$ & $\begin{array}{l}\text { ZDB-TGCON- } \\
\text { STRCT-120828-5 }\end{array}$ & $\operatorname{Tg}(n k \times 2.5: E G F P)^{e / 83}$ & ZDB-ALT-120828-8 & $\begin{array}{l}\text { Cardiogenesis and head } \\
\text { mesoderm }\end{array}$ & {$[67,84]$} \\
\hline $\begin{array}{l}\text { Tg }(n k \times 2.5: G A L 4- \\
\text { VP16, myl7:EGFP) }\end{array}$ & $\begin{array}{l}\text { ZDB-TGCON- } \\
\text { STRCT-130610-2 }\end{array}$ & $\begin{array}{l}\operatorname{Tg}(n k \times 2.5: G A L 4- \\
\text { VP16, myl7:EGFP) }\end{array}$ & ZDB-ALT-130610-3 & $\begin{array}{l}\text { Cardiogenesis and head } \\
\text { mesoderm }\end{array}$ & [67] \\
\hline
\end{tabular}

in a BAC harboring the full $s p 7$ sequences. The resulting BAC $\operatorname{Tg}(s p 7: E G F P)$ construct was used to generate a transgenic line via BAC transgenesis technology [41]. In this transgenic line, EGFP expression reproduced endogenous $s p 7$ expression in the otic primordium and skeletal structures, including osteoblasts. In the adult transgenic fish, EGFP was detected in skeletal elements, such as the tail fin bony rays, and regenerating fin rays post-amputation [39]. In vivo imaging of $\operatorname{Tg}(s p 7: E G F P)$ line revealed that a population of $s p 7: E G F P^{-}$cells is a key source of repair chondrocytes in jawbone regeneration [42]. In addition, this line contributed to produce epigenome maps, including DNA methylation and chromatin accessibility, in $s p 7: E G F P^{+}$osteoblasts from uninjured and regenerating fins [43].
$\operatorname{Tg}(R U N X 2: E G F P)$ is another transgenic line that has been extensively used for in vivo imaging of osteoblasts. The transcription factor Runx2 along with Sp7 is critical to osteoblast differentiation in zebrafish and mammals, rendering it an excellent marker of osteoblasts [4, $44,45]$. The Weidinger group originally generated the $\operatorname{Tg}(R U N X 2: E G F P)$ to study the cellular basis of fin regeneration in adult zebrafish [46]. They utilized a 557-bp multispecies-conserved regulatory element located in the last intron of the human RUNX2 gene. They cloned it into the Tol2 transposon vector pGWcfosEGFP, containing the $c F o s$ minimal promoter and EGFP, thereby generating the $T g$ (Hsa.RUNX2-Mmu.Fos:EGFP) construct, with which they created $\operatorname{Tg}(H s a$.RUNX2:EGFP) line using the Tol2 transposon system. This line expresses EGFP in all 
newly forming bones of the craniofacial and appendicular skeleton from embryo to adult [46], making it suitable to investigate bone development and regeneration. For example, the in vivo imaging of GFP expression or wholemount in situ hybridization (WISH) against $g f p$ RNA in this line demonstrated that mature osteoblasts dedifferentiate to form pre-osteoblasts following fin amputation or bone fracture, and that NF- $\mathrm{KB}$ signaling negatively regulates osteoblast dedifferentiation [46-48]. Timelapse imaging analysis of this line to explore dynamics of skull bone formation showed that $\mathrm{Sp} 7$ is required for the maturation and proliferation control of RUNX2:EGFP ${ }^{+}$ early osteoblasts [49].

Osteocalcin is a late osteoblast marker. To generate an osteocalcin reporter, the Weidinger group first cloned the $3.7-\mathrm{kb}$ promoter sequence of the medaka (Oryzias latipes) osteocalcin and inserted it into the upstream region of EGFP in pBluescript vector containing I-SceI meganuclease sites flanking the insert [50]. The resulting construct was used to create a osteocalcin reporter line $\mathrm{Tg}$ (osteocalcin:EGFP) using I-SceI mediated transgenesis [46]. This line was used to demonstrate that zebrafish osteoblasts dedifferentiate into osteogenic precursor cells in the fractured bony fin ray and skull [47], and that repair chondrocytes dedifferentiate into osteoblasts during zebrafish jawbone regeneration [42].

A better understanding of craniofacial skeleton development entails transgenic lines that can visualize cartilage development as well. As such, $T g$ (col2a1a:EGFP) and $\operatorname{Tg}(\operatorname{sox} 9 a: E G F P)$ lines were generated to illuminate chondrocyte formation and distribution during cartilage development. Collagen is the most abundant protein in the extracellular matrix [51,52] and type II collagen is an important component of cartilage [53]. Zebrafish has two paralogs of col2a1, the col2ala and col2a1b, of which col2a1a is robustly expressed in all craniofacial chondrocytes, making it an excellent marker for this cell type [54]. Dale and Topczewski identified a regulatory element in the col2a1a locus, termed R2, located from - 1720 to - 1411 bp of the transcription start site (TSS). Using the Multistep Gateway Recombination system (Invitrogen) and the Tol2kit $[55,56]$, they fused the R2 element to a minimal promoter containing a carp TATA box and the adenovirus E1b promoter upstream of EGFP, generating the $T g(r$.col2a1a.2:EGFP) construct. They also created the $\operatorname{Tg}(-1.7$ col2a1a:EGFP-CAAX) construct with the entire 1.7-kb fragment upstream of the TSS. Both resulting transgenic lines, $\operatorname{Tg}($ rr.col2a1a.2:EGFP) and $\mathrm{Tg}(-1.7$ col2a1a:EGFP-CAAX), express EGFP in craniofacial cartilage. These lines helped uncover that Wnt9a is required for palatal extension [57], and that Iroquois transcription factor inhibits chondrocyte maturation at the hyoid joint [58]. The entire $1.7-\mathrm{kb}$ upstream sequence was used to drive guanine nucleotide exchange factor subunit RIC1 and its downstream targets in chondrocytes, which revealed the underlying mechanism of RIC1-linked Mendelian syndrome [59].

The transgenic zebrafish line sox $9 a^{z c 81 T g}$, commonly known as $\operatorname{Tg}(\operatorname{sox} 9 a: E G F P)$, has been also widely used for in vivo imaging of craniofacial chondrocytes. Interestingly, the $\operatorname{Tg}(\operatorname{sox} 9 a: E G F P)$ line was generated inadvertently. To generate a transgenic reporter visualizing the central nervous system (CNS) during development, the Dorsky group isolated a 9.7-kb DNA fragment from the foxP2 locus, and used it to build the $\operatorname{Tg}($ foxp2.A:EGFP) construct via Gateway technology [60]. They then microinjected the resulting constructs into zebrafish embryos at one-cell stage, and raised the embryos to adulthood. While screening F1 embryos from founder zebrafish, they noted one founder whose embryos expressed EGFP in the pharyngeal arches where endogenous foxp 2 is not expressed. This finding suggested that in the genome of this founder, EGFP expression was driven by a nearby promoter rather than by a foxP 2 promoter per se. Indeed, further investigation revealed that the $\operatorname{Tg}(f \circ \mathrm{xp} 2 . A$ :EGFP) insertion locus in the genome was located approximately $120-\mathrm{kb}$ upstream of the sox9a TSS [61]. As a result, F1 zebrafish from the founder was termed $\operatorname{Tg}(\operatorname{sox} 9 a$ :EGFP) line instead of $\operatorname{Tg}($ foxp 2.A:EGFP) line. About $55 \mathrm{~h}$ postfertilization (hpf) at which $\mathrm{Tg}(f l i 1: E G F P)$ expression in the CNC-derived ectomesenchyme is abolished in the pharyngeal arches, the $\operatorname{Tg}(\operatorname{sox} 9 a: E G F P)$ line expresses EGFP in early cartilage rudiments developing in these arches [61]. This line was used to uncover the role of sox9a-expressing cells in musculoskeletal integration in the zebrafish jaw [62]. Time-lapse imaging of craniofacial skeleton development in this line revealed that the opercle and the adjacent ceratohyal cartilage migrate in a coordinated manner [63], and that gaps in sox9a:EGFP cartilage exhibit hallmarks of joint identity during craniofacial skeleton development [64].

\section{Pharyngeal endoderm transgenic lines}

Absence of the endoderm or the pharyngeal endoderm derived pharyngeal pouches leads to severe defects in the craniofacial skeleton of zebrafish, indicating that these tissues are critical to the craniofacial skeleton development [30]. To better understand how the pharyngeal endoderm and pouches regulate craniofacial skeleton development, transgenic reporter lines were needed to visualize these tissues during craniofacial development. The first transgenic reporter illuminating pharyngeal endoderm formation was the $\operatorname{Tg}$ (her5PAC:EGFP) transgenic line [65], although this line was originally generated to investigate the development of midbrain-hindbrain $(\mathrm{MH})$ domain of the 
vertebrate embryonic neural tube in vivo. For this purpose, Tallafuss and Bally-Cuif isolated a PAC containing the complete set of regulatory elements of her5, the first reported gene expressed in the $\mathrm{MH}$ domain, and inserted EGFP within exon 2 of the her 5 genomic region via ET-mediated homologous recombination [66]. The resulting construct was used to establish the $\operatorname{Tg}$ (her5PAC:EGFP) line via the PAC-mediated transgenesis [65]. In this line, EGFP expression reproduces endogenous her 5 expression in the $\mathrm{MH}$ domain and the pharyngeal endoderm, making this line the first transgenic reporter of the pharyngeal endoderm. They also generated the $T g(-3.4$ her5:EGFP) line harboring EGFP driven by 3.4-kb fragment upstream of the her5 TSS, which mirrors the EGFP expression pattern in the $\operatorname{Tg}$ (her5PAC:EGFP) line almost completely [65]. Since then, both lines have been extensively used. For example, time-lapse imaging analysis in the $T g(-3.4 h e r 5: E G F P)$ line revealed that the pharyngeal pouches are formed by the branching morphogenesis and that Wnt11r and Wnt4a are required for this morphogenesis [67]. This line was also employed to correlate defects in the pharyngeal endoderm with later defects in the craniofacial cartilage development [68-70].

Together with the $\operatorname{Tg}($ her5:EGFP) line, the $\operatorname{Tg}(\operatorname{sox} 17: G F P)$ line has been used to illuminate development of the endoderm, including the pharyngeal endoderm. In zebrafish and mammalian embryogenesis, a transcription factor Sox17 is the key regulator of the specification and morphogenesis of endodermal epithelia, making it an excellent pan-endoderm marker [71-73]. Chung and Stainier originally generated the $T g(\operatorname{sox} 17: G F P)$ line to identify progenitors of endodermal organs such as the liver, pancreas and intestine [74]. They first isolated the $4.2-\mathrm{kb}$ upstream regulatory region from the pEGFP1 sox 17 promoter plasmid constructed by Yutaka Kikuchi and cloned it into a Tol2 GFP transposon vector, thereby building the $\operatorname{Tg}(\operatorname{sox} 17: G F P)$ construct, with which they created the $\mathrm{Tg}($ sox 17:GFP) line using the Tol2 transposon system. In this line, GFP is expressed in almost all endodermal cells, including the endodermal cells at 50\% epiboly, the progenitors of the liver, pancreas and intestine, the condensing foregut endodermal cells, and the pharyngeal endodermal cells [74-77]. Various studies on the endoderm and craniofacial skeleton development have benefited from the $T g(\operatorname{sox} 17: G F P)$ line. For example, in vivo imaging of sox 17:GFP $P^{+}$pharyngeal endoderm correlated defects in the morphogenesis of pharyngeal endoderm with later defects in craniofacial cartilage morphology [76, 78, 79]. In addition, this line has been used to understand the developmental mechanisms underlying formation of the endodermal organs such as the liver, pancreas, and intestine [74, 80, 81].

During craniofacial development, a population of cells in the pharyngeal endoderm forms a series of pouches that governs the development of pharyngeal arches and craniofacial skeleton $[27,30]$. To better understand the role for this specific population of cells in the development of craniofacial skeleton, transgenic lines expressing reporter genes specifically in the pouches were needed. Zebrafish $n k x 2.3$ is specifically expressed in the developing pouches, but not in the pharyngeal endoderm, making it an excellent marker of the pouches [82]. To illuminate the morphogenesis of pouches, the Crump group created a $\operatorname{Tg}(n k x 2.3: G a l 4-V P 16)$ line that can drive expression of any gene governed by the UAS promoter specifically in the pouches [67]. They isolated a 5.5$\mathrm{kb}$ regulatory region upstream of the $n k x 2.3$ locus and made the $\operatorname{Tg}(n k x 2.3: G A L 4-V P 16, m y l 7: E G F P)$ construct using the Gateway technology, with which they developed the $\operatorname{Tg}(n k x 2.3: G a l 4-V P 16, m y l 7: E G F P)$ line using the Tol2 transposon system [67]. The Tg(UAS:CFP-Eco. $N f s B, m y l 7: E G F P$ ) line expresses cyan fluorescent protein (CFP) fused to nitroreductase (NTR), an E. coli enzyme that converts the prodrug metronidazole (MTZ) to cytotoxin, specifically in the pharyngeal pouches throughout pouch morphogenesis in a pattern consistent with endogenous $n k x 2.3$ expression $[67,82]$. The combination of $\operatorname{Tg}(n k x 2.3: G a l 4-V P 16, m y l 7: E G F P)$ line and $\operatorname{Tg}(U A S: C F P$ Eco.NfsB,myl7:EGFP) line revealed the pouch-specific requirements for effectors of Wnt and Dvl signaling during pouch morphogenesis. In addition, a number of transgenic constructs has been generated with the 5.5$\mathrm{kb}$ upstream regulatory region of $n k x 2.3$, including the $\operatorname{Tg}(n k x 2.3: E G F P-d v l 2)$ and $T g(n k x 2.3:$ alcama-EGFP), time-lapse imaging of which showed correlation between the rearrangement of pouch cells and the dynamic subcellular localization of Dishevelled (Dvl) and Alcama during pouch formation [67].

\section{Pharyngeal mesoderm transgenic lines}

The head mesoderm has been reported as an important source of multiple signaling necessary for pouch formation associated with the craniofacial skeleton development [27, 30]. However, the absence of transgenic reporters that can mark and manipulate the head mesoderm in live animals, has hindered the progress in understanding the cellular and molecular mechanism by which the head mesoderm controls the development of the pharyngeal endoderm and craniofacial skeleton. In zebrafish, $n k x 2.5$ is the earliest heart field marker, and expressed farther posteriorly to the mesoderm adjacent to the pharyngeal arches and pouches during craniofacial skeleton development [83]. Thus, a transgenic 
$n k x 2.5$ reporter was expected to label the head meso$\mathrm{derm}$. The Crump group isolated a 6 -kb upstream regulatory region from the $n k x 2.5$ locus and established the $\operatorname{Tg}(n k x 2.5: E G F P)$ construct using the Gateway technology [67], with which they created the $\operatorname{Tg}(n k x 2.5$ :EGFP) line with the Tol2 transposon system [67, 84]. This line faithfully reproduced endogenous $n k x 2.5$ expression in the second heart field during cardiogenesis and in the head mesoderm during craniofacial skeleton development $[67,84]$. The $\operatorname{Tg}(n k x 2.5: E G F P)$ line has been used in many studies. For example, time-lapse imaging of pharyngeal pouch formation revealed unexpected dynamic interactions between the head mesoderm and the pharyngeal endoderm during craniofacial skeleton development, along with the roles of Wnt11r and FGF8a in the mesoderm-endoderm interaction $[67,85]$. In addition, a number of transgenic constructs, including the $\operatorname{Tg}(n k x 2.5: G A L 4-V P 16, m y l 7: E G F P)$, has been generated with the 6-kb upstream regulatory region of $n k x 2.5$ [67]. In conjunction with the $\operatorname{Tg}(U A S: C F P-N T R)$, the $\operatorname{Tg}(n k x 2.5: G a l 4-V P 16, m y l 7: E G F P)$ line uncovered the requirement for $n k x 2.5: C F P-N T R^{+}$mesoderm in the development of pouches and craniofacial skeleton [67].

\section{The hematopoietic system Introduction}

The hematopoietic genes and regulatory networks as well as all mature blood lineages and maturation intermediates in zebrafish are evolutionarily conserved [86]. As in mammals, zebrafish hematopoiesis initiates with sequential primitive and definitive waves of blood cells [87]. First, the primitive waves of hematopoiesis produce erythrocytes and macrophages through unipotent precursors from the embryonic mesoderm. Afterwards, the definitive hematopoietic stem cells (HSCs) capable of generating all mature blood cell types arise from the hemogenic endothelium [88]. The transgenic reporter lines labelling each and every type of blood lineages have been introduced over the past two decades, allowing for real time imaging in live zebrafish and purification of blood cells of interest through fluorescence activated cell sorting (FACS) [89]. Here, we summarize the representative zebrafish transgenic reporter lines labeling distinct blood populations (Table 3), which have been used for characterizing various hematopoietic events.

\section{Erythroid transgenic lines}

During early embryogenesis, red blood cells (RBCs) arise from the intermediate cell mass (ICM), which is derived from the posterior lateral mesoderm (PLM) [90, 91]. To label RBCs, the Lin group at Medical College of Georgia generated a $T g($ gatala:GFP) zebrafish by injecting the linearized construct G1-GM2 comprising the zebrafish
GATA-1 promoter and GFP (GM2) into embryos [92]. The GATA-1 promoter construct is a 5.6-kb DNA fragment from a GATA-1 genomic fragment containing the $5^{\prime}$ upstream region of the GATA-1 TSS. This line has been used to study embryonic erythropoiesis [92], thrombocyte development [93], hematopoietic transplantation [86], leukemia [94] and real-time cardiac pumping dynamics [95].

\section{Myeloid transgenic lines}

Myeloid cell populations including macrophages and neutrophils originate from anterior lateral mesoderm [96]. To uncover the molecular and cellular mechanisms regulating neutrophil-mediated inflammation in vivo, the Huttenlocher group isolated a PAC containing the zebrafish $z M P O$ promoter sequences and subcloned an 8 -kb fragment of the $z M P O 5^{\prime}$-untranslated region (UTR) into the $5^{\prime}$ region of GFP ( $z M P O: G F P$ ), producing the transgenic line $\operatorname{Tg}(m p x: G F P)$ where neutrophils express GFP under the control of myeloperoxidase promoter [97]. The Lieschke group developed a macrophage-specific reporter line to track macrophages and their interactions with neutrophils in real time and in vivo [98]. The promoter of a macrophage-specific marker mpeg1 was utilized to generate the line. The proximal $1.86-\mathrm{kb}$ DNA fragment of mpeg1 $5^{\prime}$-UTR was subcloned into the $5^{\prime}$ region of either EGFP or mCherry, and Tol2-mediated transgenesis was performed to generate $\operatorname{Tg}($ mpeg1:EGFP) or Tg(mpeg1:mCherry) that expresses EGFP or mCherry in the macrophages, respectively [98]. $\operatorname{Tg}(m p x: G F P)$, Tg(mpeg1:EGFP) and Tg(mpeg1:mCherry) lines can address behavior and development of myelopoids such as phagocytosis of senescent neutrophils [98]. These lines have been used to take real-time and in vivo images of responses against inflammation [97], wound detection [99], neutrophil motility [100], the role of eosinophils in immunity [101], tissue regeneration [102, 103], cardiac wound healing[104], metabolic diseases [105], microglia development [106], axon degeneration [107] and HSC development [108].

\section{HSC transgenic lines}

The first primitive wave of hematopoiesis is followed by the definitive wave of hematopoiesis, wherein HSCs give rise to distinct types of blood cells. HSCs can both selfrenew and differentiate into all mature blood cell types over the lifetime of an individual [109]. Definitive HSCs arise from hemogenic endothelium, a special population of endothelial cells within the ventral wall of the dorsal aorta that transdifferentiates into HSCs [88]. Specified HSCs budding out from the hemogenic endothelium circulate through the vascular system, eventually homing to the caudal hematopoietic tissue $(\mathrm{CHT})$ where HSCs 
Table 3 Transgenic reporter zebrafish lines targeting the hematopoietic system

\begin{tabular}{|c|c|c|c|c|c|}
\hline Construct name & Construct ID & Transgenic name & Transgenic ID & Target & References \\
\hline Tg(gata1a:GFP) & $\begin{array}{l}\text { ZDB-TGCON- } \\
\text { STRCT-070117-153 }\end{array}$ & Tg(gatala:GFP) 19781 & ZDB-ALT-051018-2 & Red blood cells & {$[92]$} \\
\hline $\operatorname{Tg}(m p x: G F P)$ & $\begin{array}{l}\text { ZDB-TGCON- } \\
\text { STRCT-070118-1 }\end{array}$ & $\operatorname{Tg}(m p x: G F P)^{u w m 1}$ & ZDB-ALT-070502-1 & Neutrophils & [97] \\
\hline $\operatorname{Tg}($ mpeg 1:EGFP) & $\begin{array}{l}\text { ZDB-TGCON- } \\
\text { STRCT-120117-1 }\end{array}$ & $\operatorname{Tg}(m p e g 1: E G F P)^{g / 22}$ & ZDB-ALT-120117-1 & Macrophages & [98] \\
\hline Tg(mpeg 1:mCherry) & $\begin{array}{l}\text { ZDB-TGCON- } \\
\text { STRCT-120117-2 }\end{array}$ & $\operatorname{Tg}(m p e g 1: m \text { Cherry })^{9 / 23}$ & ZDB-ALT-120117-2 & Macrophages & [98] \\
\hline $\operatorname{Tg}(-6.0 i \operatorname{tg} a 2 b: E G F P)$ & $\begin{array}{l}\text { ZDB-TGCON- } \\
\text { STRCT-070117-128 }\end{array}$ & $\operatorname{Tg}(-6.0 i \operatorname{tga} 2 b: E G F P)^{1 / 2}$ & ZDB-ALT-051223-4 & $\mathrm{HSCS}$ & {$[86]$} \\
\hline $\operatorname{TgPAC}(m y b: 2 x m y b-E G F P)$ & $\begin{array}{l}\text { ZDB-TGCON- } \\
\text { STRCT-071017-1 }\end{array}$ & $\begin{array}{l}\operatorname{Tg} P A C(m y b: 2 x m y b- \\
E G F P)^{2 f 169}\end{array}$ & ZDB-ALT-071017-1 & HSCs & [112] \\
\hline Tg(Imo2:DsRed) & $\begin{array}{l}\text { ZDB-TGCON- } \\
\text { STRCT-071017-2 }\end{array}$ & $\operatorname{Tg}(\operatorname{Imo2}: \mathrm{Ds} R e d)^{2 f 73}$ & ZDB-ALT-080122-9 & Endothelium & [112] \\
\hline Tg(Mmu.Runx1:EGFP) & $\begin{array}{l}\text { ZDB-TGCON- } \\
\text { STRCT-150512-1 }\end{array}$ & $\operatorname{Tg}($ Mmu.Runx1:EGFP) cz2009 & ZDB-ALT-150512-1 & $\mathrm{HSCS}$ & [110] \\
\hline $\begin{array}{l}\text { Tg(Mmu.Runx1:NLS- } \\
\text { mCherry) }\end{array}$ & $\begin{array}{l}\text { ZDB-TGCON- } \\
\text { STRCT-150512-2 }\end{array}$ & $\begin{array}{l}\text { Tg(Mmu.Runx1:NLS- } \\
\text { mCherry) }\end{array}$ & ZDB-ALT-150512-2 & HSCS & [110] \\
\hline $\operatorname{Tg}(k d r l: C r e)$ & $\begin{array}{l}\text { ZDB-TGCON- } \\
\text { STRCT-100419-2 }\end{array}$ & $\operatorname{Tg}(k d r l: C r e)^{5898}$ & ZDB-ALT-100419-3 & $\begin{array}{l}\text { Endothelium-specific Cre } \\
\text { line }\end{array}$ & {$[88]$} \\
\hline $\begin{array}{l}\text { Tg(actb2:LOXP-STOP-LOXP- } \\
\text { DsRedEx) }\end{array}$ & $\begin{array}{l}\text { ZDB-TGCON- } \\
\text { STRCT-100301-1 }\end{array}$ & $\begin{array}{l}\text { Tg(actb2:LOXP-STOP-LOXP- } \\
\text { DsRedEx) }\end{array}$ & ZDB-ALT-100301-1 & $\begin{array}{l}\text { Cre-mediated genetic } \\
\text { switch line }\end{array}$ & [88] \\
\hline TgBAC(gata2b:KALTA4) & $\begin{array}{l}\text { ZDB-TGCON- } \\
\text { STRCT-150602-8 }\end{array}$ & TgBAC(gata2b:KALTA4)sd32 & ZDB-ALT-150602-13 & $\begin{array}{l}\text { Hemogenic endothelium- } \\
\text { specific Gal4 line }\end{array}$ & [125] \\
\hline $\operatorname{Tg}(4 x \cup A S: G F P)$ & $\begin{array}{l}\text { ZDB-TGCON- } \\
\text { STRCT-100809-1 }\end{array}$ & $\operatorname{Tg}(4 x \cup A S: G F P)^{h z m 3}$ & ZDB-ALT-100809-1 & Gal4/UAS system & {$[126,127]$} \\
\hline Tg(UAS:Cre,cryaa:Venus) & $\begin{array}{l}\text { ZDB-TGCON- } \\
\text { STRCT-150602-10 }\end{array}$ & $\operatorname{Tg}(\text { UAS:Cre,cryaa:Venus })^{2 d 17}$ & ZDB-ALT-150602-15 & Gal4/UAS system & {$[125]$} \\
\hline $\operatorname{Tg}(\operatorname{rag} 1: G F P)$ & $\begin{array}{l}\text { ZDB-TGCON- } \\
\text { STRCT-070117-55 }\end{array}$ & $\operatorname{Tg}\left(\right.$ rag 1:GFP) ${ }^{1 a 5}$ & ZDB-ALT-051001-2 & Lymphocytes & [133] \\
\hline $\operatorname{Tg}(\operatorname{rag} 2: G F P)$ & $\begin{array}{l}\text { ZDB-TGCON- } \\
\text { STRCT-070117-56 }\end{array}$ & $\operatorname{Tg}(\text { rag2:GFP) })^{\operatorname{lac}}$ & ZDB-ALT-051001-4 & Lymphocytes & [132] \\
\hline
\end{tabular}

expand and mature [110]. Afterwards, HSCs migrate to the kidney marrow to act as multipotent blood progenitor cells [111].

To label this HSC population, the Zon group generated three valuable HSC-specific transgenic reporter lines. First, the $T g$ (-6.0itga2b:EGFP) line was originally created to assess zebrafish thrombocytes and prothrombocytes, but turned out to be more specific for the HSC population [86]. The transgenic construct was generated using EGFP driven by the promoter of platelet glycoprotein IIb (itga $2 b$ ) cloned from PAC 166I10. The second transgenic line $\operatorname{Tg} P A C(m y b: 2 x m y b-E G F P)$ was generated by homologous recombination of a 3.7-kb EGFP construct into the UTR precisely before the start site of a PAC clone containing $c m y b$ [112]. Combination of $\operatorname{TgPAC}(m y b: 2 x m y b$ EGFP) and endothelium-specific $\operatorname{Tg}$ (lmo2:DsRed) labels HSCs at $36 \mathrm{hpf}$ [112]. Finally, the Zon group generated $\operatorname{Tg}$ (Mmu.Runx1:EGFP) and $\operatorname{Tg}(\mathrm{Mmu}$. Runx1:NLS-mCherry), wherein the mouse Runx $1+23$ enhancer drives either EGFP or nuclear mCherry. The double transgenic line $T g(M m u . R u n x 1: E G F P) ; \operatorname{Tg}(M m u$. Runx1:NLS-mCherry) showed consistent expression of both fluorescent proteins, confirming the HSC specific expression of the reporter in the lines [110]. To generate the transgenic construct, the Runx $1+23$ enhancer was amplified from C57/BL6 mouse genomic DNA [113]. Subsequently, the resulting Runx $1+23$ enhancer DNA fragment and the $\beta$-globin minimal promoter were simultaneously cloned into the Tol 2 plasmid. These HSC-specific transgenic lines have been used to study embryonic HSC emergence [88, 114-116], thrombocyte development [117], environmental regulation of HSCs [110], mechanosensory regulation of HSC specification $[118,119]$, brain development related to DNA damage [120] and leukemia [121].

In addition to the aforementioned reporter lines transiently expressing markers of HSC populations, several transgenic lines that permanently label HSC precursors have been also generated to understand the origin of HSCs with lineage-tracing studies. To test whether HSCs 
arise from endothelial cells in the zebrafish embryo, the Traver group used a permanent marking system consisting of a floxed reporter transgene and a Cre line driven by the endothelium-specific $k d r l$ upstream promoter/ enhancer elements [88]. The transgenic construct was generated by cloning a $6.8-\mathrm{kb}$ DNA fragment of the $k d r l$ promoter/ enhancer sequences [122] into the upstream region of a Cre recombinase. The resulting construct $\mathrm{Tg}(\mathrm{kdrl}: \mathrm{Cre})$ was subcloned into meganuclease plasmid vector, which was then linearized and injected into onecell-stage zebrafish embryos. In parallel, $\mathrm{Tg}$ (actb2: $L O X P$ STOP-LOXP-DsRedEx), a Cre-mediated genetic switch line, was generated with a $10.5-\mathrm{kb}$ upstream fragment of the $\beta$-actin promoter/enhancer followed by a $5.7-\mathrm{kb}$ floxed STOP cassette and DsRed [88]. DsRed serves as a reporter for Cre-mediated removal of the STOP cassette. The transgenic construct was ligated into the Tol2 vector [123] and the final construct was co-injected with Tol2 mRNA into one-cell stage embryos to produce the transgenic founders. This switch line undergoes excision of the STOP cassette in Cre-expressing cells, permanently marking these cells and their progeny with DsRed expression. Using these combinatorial transgenic lines, Bertrand et al. demonstrated that HSCs originate from embryonic endothelium in the adult kidney marrow. All types of blood cells from zebrafish whole kidney marrow expressed DsRed, suggesting that all the blood lineages arise from endothelial population. In addition, these lines have also been used in endocardial lineage tracing during zebrafish heart regeneration [124].

Furthermore, the Traver group narrowed down the source of HSC populations in the hemogenic endothelium in the ventral wall of the dorsal aorta. Using gata $2 b$ as the key marker for this HSC precursor cells, they generated $\operatorname{TgBAC}$ (gata2b:KALTA4) to trace cells arising from the hemogenic endothelium [125]. The Gal4 variant KalTA4 was inserted before the start site of gata $2 b$ on the BAC through BAC recombineering $[126,127]$, and the modified BAC plasmid was injected with Tol 2 mRNA into $\operatorname{Tg}(4 x U A S: G F P)$ embryos. Subsequently, the candidate founders were screened for GFP expression in the endothelium. To permanently label gata $2 b$-specific hemogenic endothelium for lineage tracing, Butko et al. used triple transgenic zebrafish lines TgBAC(gata2b:KALTA4); Tg(UAS:Cre, cryaa:Venus); $\operatorname{Tg}$ (actb2:LOXP-STOP-LOXP-DsRedEx). In this triple transgenic line, tissue-specifically expressed GAL4 turns on the UAS promoter to induce Cre, which in turn activates permanent DsRed switch in the hemogenic endothelium. The presence of DsRed ${ }^{+}$cells in the CHT, thymus and kidney in $3 \mathrm{dpf}$ embryos indicates that HSCs originate from the gata $2 b$-specific hemogenic endothelium in the dorsal aorta [125].

\section{Lymphoid transgenic lines}

Unlike the primitive wave of hematopoiesis, lymphopoiesis originates solely from definitive HSC progenitor cells [128]. rag1 and rag2 are traditionally used markers for lymphocyte populations during early zebrafish development and are expressed in the thymus and adult kidney where zebrafish lymphocyte maturation occurs [129, 130]. The Lin group generated lymphoid lineage specific transgenic reporter lines using these rag1 and rag2 drivers [131, 132]. First, $\operatorname{Tg}($ rag1:GFP) was generated using reporter constructs containing a 4.7-kb fragment $5^{\prime}$ of the zebrafish rag1 TSS. Chi-induced homologous recombination [133] inserted the GFP gene into the PAC containing the rag1 promoter [131]. In addition, to generate $\operatorname{Tg}(\mathrm{rag} 2 \mathrm{GFP})$ construct, a $6.5-\mathrm{kb}$ fragment of the rag2 TSS was subcloned from the PAC into the $5^{\prime}$ region of a modified GFP reporter gene (GM2) on pBluescript KS(-) plasmid [132]. These lymphoid-specific lines have been used to study lymphocyte development [86], olfactory neuron development [132] and T cell leukemia [134, 135].

\section{Summary}

Hematopoiesis is highly conserved in zebrafish and mammals. Over the past two decades, diverse blood-specific transgenic reporter lines along with advanced imaging technologies, FACS sorting analysis and various genetic approaches have helped further our understanding of the development and physiological roles of hematopoietic cell lineages. The increasing number of more tailored transgenic fluorescent zebrafish lines is anticipated to widen our understanding of hematopoiesis ontogeny.

\section{The nervous system \\ Habenula transgenic lines}

The habenula is an evolutionarily conserved brain area of the limbic system that connects the telencephalic nuclei to the brain stem nuclei, such as the interpeduncular nucleus (IPN), ventral tegmental area, and raphe [136]. It is implicated in various behaviors such as pain, stress, anxiety, sleep and reward [137]. Furthermore, the habenulae of many vertebrates show left-right asymmetry with respect to size and neuronal circuits, making it a good model to examine brain asymmetry [138]. To study the physiological roles and asymmetrical development of the habenula, transgenic animal models in which the habenula can be labeled and manipulated are required.

To verify the asymmetrical innervations of the zebrafish dorsal habenula, a homologous region to the mammalian medial habenula [139], Okamoto et al. cloned a 5-kb $5^{\prime}$ upstream sequence and a $0.3-\mathrm{kb}$ intron of the pou4f $f$ gene that encodes a POU-domain transcription factor into the upstream region of the zebrafish $h s p 70$ promoter 
and EGFP sequences [140], resulting in creation of the $T g$ (pou4f1-hsp70l:GFP) construct (Table 4). Subsequently, the linearized construct was microinjected into zebrafish embryos to produce transgenic zebrafish [141], in which the medial subdomain and the axonal projections of the dorsal habenula were labeled [140, 142, 143]. The labeled medial subdomain was larger in the right dorsal habenula than in the left [140]. Moreover, the axonal projections from the GFP-expressing neurons specifically terminated in the ventral and intermediate IPN [140].
In addition, Okamoto et al. developed a BAC construct to label and manipulate the zebrafish ventral habenula, a homologous region to the mammalian lateral habenula [139]. The GAL4-VP16 sequence was introduced via BAC recombineering into the $\mathrm{BAC}$ clone $(\mathrm{CH} 211$ 172G6) [144] containing the zebrafish amine oxidase copper containing 1 (aoc1) gene, a ventral habenula specific gene [139], resulting in $\operatorname{TgBAC}$ (aoc1:GAL4-VP16) construct [145]. To facilitate its genomic integration, the BAC construct was modified further by introducing an

Table 4 Transgenic reporter zebrafish lines targeting the nervous system

\begin{tabular}{|c|c|c|c|c|c|}
\hline Construct name & Construct ID & Transgenic name & Transgenic ID & Target & References \\
\hline $\operatorname{Tg}($ pou4f1-hsp70l:GFP) & $\begin{array}{l}\text { ZDB-TGCON- } \\
\text { STRCT-070117-170 }\end{array}$ & $\operatorname{Tg}(\text { pou4f1-hsp70l:GFP) })^{r w 0110 b}$ & ZDB-ALT-050317-18 & $\begin{array}{l}\text { Medial division of the } \\
\text { dorsal habenula }\end{array}$ & {$[140]$} \\
\hline TgBAC(aoc1:GAL4-VP16) & $\begin{array}{l}\text { ZDB-TGCON- } \\
\text { STRCT-150312-5 }\end{array}$ & $\begin{array}{l}\text { TgBAC(aOC1:GAL4- } \\
\text { VP16) }\end{array}$ & ZDB-ALT-150312-5 & Ventral habenula & {$[145]$} \\
\hline $\operatorname{Tg}(o l i g 2: E G F P)$ & $\begin{array}{l}\text { ZDB-TGCON- } \\
\text { STRCT-070117-167 }\end{array}$ & $\operatorname{Tg}(o l i g 2: E G F P)^{v u 12}$ & ZDB-ALT-041129-8 & OLs, RG, MNs & {$[150]$} \\
\hline $\begin{array}{l}\operatorname{Tg}(e l a v / 3: E G F P) / \\
\operatorname{Tg}(H u C: E G F P)\end{array}$ & $\begin{array}{l}\text { ZDB-TGCON- } \\
\text { STRCT-070117-150 }\end{array}$ & $\begin{array}{l}\text { Tg(elavl3:EGFP) / } \\
\operatorname{Tg}(H u C: E G F P)^{k n u 3}\end{array}$ & ZDB-ALT-060301-2 & $\begin{array}{l}\text { Differentiated neurons } \\
\text { (motor and sensory) }\end{array}$ & {$[140]$} \\
\hline $\begin{array}{l}\text { Tg(elavl3:Kaede)/ } \\
\operatorname{Tg}(\text { HuC:Kaede) }\end{array}$ & $\begin{array}{l}\text { ZDB-TGCON- } \\
\text { STRCT-070117-93 }\end{array}$ & $\begin{array}{l}\text { Tg(elavl3:Kaede) / } \\
\text { Tg(HuC:Kaede) })^{r w 0130 a}\end{array}$ & ZDB-ALT-060619-4 & $\begin{array}{l}\text { Differentiated neurons } \\
\text { (motor and sensory }\end{array}$ & {$[160]$} \\
\hline $\begin{array}{l}\text { Tg2(elav/3:GAL4)/ } \\
\operatorname{Tg} 2(\text { HuC:GAL4) }\end{array}$ & $\begin{array}{l}\text { ZDB-TGCON- } \\
\text { STRCT-130919-1 }\end{array}$ & $\begin{array}{l}\text { Tg2(elav13:GAL4) / } \\
\text { Tg2(HuC:GAL4) zf409 }\end{array}$ & ZDB-ALT-130919-2 & $\begin{array}{l}\text { Differentiated neurons } \\
\text { (motor and sensory }\end{array}$ & {$[161]$} \\
\hline $\begin{array}{l}\text { Tg(elav/3:GCaMP3) / } \\
\text { Tg(HuC:GCaMP3) }\end{array}$ & $\begin{array}{l}\text { ZDB-TGCON- } \\
\text { STRCT-131122-1 }\end{array}$ & $\begin{array}{l}\text { Tg(elav13:GCaMP3) / } \\
\operatorname{Tg}(\text { HuC:GCaMP3)ens100 }\end{array}$ & ZDB-ALT-131122-1 & $\begin{array}{l}\text { Differentiated neurons } \\
\text { (motor and sensory }\end{array}$ & {$[162]$} \\
\hline $\operatorname{Tg}(1 m b p: E G F P)$ & $\begin{array}{l}\text { ZDB-TGCON- } \\
\text { STRCT-120103-2 }\end{array}$ & $\operatorname{Tg}(1 m b p: E G F P)^{u e 1}$ & ZDB-ALT-120103-1 & $\begin{array}{l}\text { Myelin sheaths, OLs and } \\
\text { Schwann cells }\end{array}$ & {$[163]$} \\
\hline $\operatorname{Tg}(m b p: E G F P-C A A X)$ & $\begin{array}{l}\text { ZDB-TGCON- } \\
\text { STRCT-120103-3 }\end{array}$ & $\operatorname{Tg}(m b p: E G F P-C A A X)^{u e 2}$ & ZDB-ALT-120103-2 & $\begin{array}{l}\text { Myelin sheaths, OLs and } \\
\text { Schwann cells }\end{array}$ & {$[167]$} \\
\hline $\operatorname{Tg}(m b p a: G A L 4-V P 16)$ & $\begin{array}{l}\text { ZDB-TGCON- } \\
\text { STRCT-150803-1 }\end{array}$ & $\operatorname{Tg}(m b p a: G A L 4-V P 16)^{k m 5}$ & ZDB-ALT-150803-1 & $\begin{array}{l}\text { Myelin sheaths, OLs and } \\
\text { Schwann cells }\end{array}$ & {$[168]$} \\
\hline Tg(UAS:ECo.NfsB-mCherry) & $\begin{array}{l}\text { ZDB-TGCON- } \\
\text { STRCT-110215-5 }\end{array}$ & $\begin{array}{l}\text { Tg(UAS:ECO.NfsB- } \\
\text { m(herry) }\end{array}$ & ZDB-ALT-110215-7 & Gal4/UAS-NTR system & {$[168]$} \\
\hline $\operatorname{Tg}(-4.9$ sox $10: E G F P)$ & $\begin{array}{l}\text { ZDB-TGCON- } \\
\text { STRCT-070117-69 }\end{array}$ & $\operatorname{Tg}(-4.9 \text { sox } 10: E G F P)^{b a 2}$ & ZDB-ALT-050913-4 & $\begin{array}{l}\text { Neural crest derived cells } \\
\text { (Schwann, DRG) and OL } \\
\text { lineage cells }\end{array}$ & {$[180]$} \\
\hline $\operatorname{Tg}(g f a p: G F P)$ & $\begin{array}{l}\text { ZDB-TGCON- } \\
\text { STRCT-070117-154 }\end{array}$ & $\operatorname{Tg}(g f a p: G F P)^{m i 2001}$ & ZDB-ALT-060623-4 & $\begin{array}{l}\text { RGs in brain, SC, retina and } \\
\text { peripheral spinal nerves }\end{array}$ & {$[182]$} \\
\hline Tg(gfap:NTR-mCherry) & $\begin{array}{l}\text { ZDB-TGCON- } \\
\text { STRCT-160630-2 }\end{array}$ & Tg(gfap:NTR-mCherry) ${ }^{\text {scz059 }}$ & ZDB-ALT-160630-2 & $\begin{array}{l}\text { RGs in brain, SC, retina and } \\
\text { peripheral spinal nerves }\end{array}$ & {$[186]$} \\
\hline Tg(gfap:Cre-ERT2,cryaa:YFP) & $\begin{array}{l}\text { ZDB-TGCON- } \\
\text { STRCT-150902-1 }\end{array}$ & $\begin{array}{l}\text { Tg(gfap:Cre- } \\
\text { ERT2,cryaa:YFP) zd16 }\end{array}$ & ZDB-ALT-150902-1 & $\begin{array}{l}\text { RGs in brain, SC, retina and } \\
\text { peripheral spinal nerves }\end{array}$ & {$[187]$} \\
\hline $\begin{array}{l}\text { Tg(-3.9nes:GFP)/Tg(- } \\
\text { 3.9nestin:GFP) }\end{array}$ & $\begin{array}{l}\text { ZDB-TGCON- } \\
\text { STRCT-100308-3 }\end{array}$ & $\begin{array}{l}\mathrm{Tg}(-3.9 n e s: G F P) / \mathrm{Tg}(- \\
\text { 3.9nestin:GFP)zf168 }\end{array}$ & ZDB-ALT-100308-4 & NSCs & {$[183]$} \\
\hline $\operatorname{Tg}(g f a p: E G F P)$ & $\begin{array}{l}\text { ZDB-TGCON- } \\
\text { STRCT-070410-2 }\end{array}$ & $\operatorname{Tg}(g f a p: E G F P)^{n t 11}$ & ZDB-ALT-070410-12 & $\begin{array}{l}\text { RGs in brain, } S C \text {, retina and } \\
\text { peripheral spinal nerves }\end{array}$ & {$[183]$} \\
\hline TgBAC(nes:EGFP) & $\begin{array}{l}\text { ZDB-TGCON- } \\
\text { STRCT-110309-7 }\end{array}$ & TgBAC(nes:EGFP) $)^{\text {tud100 }}$ & ZDB-ALT-110309-7 & NSCs & {$[191]$} \\
\hline $\begin{array}{l}\text { Tg(UAS-E1B:DsRed,Hsa. } \\
\text { MAPT_P301L) }\end{array}$ & $\begin{array}{l}\text { ZDB-TGCON- } \\
\text { STRCT-111028-1 }\end{array}$ & $\begin{array}{l}\text { Tg(UAS-E1B:DsRed,Hsa. } \\
\text { MAPT_P301L)mde3 }\end{array}$ & ZDB-ALT-111028-1 & $\begin{array}{l}\text { Tauopathic neurons (CNS } \\
\text { neurons) }\end{array}$ & [195-199] \\
\hline $\operatorname{Tg}(s / c 6 a 3: E G F P)$ & $\begin{array}{l}\text { ZDB-TGCON- } \\
\text { STRCT-111206-9 }\end{array}$ & $\begin{array}{l}\operatorname{Tg}(\text { dat:EGFP)/ } \\
\operatorname{Tg}(\text { slc6a3:EGFP)ot80 }\end{array}$ & ZDB-ALT-111206-10 & Dopaminergic neurons & {$[202]$} \\
\hline $\operatorname{Tg}(s / c 6 a 3: C F P-N T R)$ & $\begin{array}{l}\text { ZDB-TGCON- } \\
\text { STRCT-160128-1 }\end{array}$ & $\begin{array}{l}\text { Tg(dat:CFP-NTR) / } \\
\text { Tg(slc6a3:CFP-NTR) }{ }^{o t 1413}\end{array}$ & ZDB-ALT-160128-7 & Dopaminergic neurons & {$[204]$} \\
\hline
\end{tabular}


iTol2 cassette via homologous recombination, which was then used to generate transgenic fish [146]. GAL4-VP16 driven $\mathrm{GFP}^{+}$cells were specifically localized in the ventral habenula, and their axons projected to the median raphe [145]. In this transgenic fish, optogenetics [147] and targeted toxin expression [145] can label or functionally deactivate the ventral habenula.

\section{Oligodendrocyte transgenic lines}

Multipotent neural progenitor cells produce diverse kinds of neural cells including interneurons, motor neurons and glial cells during vertebrate development. The progenitor cells of the pMN domain in the spinal cord, a part of the CNS, are the representative cell clusters for studying mechanisms underlying early neuroglia development. Since this population is specified by an oligodendrocyte lineage transcription factor 2 (Olig2), Shin et al. generated an olig2 reporter zebrafish line with $\operatorname{Tg}$ (olig2:EGFP) construct that was created by inserting EGFP into a BAC clone harboring olig2 regulatory sequences (NCBI accession number NM_178100) via BAC recombineering [148, 149]. This line visualizes progenitor cells and radial glia (RG) of the pMN domain, motor neurons (MNs), oligodendrocyte lineage cells in the spinal cord at early developmental stages, and oligodendrocytes (OLs) in the adult stage [150]. It has been extensively used to study the developmental mechanisms of MNs and OLs from olig2 ${ }^{+}$ progenitor cells [148, 151], regeneration of MNs after injury $[152,153]$ and the specification and differentiation of OLs [154]. In addition, this transgenic line has been exploited to mark cerebrospinal fluid contacting neurons in the spinal cord [155] and eurydendroid cells in the cerebellum [156].

\section{HuC transgenic lines}

$\mathrm{HuC}$, a homolog of Drosophila elav, is a vertebrate neuron-specific gene [157] that plays important roles in post-mitotic differentiation and maintenance of neuronal cells [158]. As $\mathrm{HuC}$ is critical during the early stage of neuronal differentiation, its reporter line was needed to study zebrafish neurogenesis. Thus, Park et al. cloned a 4.6-kb genomic DNA fragment upstream of zebrafish $\mathrm{HuC}$ into the $5^{\prime}$ end of the start codon of the GFP gene in CS2A(-) plasmid. The resulting construct $T g(h u c: g f p)$ was linearized and microinjected into zebrafish embryos to generate the transgenic line [159], in which all differentiated neurons in the CNS, including motor and sensory neurons, were labeled [159]. This transgenic line was used to determine the developmental status of neurons [159]. The Huc promoter derived from $\mathrm{Tg}(h u c: g f p)$ construct has been extensively used to develop diverse transgenic lines such as $\mathrm{Tg}$ (huc:kaede) using photoactivatable fluorescent proteins for lineage tracing [160],
Tg(huc:gal4) using GAL4/UAS transactivation system for the targeted gene expression [161], and $T g$ (huc:GCamp3) for the detection of neuronal activity [162].

\section{Myelination transgenic lines}

Myelin sheaths are lipid-rich, multilayered membranes around axons, and are generated by OLs in the CNS and Schwann cells in the peripheral nervous system (PNS). They are required for nerve conduction velocity, protection of the axons from environmental risk factors, and supply of some energy sources such as lactate. Upon acute injury, myelin sheaths are lost, yet later on they are regenerated by myelinating glial cells. However, in chronic demyelinating conditions such as multiple sclerosis (MS), regeneration of myelin sheaths is practically impossible. Therefore, treatment of demyelinating diseases entails our deeper understanding of formation of the myelin sheaths. Jung et al. generated transgenic zebrafish to visualize myelinating glial cells and myelin sheaths in the zebrafish CNS and PNS [163]. They constructed $T g$ (mbp:egfp) by cloning a $2-\mathrm{kb}$ regulatory element of the zebrafish myelin basic protein $(\mathrm{mbp})$ into a Tol2-GFP vector lacking the cytomegalovirus (CMV) promoter [163] and established a transgenic line using transposonmediated integration [164]. In this line, as expected, GFP specifically labeled myelin sheaths and OLs and Schwann cells from embryos to adulthood [163]. This transgenic model has aided in the investigation of the development of OLs in vivo [165] and been used for high-resolution screening of chemical compounds that regulate myelination [166]. In addition, the $m b p$ promoter in $T g(m b p: e g f p)$ was used to develop a $T g(m b p: E G F P-C A A X)$ line using membrane-targeted EGFP to study the dynamics of myelination [167]. Furthermore, using a chemogenetic ablation system, demyelination zebrafish models such as Tg(mbp:gal4vp16;uas:nfsb-mcherry) have been generated [168, 169].

\section{Neural crest cell (NCC) transgenic lines}

NCCs originate from the neural plate border and migrate to diverse locations to form various cell lineages such as neurons and glia in the PNS, craniofacial cartilage, and smooth muscle [170]. SRY-box transcription factor 10 (Sox10) is a key transcription factor for studying the ontogeny of NC [171] as Sox10 mutations are associated with developmental defects in PNS neurons, ganglia, myelin sheath, and melanocytes [172-174]. Carney et al. generated a transgenic line to monitor NC-derived cells in vivo using the $\operatorname{Tg}$ (sox10:egfp) construct [175]. They cloned a 4.9-kb genomic fragment of the zebrafish sox 10 promoter sequences into the XLT.GFPLT.CS2 + vector containing the egfp gene, and then generated a transgenic line using the linearized construct. The resulting 
line marked sox $10^{+} \mathrm{NC}$-derived cells, including Schwann cells, dorsal root ganglion and cranial ganglia [175], uncovered a role of Sox10 in the development of sensory neurons [175], and revealed mechanism underlying NC migration during craniofacial morphogenesis $[176,177]$. As Sox10 is necessary for the differentiation of OLs in the CNS [178], this transgenic line also labels OL lineage cells [179] and has been used to identify novel genes regulating the development of OL with a microarray-based assay [179].

\section{RG transgenic lines}

RG are an early form of glial cells observed during the vertebrate neural development, give rise to intermediate neural progenitors and neurons, such as neural stem cells (NSCs), and act as scaffold cells to help the new neurons migrate towards their target locations in the CNS [180, 181]. Thus, defects in the development and function of RG cause neurodevelopmental diseases such as lissencephaly (which means "smooth brain") [181], highlighting that RG is critical to CNS development. Bernardos et al. generated transgenic zebrafish, in which GFP expression was driven by the regulatory sequences of zebrafish glial fibrillary acidic protein (gfap). They cloned gfap regulatory sequences into the pEGFP-1 vector (Clontech), which was linearized and then microinjected into zebrafish embryos. The resulting $\operatorname{Tg}(g f a p: G F P)$ line displays RG in the brain, spinal cord, retina and the peripheral spinal nerves [182]. In addition, this line has been used to study the characterization of neural progenitor cells in the adult brain [183], the behavior of NSCs in the normal and injured adult brain [184], and functions of Müller glia in the adult retina [185]. Finally, the gfap promoter has been used to generate several other transgenic lines, such as $T g(g f a p: n f s b$-mcherry) that can ablate RG [186] and $\operatorname{Tg}\left(g f a p: C r e^{E R T 2}\right)$ that can track RG lineages [187].

\section{NSC transgenic lines}

NSCs play a crucial role in the production of various types of neurons and glia for the formation of the nervous systems and the maintenance of the stem cell niche, which is a key regulator of stem cells in neurogenesis [188]. The mechanisms underlying generation of various differentiated cell types in the CNS have garnered interest. Nestin, an intermediate filament protein, is a widely employed marker of multipotent NSCs [189]. Lam et al. established a transgenic line expressing GFP under the control of the nestin promoter [183]. They cloned a 3.9-kb nestin regulatory region into the pCS2:GFP-SceI vector, and the resulting $T g$ (nestin:gfp) construct was microinjected with I-SceI meganuclease [50, 183]. The Tg(nestin:gfp) line labeled the progenitor cells with RG-like morphology and self-renewal capacity located in the ventricular zone of the adult CNS [183]. This line has been also used to study the heterogeneity of neural progenitor cells in the adult brain [190] and the regeneration of the injured brain and spinal cord in adult zebrafish [103, 190]. Finally, Kaslin et al. developed a $\operatorname{TgBAC}$ (nestin:GFP) zebrafish line using $\mathrm{BAC}$ recombineering to investigate the stem cell niche in adult cerebellum [191].

\section{Tau transgenic lines}

Tau is a microtubule-associated protein, is abundantly expressed in the CNS neurons, and maintain the stability of microtubules in neuronal axons [192]. These proteins undergo biochemical modifications such as phosphorylation for cytoskeletal plasticity [193]. However, abnormally phosphorylated tau proteins form neurofibrillary tangles that lead to cell death and thus several neurodegenerative diseases, including Alzheimer's disease and chronic traumatic encephalopathy [194]. To develop therapeutic agents to treat and prevent disease progression, it is important to investigate the underlying mechanism of their pathologies. Paquet et al. generated transgenic zebrafish that recapitulate the pathological features of tauopathy [195]. To generate the tauopathy model, they first employed a bidirectional expression system based on the Gal4/UAS system, which allows for simultaneous expression of transgenes in forward or reverse orientations [195]. They inserted the $E 1 b$ promoter into the flanking sites of the UAS promoter and then cloned human TAU-P301L and DsRed fluorescent protein gene in both directions of the UAS promoter in the pT2KXIGdeltaIN plasmid, resulting in construction of $\operatorname{Tg}($ UAS-E1B:DsRed,Hsa.MAPT_P301L) plasmid, with which the cognate transgenic line was established using Tol2-mediated integration. This line was used to study a role for BDNF signaling in tauopathy [196], microglial dynamics against tauopathic neurons [197], and the mechanism by which pathological tau proteins aggregate [198, 199].

\section{Dopaminergic neuron transgenic lines}

Dopaminergic neurons, which synthesize dopamine (DA) from the amino acid tyrosine, play important roles in the regulation of several physiological and behavioral processes, including voluntary movement, mood, reward, addiction, and memory in the CNS [200]. Deficiency of DA and loss of dopaminergic neurons in the substantia nigra elicit several neurological disorders such as Parkinson's disease (PD) and impaired motor activity [201]. Therefore, it is necessary to study the pathological mechanisms of PD in association with the development of DA neurons. To label DA neurons in vivo, Xi et al. cloned EGFP gene into dopamine transporter (dat) exon 1 in the 
PAC clone containing the 13-kb of regulatory sequences of dat and transferred the resulting PAC-EGFP to pGEMTol2 vector [202], thereby generating Tol2-PAC-EGFP construct, with which they created the $T g($ dat:EGFP) line using Tol2-mediated transgenesis. This line expresses EGFP under the control of dat regulatory elements and thus labeled DA neurons in the ventral diencephalon, retina, olfactory bulb, pretectum and caudal hypothalamus [202]. In this line, individual DAT-expressing neurons can be tracked before and after treatment with L-DOPA, a precursor of dopamine [203]. Moreover, a $T g$ (dat:CFPNTR) line that can ablate DA neurons chemogenetically was developed to investigate PD with locomotor phenotype [204].

\section{The urogenital system} Introduction

Nephron segment patterning and cellular composition are conserved between zebrafish and mammals [205]. Zebrafish embryos develop functional pronephros by $2 \mathrm{dpf}$ and a fully functioning mature pronephric kidney by $4 \mathrm{dpf}[206,207]$. Many lines labeling pronephric structures have been established (Table 5), allowing the precise determination of the location, function, and expression profiles of particular cells in the kidney and providing extraordinary tools to model and visualize the biological processes underlying kidney development and disease [208].

While fish generate nephrons throughout their lifespan and regenerate nephrons de novo after injury, mammals can only partly repair their nephrons and cannot form new ones [209, 210]. As such, fish are an appropriate model to study molecular mechanism underlying renal regeneration, which in turn may lead to development of therapeutic activation of mammalian renal regeneration. Zebrafish renal disease models can be generated with genetic alteration, transient gene knockdown or genomeediting technology. Crossing these zebrafish models to transgenic fluorescent zebrafish lines may yield embryos with abnormal pronephros that can be imaged with in vivo fluorescence microscopy. Zebrafish kidney injury models successfully recapitulate the features of mammalian acute kidney injury (AKI), such as characteristic histological changes, reduced renal function and pericardial edema [211-213].

Development of germline requires the specification and survival of primordial germ cells (PGCs) in the embryo as well as the maintenance of gamete production during

Table 5 Transgenic reporter zebrafish lines targeting the urogenital system

\begin{tabular}{|c|c|c|c|c|c|}
\hline Construct name & Construct ID & Transgenic name & Transgenic ID & Target & References \\
\hline $\operatorname{Tg}(w t 1 b: E G F P)$ & $\begin{array}{l}\text { ZDB-TGCON- } \\
\text { STRCT-071127-1 }\end{array}$ & $\operatorname{Tg}(-26 w t 1 b: E G F P)^{l i t}$ & ZDB-ALT-071127-1 & Pronephric kidney & {$[215-220]$} \\
\hline $\operatorname{Tg}(\operatorname{Ih} \times 1 a: E G F P)$ & $\begin{array}{l}\text { ZDB-TGCON- } \\
\text { STRCT-100323-1 }\end{array}$ & $\operatorname{Tg}(\operatorname{Ih} \times 1 a: E G F P)^{p t 303}$ & ZDB-ALT-100323-3 & $\begin{array}{l}\text { Marginal cells, shield, } \\
\text { notochord and bilateral } \\
\text { mesoderm }\end{array}$ & {$[220,222,223]$} \\
\hline $\operatorname{Tg} 2(c d h 17: E G F P)$ & $\begin{array}{l}\text { ZDB-TGCON- } \\
\text { STRCT-140116-2 }\end{array}$ & $\operatorname{Tg} 2(c d h 17: E G F P)^{p t 305}$ & ZDB-ALT-140116-11 & $\begin{array}{l}\text { Whole length pronephric } \\
\text { tubule }\end{array}$ & {$[220]$} \\
\hline $\operatorname{Tg}($ sox10:EGFP) & $\begin{array}{l}\text { ZDB-TGCON- } \\
\text { STRCT-150414-3 }\end{array}$ & $\operatorname{Tg}(P T: E G F P)^{n z 4}$ & ZDB-ALT-150414-3 & $\begin{array}{l}\text { Proximal pronephric } \\
\text { tubule }\end{array}$ & {$[225,226]$} \\
\hline Tg(enpep:EGFP) & $\begin{array}{l}\text { ZDB-TGCON- } \\
\text { STRCT-101123-2 }\end{array}$ & Tg(enpep:GFP)p152 & ZDB-ALT-101123-3 & $\begin{array}{l}\text { Pronephric tubules, } \\
\text { ducts and podocyte-like } \\
\text { cells of glomeruli }\end{array}$ & {$[227-231]$} \\
\hline $\operatorname{Tg}(g t s h \beta: G F P)$ & $\begin{array}{l}\text { ZDB-TGCON- } \\
\text { STRCT-141007-2 }\end{array}$ & $\operatorname{Tg}(\text { Eco.Tshb:EGFP) })^{i h b 50}$ & ZDB-ALT-141007-2 & $\begin{array}{l}\text { Proximal pronephric } \\
\text { tubule, pituitary gland } \\
\text { and adult pronephric } \\
\text { duct epithelium }\end{array}$ & {$[232,233]$} \\
\hline $\operatorname{Tg}(-2.5 n p h s 2: E G F P)$ & $\begin{array}{l}\text { ZDB-TGCON- } \\
\text { STRCT-120613-1 }\end{array}$ & $\begin{array}{l}\text { Tg(podocin:GFP)/Tg(- } \\
2.5 n p h s 2: E G F P)^{k i 1}\end{array}$ & ZDB-ALT-120613-1 & $\begin{array}{l}\text { Podocytes and glomeru- } \\
\text { lar epithelial cells }\end{array}$ & {$[234-239]$} \\
\hline Tg(nphs2:GAL4-VP16) & $\begin{array}{l}\text { ZDB-TGCON- } \\
\text { STRCT-150504-7 }\end{array}$ & $\begin{array}{l}\text { Tg(podocin:Gal4VP16/ } \\
\text { Tg(nphs2:GAL4-VP16) } \text { fb202 }^{\text {(f) }}\end{array}$ & ZDB-ALT-150504-5 & $\begin{array}{l}\text { Podocytes and glomeru- } \\
\text { lar epithelial cells }\end{array}$ & {$[210,240,241]$} \\
\hline $\operatorname{Tg}(d d \times 4: d d x 4-E G F P)$ & $\begin{array}{l}\text { ZDB-TGCON- } \\
\text { STRCT-070814-1 }\end{array}$ & $\operatorname{Tg}\left(\right.$ vasa:vasa-EGFP) ${ }^{z f 45}$ & ZDB-ALT-070814-1 & PGCs & {$[243-245,252-254]$} \\
\hline $\operatorname{Tg}($ piwil1:EGFP) & $\begin{array}{l}\text { ZDB-TGCON- } \\
\text { STRCT-110126-5 }\end{array}$ & $\begin{array}{l}\operatorname{Tg}(\text { ziwi:EGFP) / } \\
\operatorname{Tg}(\text { piwil1:EGFP) uc1 }\end{array}$ & ZDB-ALT-110126-6 & PGCs & {$[245,257-260]$} \\
\hline $\begin{array}{l}\text { Tg(piwil1:EGFP-UTRna- } \\
\text { nos3) }\end{array}$ & $\begin{array}{l}\text { ZDB-TGCON- } \\
\text { STRCT-181226-1 }\end{array}$ & $\begin{array}{l}\text { Tg(piwil1:EGFP- } \\
\text { UTRnanos3) }\end{array}$ & ZDB-ALT-181226-1 & PGCs & {$[261-263]$} \\
\hline $\operatorname{Tg}(g s d f: E G F P)$ & $\begin{array}{l}\text { ZDB-TGCON- } \\
\text { STRCT-130910-1 }\end{array}$ & $\operatorname{Tg}(g s d f: E G F P)^{i n r 2}$ & ZDB-ALT-130910-2 & $\begin{array}{l}\text { Sertoli and granulosa } \\
\text { cells }\end{array}$ & {$[264,265]$} \\
\hline
\end{tabular}


the reproductive life cycle of the adult. This process is fundamental to all metazoans, and some components of the genetic pathway regulating germ cell development and function are evolutionarily conserved. Study on this process entails establishment of in vivo methods for functional analysis of genes involved in zebrafish gonad development and creation of transgenic lines to visualize the gonads throughout the zebrafish life cycle.

\section{Kidney transgenic lines}

The Wilms' tumor suppressor gene $w t 1$ is essential for kidney development and highly conserved among vertebrates. However, most fish species possess two wt1 paralogs, $w t 1 a$ and $w t 1 b$, while mammals have only one $w t 1$ gene [214]. Human WT1 mutations cause Wilms' tumor, which is childhood kidney cancer, and the developmental anomalies of the urogenital tract. Transgenic lines echoing $w t 1$ gene expressions profile have been generated to examine the structure and development of the zebrafish embryonic kidney, the pronephros, and the roles of the $w t 1$ genes in the pronephros development. Among them, the $T g(w t 1 b: e G F P)$ line was produced by co-injecting into one-cell stage zebrafish embryos I-SceI meganuclease and $T g(w t 1 b: e G F P)$ plasmid that drives EGFP expression under a $25.9-\mathrm{kb}$ fragment encompassing the entire region between $w t 1 b$ and the $5^{\prime}$ neighboring gene ga17 minus translational start site of $w t 1 b$ [215]. In this line, GFP expression recapitulates the expression pattern of endogenous $w t 1 b$ in the glomeruli. Also labeled in this line are the pronephric tubules and the proximal regions of the ducts, in which endogenous wt1b gene is not observed, allowing for visualization of the entire pronephric kidney encompassing glomeruli, tubules and ducts [216]. Fluorescence imaging of $\mathrm{Tg}(w t 1 b: e G F P)$ zebrafish larvae revealed the segmental organization of each nephron into glomerulus, neck, proximal convoluted and straight tubules, corpuscle of Stannius and pronephric duct, which fuse to the cloaca at $2 \mathrm{dpf}[217,218]$. The $\operatorname{Tg}(w t 1 b: e G F P)$ line has contributed to the research on the development and regeneration of kidney as well as the drug screening against nephrotoxicity and genetic kidney diseases including hereditary glomerulopathies and cystic kidney diseases [217, 219, 220].

The Lim1 homeobox protein, Lhx1, is essential for establishing the kidney field in embryonic development and in kidney regeneration after injury [221]. To develop a quantitative high-content screening assay for agents that increase the Lhx1a expression during development, the $\operatorname{Tg}(\operatorname{lh} x 1 a: E G F P)$ line was generated through I-SceI meganuclease-mediated transgenesis [222]. This line labels marginal cells, shield, notochord and bilateral intermediate mesoderms that give rise to the kidney, in addition to the polster and the diencephalon. At later stages, this line also marks the pronephric proximal and distal tubules and duct as well as the anterior lateral line ganglia, forebrain, hindbrain, midbrain, otic vesicle, posterior lateral line ganglia, spinal cord and tailbud [222]. The renal progenitors isolated from $\operatorname{Tg}(\operatorname{lh} x 1 a$ :EGFP) can generate new nephrons when introduced into a damaged host kidneys [223]. A high-content assay using $\operatorname{Tg}(\operatorname{lh} x 1 a: E G F P)$ zebrafish embryos was developed employing cognition network technology, an artificial intelligence-based image analysis, that can identify small molecules expanding the kidney field [220]. HDAC inhibitors that facilitate recovery from AKI in zebrafish larvae were screened using this zebrafish system as a regeneration model for drug discovery [220].

The zebrafish homolog of mammalian kidney-specific cadherin, $c d h 17$, is expressed in the epithelium and ducts of the entire tubule during larval development and adult [224]. To establish $c d h 17$ reporter zebrafish, a $5-\mathrm{kb}$ genomic region containing the promoter and the $5^{\prime}$ UTR sequences of the $c d h 17$ locus was cloned into the $5^{\prime}$ region of the pI-SceI:EGFP plasmid, which was in turn used to generate the $\operatorname{Tg}(c d h 17: e g f p)$ transgenic line via I-SceI meganuclease-mediated transgenesis [220]. This line at $48 \mathrm{hpf}$ labels the kidney including a pair of tubular structures that converge at the cloaca and the tubular subdomains, excluding the glomeruli. At later points of development, however, the entire embryonic tubular segments are labelled. Easily detected in this line is kidney field expansion, which helps identify novel agents that may have the potential to augment kidney regeneration after injury [220].

To visualize pronephric tubular injury caused by gentamicin in zebrafish larvae, the $\operatorname{Tg}(P T: E G F P)$ line was generated by expressing EGFP under the sox 10 promoter [225]. This line labels cells in the proximal pronephric tubule and NCCs [225]. In contrast, the $\operatorname{Tg}(c d h 17: E G F P)$ line labels the whole length of the pronephric tubule [220]. These two lines were combined to identify the spatial expression of molecular markers in the infectionassociated AKI [226].

The gene enpep encodes glutamyl aminopeptidase implicated in the regulation of blood pressure, blood vessel formation and tumorigenesis. The $T g$ (enpep:egfp) line was generated, in which EGFP expression is driven by the 2.3-kb enpep promoter [227]. Tg(enpep:GFP) larvae label both pronephric tubules and ducts as well as podocytelike cells of the glomeruli in early development [227]. This line has been used to identify and characterize the genes associated with pronephric development, kidney diseases and cellular dynamics during adult zebrafish kidney regeneration [228-231].

To understand a role for $g t s h \beta$ in kidney tubule morphogenesis, the $\operatorname{Tg}(g t s h \beta: G F P)$ line was created, in which 
GFP is expressed under the control of the $g t s h \beta$ promoter [232]. In this line, GFP is expressed in proximal pronephric tubules as well as in pituitary gland during embryogenesis and kidney duct epithelium in adult fish, conferring a tool to study the tubular development with genetic or chemical approaches [232]. This line has deepened our understanding of the signaling pathways that trigger renal tubular damage during lethal lipopolysaccharide (LPS)-induced septic shock in an AKI model, suggesting that this transgenic zebrafish is an ideal model to carry out in vivo screen for potential antisepsis therapeutic strategies [233].

The $T g$ (podocin:GFP) line was generated using the $T g(-$ 2.5nphs2:EGFP) construct via Tol2 transposon-mediated transgenesis. EGFP expression is driven by the $2.5-\mathrm{kb}$ zebrafish podocin promoter [234]. The loss of glomerular GFP expression in the $\operatorname{Tg}$ (podocin:GFP) embryos indicates developmental aberrations of and injury to the glomerulus [235-239]. To investigate the podocyte injury, several techniques to induce zebrafish AKI are available. For example, $\operatorname{Tg}$ (nphs2:GAL4-VP16) [240] and $T g$ (pod:NTR-mCherry) [210, 241] lines were established to temporally ablate or injure podocytes, the visceral glomerular epithelial cells, by expressing NTR under the control of the zebrafish $n p h s 2$ promoter. To visualize the spatiotemporal pattern of mesonephrogenesis and investigate the development and postinjury regeneration of the mesonephros in adult zebrafish, cytotoxin was induced in podocytes of larval or adult transgenic zebrafish that expressed NTR under the control of the podocin promoter, eliciting glomerular injury including podocyte loss, reduced expression of podocyte marker genes and foot process effacement [210, 240, 241].

\section{Germline and gonadal transgenic lines}

$d d x 4$ [DEAD (Asp-Glu-Ala-Asp) box polypeptide 4], which was previously known as vasa or vas, is a conserved gene belonging to the DEAD box helicase family. Being specifically expressed in the germline across metazoans, it has been extensively used as a germ cell marker [242]. The $T g($ vasa:vasa-EGFP) zebrafish was generated using the $\operatorname{Tg}($ vasa:vasa-eGFP) or $\operatorname{Tg}(d d x 4: d d x 4-E G F P)$ construct that includes the vasa regulatory region fused to egfp [243]. This line expresses EGFP in the PGCs from 24 hpf onwards [243]. During early development, however, only maternal GFP signal is detected in the germline, and zygotic transcription of vasa-egfp driven by the vasa regulatory region begins after sexual differentiation when the germ cells enter meiosis [244, 245]. This line has been widely used to investigate roles of the genes involved in gonad development [246-251] as well as the gonadal stem cell features [252, 253]. To visualize the germline in real time and in vivo from $1 \mathrm{dpf}$ through
12 weeks post-fertilization, the $T g($ vasa:vasa-EGFP) line was combined with zebrafish mutants mitfa $^{\mathrm{w} 2 / \mathrm{w} 2}$ (melanocyte inducing transcription factor a; ZFIN ID ZDBALT-990423-22) or $m p v 17^{b 18 / b 18}$ (mitochondrial inner membrane protein 17; ZDB-GENO-141218-8), which renders both larvae and adult zebrafish transparent [254].

ziwi encodes an RNA-binding zinc finger protein and similar to vasa, it is specifically expressed in the zebrafish germline throughout development [255, 256]. $\operatorname{Tg}$ (piwill:EGFP) was generated using the $\mathrm{Tg}$ (piwil1:EGFP) construct comprising the promoter elements of ziwi (piwil1), the zebrafish homolog for Drosophila piwi, fused to egfp [245]. In this line, ziwi:EGFP is maternally supplied in embryos and zygotic EGFP is first detected around at $7 \mathrm{dpf}$ [245], implying that this line is less dependent on maternal EGFP to label germ cells early in development than the $T g$ (vasa:vasa-EGFP) line. The Tg(piwill:EGFP) line has characterized the roles of the genes involved in gonad development [257-260].

Another transgenic line that can display the PGCs, Tg(piwill:egfp-UTRnanos3), was generated using the Tg(piwil1:EGFP-UTRnanos3) construct [261]. This line labels PGCs at the shield stage, oogonia and oocytes at early stages in the ovary, and spermatogonia, spermatocyte and spermatid at early stage in the testis, thus illuminating the zebrafish germline throughout the lifespan [261]. This line has been utilized to analyze gene functions in gonadal development $[262,263]$.

$g s d f$ is expressed in the Sertoli and granulosa cells. To illuminate these cells, the $T g(g s d f: E G F P)$ line was generated using the $\operatorname{Tg}(g s d f: E G F P)$ construct including the 2 -kb proximal promoter region of $g s d f$ via Tol2 transposase-mediated transgenesis [264]. EGFP expression is first detected at $16 \mathrm{dpf}$ and progresses from the posteroventral region lining the swim bladder towards the anteroventral region and the urogenital papilla at 19-42 dpf prior to the sexual differentiation of the gonad [264]. This line has been also employed to visualize the 3D architecture of the testis and its cellular content [265].

\section{Digestive system Introduction}

The zebrafish digestive system can be divided into the gastrointestinal (GI) tract including esophagus, intestinal bulb, mid intestine, posterior intestine and anus, and accessory organs such as liver and pancreas. To investigate developmental process of the digestive system in zebrafish, transgenic fluorescent zebrafish lines have been widely used. Here, we summarize the representative zebrafish transgenic reporter lines that label various cell types in the GI tract, liver and pancreas (Table 6). 
Table 6 Transgenic reporter zebrafish lines targeting the digestive system

\begin{tabular}{|c|c|c|c|c|c|}
\hline Construct name & Construct ID & Transgenic name & Transgenic ID & Target & References \\
\hline $\operatorname{Tg}(f a b p 2: R F P)$ & $\begin{array}{l}\text { ZDB-TGCON- } \\
\text { STRCT-110208-2 }\end{array}$ & $\operatorname{Tg}(f a b p 2: R F P) a s 200$ & ZDB-ALT-110208-3 & $\begin{array}{l}\text { Intestinal bulb and mid } \\
\text { intestine }\end{array}$ & {$[269,271-274]$} \\
\hline $\operatorname{TgBAC}(\mathrm{cldn} 151 \mathrm{a}-\mathrm{GFP})$ & $\begin{array}{l}\text { ZDB-TGCON- } \\
\text { STRCT-140613-1 }\end{array}$ & $\operatorname{TgBAC}(\mathrm{cldn} 15 / \mathrm{a}-\mathrm{GFP})^{p d 1034}$ & ZDB-ALT-140613-1 & $\begin{array}{l}\text { Epithelial cells (intestinal } \\
\text { bulb to posterior intestine) }\end{array}$ & {$[275-279]$} \\
\hline $\operatorname{Tg}(-8.3 b p h o x 2 b: K a e d e)$ & $\begin{array}{l}\text { ZDB-TGCON- } \\
\text { STRCT-150305-1 }\end{array}$ & $\operatorname{Tg}(-8.3 b p h o \times 2 b: K a e d e)^{e m 2}$ & ZDB-ALT-150305-1 & ENS & {$[280-284]$} \\
\hline $\operatorname{Tg}(-2.8 f a b p 10 a: E G F P))$ & $\begin{array}{l}\text { ZDB-TGCON- } \\
\text { STRCT-070117-123 }\end{array}$ & $\operatorname{Tg}(-2.8 f a b p 10 a: E G F P))^{2 f 235}$ & ZDB-ALT-110523-10 & Hepatocytes & {$[297-302]$} \\
\hline Tg(EPV.TP1-Mmu.Hbb:EGFP) & $\begin{array}{l}\text { ZDB-TGCON- } \\
\text { STRCT-090625-1 }\end{array}$ & $\begin{array}{l}\text { Tg(EPV.TP1-Mmu. } \\
H b b: E G F P)^{u m 14}\end{array}$ & ZDB-ALT-090625-1 & Intrahepatic biliary cells & [304-308] \\
\hline $\operatorname{TgBAC}($ hand2:EGFP) & $\begin{array}{l}\text { ZDB-TGCON- } \\
\text { STRCT-1 10128-8 }\end{array}$ & $\operatorname{TgBAC}($ hand2:EGFP) & ZDB-ALT-110128-40 & Hepatic stellate cells & {$[309-312,325]$} \\
\hline Tg(ela3l:EGFP) & $\begin{array}{l}\text { ZDB-TGCON- } \\
\text { STRCT-070117-92 }\end{array}$ & $\operatorname{Tg}(e l a 31: E G F P)^{g z 2}$ & ZDB-ALT-060710-10 & Pancreatic exocrine cells & [313] \\
\hline $\operatorname{Tg}(g c g a: G F P)$ & $\begin{array}{l}\text { ZDB-TGCON- } \\
\text { STRCT-070215-2 }\end{array}$ & $\operatorname{Tg}(g c g a: G F P)^{i a 1}$ & ZDB-ALT-070215-2 & Pancreatic a-cells & {$[314,317,318]$} \\
\hline $\operatorname{Tg}(m n \times 1: G F P)$ & $\begin{array}{l}\text { ZDB-TGCON- } \\
\text { STRCT-070117-40 }\end{array}$ & $\operatorname{Tg}(m n \times 1: G F P)^{m / 2}$ & ZDB-ALT-051025-4 & Pancreatic $\beta$-cells & {$[315,316]$} \\
\hline Tg(ins:DsRed) & $\begin{array}{l}\text { ZDB-TGCON- } \\
\text { STRCT-080826-1 }\end{array}$ & $\operatorname{Tg}\left(\right.$ ins:DsRed) ${ }^{m 1018}$ & ZDB-ALT-080826-1 & Pancreatic $\beta$-cells & {$[317,318]$} \\
\hline $\operatorname{Tg}(X \mid a . E e f 1 a 1: G F P)$ & $\begin{array}{l}\text { ZDB-TGCON- } \\
\text { STRCT-070117-34 }\end{array}$ & $\operatorname{Tg}(X \mid a . E e f 1 a 1: G F P)^{5854}$ & ZDB-ALT-030702-2 & $\begin{array}{l}\text { Digestive tract, liver and } \\
\text { pancreas }\end{array}$ & {$[298,320-324]$} \\
\hline
\end{tabular}

\section{GI tract}

The intestinal architecture of the zebrafish closely resembles the mammalian counterpart [266-268]. To understand molecular mechanism underlying development of the intestinal lumen and enteric nervous system (ENS), various transgenic fluorescent zebrafish lines have been generated.

To establish a gut-specific expression of target genes, the Jen-Leih Wu group at Academia Sinica constructed a plasmid harboring $4.5-\mathrm{kb}$ intestine specific promoter of zebrafish intestine fatty acid-binding protein $(I-F A B P)$ fused to RFP. This plasmid was linearized and microinjected into zebrafish embryos to generate the $\operatorname{Tg}(f a b p 2: R F P)$ line, which labeled the zebrafish intestinal bulb and mid intestine [269]. His group also reported that the 192-bp region in the $I-F A B P$ promoter sufficed for gut-specific expression [270]. This $T g(f a b p 2: R F P)$ line carrying the $4.5-\mathrm{kb}$ promoter has been widely used to study functional organization of zebrafish intestine and human GI diseases such as inflammatory bowel disease and enterocolitis [271-274].

In addition, the Bagnat group at Duke University Medical Center linearized the TgBAC(cldn15la:GFP) construct with AsiSI (New England Biolabs) and microinjected the linearized construct into one-cell stage zebrafish embryos to generate the $\operatorname{TgBAC}(\mathrm{cldn15la:GFP})$ line, which exhibits GFP expression in the membranes of epithelial cells spanning from the intestinal bulb to posterior intestine [275]. This line has been used to uncover the mechanism of the intestinal epithelial formation and patterning as well as intestinal barrier function and inflammation in zebrafish [275-279].

The ENS is the largest part of the vertebrate PNSs. To image the ENS development in real time and in vivo, the Iain Shepherd group at Emory University constructed a plasmid encoding the wavelength-sensitive fluorescent protein Kaede under the control of the enhancer of paired-like homeobox $2 b$ (phox $2 b$ ), a gene involved in the development of enteric neuron progenitors [280]. Subsequently, they microinjected the resulting construct with Tol2 transposase mRNA into embryos to generate the $T g(-8.3$ bphox $2 b:$ Kaede) line. This line has been used to study de novo enteric neurogenesis in post-embryonic zebrafish, a role of retinoic acid in colonization of the gut by vagal neural crest cells [281, 282], and Hirschsprung disease caused by failure of the ENS [283, 284].

\section{Liver}

Cell types and metabolic pathways in the liver are comparable between zebrafish and mammals [285-289]. Hence, zebrafish has emerged as an important animal model to study the development [290,291] and diseases of the liver [292-296]. Transgenic lines that express fluorescent proteins in hepatocytes, intrahepatic biliary cells and hepatic stellate cells have been developed.

To label zebrafish hepatocytes with EGFP, the Wu group at National Taiwan Ocean University cloned the promoter region of liver-FABP $(L-F A B P)$ into the 
pEGFP-C1. The resulting construct $p L F 2.8-E G F P$ was used to generate the $\operatorname{Tg}(-2.8 f a b p 10 a: E G F P)$ line [297]. More than 50 studies have taken advantage of this line to investigate liver development. For example, this line was used to determine the role of cellular signaling pathways in liver development [298, 299] as well as druginduced hepatic injury or genetically-induced hepatic diseases [300-302]. Of note, the Didier Stainier group at University of California, San Francisco established the $\mathrm{Tg}$ (fabp10a:DsRed) line to study patterning and differentiation of the hepatopancreatic ductal system [303].

To create a Notch reporter line, the Steven Leach group at Johns Hopkins University fused six copies of the Epstein-Barr Virus terminal protein 1 (EPV.TP1) promoter region to $\beta$-globin minimal promoter and EGFP using the Gateway technology. The resulting construct $T g$ (EPV.Tp1-Mmu.Hbb:EGFP) and Tol2 transposase mRNA were co-microinjected into zebrafish embryos. As a result, the $T g(E P V . T p 1-M m u . H b b: E G F P)$ line was generated, which labels intrahepatic biliary cells [304]. This line has been adopted to reveal molecular mechanisms by which endodermal notch signaling, cannabinoid receptor signaling and inhibitor of DNA binding (Id) protein induce bile duct development and liver diseases [305-308].

To generate a transgenic fluorescent zebrafish line that marks hepatic stellate cells, the Stainier group employed the regulatory region of heart and neural crest derivatives expressed 2 (hand2), which encodes a basic helix-loophelix transcription factor implicated in organ development, determination of intestine left-right asymmetry and nervous system development. A BAC clone harboring the regulatory region of hand 2 was used to generate the $\operatorname{TgBAC}$ (hand2:EGFP) line by BAC transgenesis. Because activation of hepatic stellate cells plays a key role in regeneration upon hepatic injury, this line has been employed to study liver diseases, to visualize activation of hepatic stellate cells upon ethanol-induced hepatic injury, and to create NTR / MTZ induced hepatic fibrosis models [309-312].

\section{Pancreas}

The pancreas consists of endocrine and exocrine systems. To study differentiation, proliferation and morphogenesis of exocrine cells, the Gong group at National University of Singapore used the elastaseA (elaA) regulatory sequence $(-1.8 \mathrm{~kb})$ for exocrine specific expression of GFP. The $\operatorname{Tg}(E l a A: E G F P)$ plasmid was linearized and microinjected into one-cell stage embryos to generate the $\operatorname{Tg}($ ela3l:EGFP) line [313]. The pancreatic endocrine system, pancreatic islets, consists of $\alpha$-, $\beta$ - and $\delta$-cells that secrete glucagon, insulin and somatostatin, respectively. The Argenton group at University of Padua used the glucagon a (gcga) promoter region to generate the $T g(g c g a: G F P)$ line that expresses GFP in glucagon producing pancreatic $\alpha$-cells [314]. Insulin producing pancreatic $\beta$-cells can be visualized by the $\operatorname{Tg}(m n x 1: G F P)$ or $\operatorname{Tg}$ (ins:RFP) line. $m n x 1$ encodes a homeobox transcription factor that is involved in motoneuron differentiation and pancreas development. The Sanes group at Washington University in St. Louis isolated the regulatory region of motor neuron and pancreas homeobox 1 (mnx1; also called $h b 9)$ from a PAC clone. To study neuromuscular synapses, the regulatory region was fused to GFP and then microinjected into embryos to establish the $\operatorname{Tg}(m n x 1: G F P)$ line [315]. Later on, the Dirk Meyer group at University of Innsbruck used the $\operatorname{Tg}(m n x 1$ :GFP); $T g$ (ins:dsRed) line to show that the pancreatic $m n x 1$ expression precedes expression of insulin (ins), and to determine the underlying mechanisms of $\beta$-cell fate specification [316]. The $T g$ (ins:dsRed) line was generated by the Driever group at University of Freiburg and first reported by the Stainier group [317]. The Tg(ins:dsRed) line and $\operatorname{Tg}(g c g a: G F P) ; \operatorname{Tg}($ ins:dsRed) line have been used to investigate development and regeneration of pancreas $[317,318]$ as well as to screen a small molecule library to identify enhancers of $\beta$-cell regeneration [319].

\section{Endodermal organs}

The $\mathrm{Tg}(X l a$.Eef1a1:GFP) line (more popularly called the gutGFP line) was generated incidentally by the Herwig Baier group at University of California, San Francisco. Microinjection of linearized plasmid pESG that encodes GFP downstream of the Xenopus elongation factor $(\mathrm{EF})-1 \alpha$ promoter into zebrafish embryos yielded the line. GFP expression in this line was ubiquitous at early stage, yet was restricted to the endoderm, eye and hatching gland by $22 \mathrm{hpf}$ [320]. The insertion site of the transgene has not been characterized yet. As this line expresses GFP in the developing digestive tract, liver and pancreas, most of early research on these organs had benefited from the gutGFP line. Using this line, the Stainier group published three papers on zebrafish liver, pancreas and intestinal epithelium morphogenesis, respectively [320322]. These papers laid the foundation for the research on the zebrafish GI tract and its accessory organs. As such, it is not surprising that this line has significantly contributed to uncover molecular mechanisms underlying development of these organs. For example, Wnt signaling was shown to be required for liver development and regeneration [298], pancreas associated transcription factor 1a (Ptf1a) was reported to regulate endocrine versus exocrine fate in pancreas development [323], and the target of rapamycin (TOR) signaling was demonstrated to regulate intestinal epithelium morphogenesis [324]. 


\section{Intracellular organelles}

Introduction

Zebrafish is an excellent animal model to study embryogenesis and human diseases because it allows for visualization and manipulation of cellular organelles and processes [326]. Development of organisms is governed by the spatial and temporal regulations of proliferation, apoptosis, migration, differentiation and morphological specialization. Proteins are synthesized at the endoplasmic reticulum, glycosylated at the Golgi complex, and trafficked to target locations, either intracellular or extracellular [327]. Secretory proteins go through the secretory pathway comprising diverse protein complexes at each step to recruit Rab GTPases and SNARE proteins to tether vesicles to target organelles and facilitate membrane fusion [328]. The understanding of this pathway from the perspective of intracellular organelles is fundamental to study the behavior and biology of cells in organisms. Many human genetic diseases such as mitochondriopathies [329] and diseases of protein trafficking [330] are linked to abnormal organelle functions. Hence, development of transgenic reporter lines labeling organelles was required.

\section{Nucleus transgenic lines}

To visualize overall zebrafish embryonic development, the $\mathrm{Tg}$ (actb2:H2B-GFP) line was generated (Table 7). Under the regulation of $\beta$-actin promoter, this line expresses fusion proteins of human histone- 2 and GFP that localize to chromatin, and has been used to analyze cell cycle length, nuclear architecture and the temporal dynamics of the nuclear compartment [331]. When driven by tissue specific promoters such as islet [Tg(isl1a:NLS-GFP)], mylpfa [Tg(mylpfa:Hsa.HIST1H2BJ-GFP] and runx [(Tg(Mmu.Runx 1:NLS-mCherry)], these lines can easily monitor neuronal, muscular and hematopoietic development in real time and in vivo [332-334].

\section{Golgi apparatus transgenic lines}

To image the trans-Golgi secretory pathway in the developing embryos in real time and in vivo, the Gerhart group cloned amino acids 1-6 from human B4GALT1 fused to GFP to the region downstream of the zebrafish semiubiquitous $\beta$-actin promoter using Gateway technology, thereby creating $\operatorname{Tg}(\beta$-act:GalT-GFP). Galactotransferase (GalT) is a Golgi-retained enzyme. Using this construct and Tol2 mediated transgenesis [335], they generated the

Table 7 Transgenic reporter zebrafish lines targeting intracellular organelles

\begin{tabular}{|c|c|c|c|c|c|}
\hline Construct name & Construct ID & Transgenic name & Transgenic ID & Target & References \\
\hline $\operatorname{Tg}(a c t b 2: H 2 B-G F P)$ & $\begin{array}{l}\text { ZDB-TGCON- } \\
\text { STRCT-170619-1 }\end{array}$ & $\operatorname{Tg}(a c t b 2: H 2 B-G F P)^{2 f 712}$ & ZDB-ALT-170619-1 & Chromatin (Nucleus) & {$[331]$} \\
\hline $\operatorname{Tg}($ is/1a:NLS-GFP) & $\begin{array}{l}\text { ZDB-TGCON- } \\
\text { STRCT-201203-1 }\end{array}$ & $\operatorname{Tg}(i s / 1 a: N L S-G F P)^{f h 558}$ & ZDB-ALT-201203-5 & Neurons & {$[334]$} \\
\hline $\begin{array}{l}\text { Tg(Mmu.Runx1:NLS- } \\
\text { mCherry) }\end{array}$ & $\begin{array}{l}\text { ZDB-TGCON- } \\
\text { STRCT-150512-2 }\end{array}$ & $\begin{array}{l}\text { Tg(Mmu.Runx 1:NLS- } \\
\text { mCherry) }\end{array}$ & ZDB-ALT-150512-2 & Hematopoietic cells & {$[110]$} \\
\hline $\begin{array}{l}\text { Tg(mylpfa:Hsa.HIST1H2BJ- } \\
\text { GFP) }\end{array}$ & $\begin{array}{l}\text { ZDB-TGCON- } \\
\text { STRCT-160728-1 }\end{array}$ & $\begin{array}{l}\text { Tg(mylpfa:Hsa.HIST1H2BJ- } \\
\text { GFP) }\end{array}$ & ZDB-ALT-160728-1 & Muscular cells & {$[333]$} \\
\hline Tg(actb2:Hsa.B4GALT1-GFP) & $\begin{array}{l}\text { ZDB-TGCON- } \\
\text { STRCT-120419-3 }\end{array}$ & $\begin{array}{l}\text { Tg(actb2:Hsa.B4GALT1- } \\
\text { GFP) }\end{array}$ & ZDB-ALT-120419-5 & Golgi apparatus & {$[336]$} \\
\hline $\operatorname{Tg}($ h2afx:EGFP-rab5c) & $\begin{array}{l}\text { ZDB-TGCON- } \\
\text { STRCT-111017-3 }\end{array}$ & $\operatorname{Tg}(h 2 a x: E G F P-r a b 5 c)^{m w 5}$ & ZDB-ALT-111017-5 & Early endosome & {$[341]$} \\
\hline $\operatorname{Tg}(h 2 a f x: E G F P-r a b 7 a)$ & $\begin{array}{l}\text { ZDB-TGCON- } \\
\text { STRCT-111017-4 }\end{array}$ & $\operatorname{Tg}(h 2 a x: E G F P-r a b 7 a)^{m w 7}$ & ZDB-ALT-111017-6 & Late endosome & {$[341]$} \\
\hline $\operatorname{Tg}(h 2 a f x: E G F P-r a b 11 a)$ & $\begin{array}{l}\text { ZDB-TGCON- } \\
\text { STRCT-111017-5 }\end{array}$ & $\operatorname{Tg}(h 2 a x: E G F P-r a b 11 a)^{m w 6}$ & ZDB-ALT-111017-7 & Recycling endosome & {$[341]$} \\
\hline$T g(C M V: E G F P-m a p 1 / c 3 b)$ & $\begin{array}{l}\text { ZDB-TGCON- } \\
\text { STRCT-091029-1 }\end{array}$ & $\begin{array}{l}\text { GFP-LC3, Tg(CMV:EGFP- } \\
\text { map 1/c3b zf155 }\end{array}$ & ZDB-ALT-091029-2 & Lysosomes & {$[349]$} \\
\hline Tg(CMV:EGFP-gabarapa) & $\begin{array}{l}\text { ZDB-TGCON- } \\
\text { STRCT-091029-2 }\end{array}$ & $\begin{array}{l}\text { GFP-Gabarap, Tg(CMV:EGFP- } \\
\text { gabarap) }\end{array}$ & ZDB-ALT-091029-1 & Lysosomes & {$[349]$} \\
\hline $\operatorname{Tg}(f a b p 10 a: E G F P-m a p 1 / c 3 b)$ & $\begin{array}{l}\text { ZDB-TGCON- } \\
\text { STRCT-120710-1 }\end{array}$ & $\begin{array}{l}\text { Tg(fabp 10a:EGFP- } \\
\text { map 1/c3b) })^{g z 22}\end{array}$ & ZDB-ALT-120710-1 & Liver lysosomes & {$[351]$} \\
\hline $\begin{array}{l}\text { Tg(Xla.Eefla1:GFP-LC3-RFP- } \\
L C 3 \triangle G)\end{array}$ & $\begin{array}{l}\text { ZDB-TGCON- } \\
\text { STRCT-171018-1 }\end{array}$ & $\begin{array}{l}\text { Tg(Xla.Eef1a 1:GFP-LC3-RFP- } \\
L C 3 \triangle G)^{j t 2}\end{array}$ & ZDB-ALT-171018-4 & Lysosomes & {$[352-354]$} \\
\hline $\operatorname{Tg}(g n a t 2: G F P-m a p 1 / c 3 b)$ & $\begin{array}{l}\text { ZDB-TGCON- } \\
\text { STRCT-140416-5 }\end{array}$ & Tg(gnat2:GFP-map 1/c3b)w138 & ZDB-ALT-140416-5 & $\begin{array}{l}\text { Photoreceptor cell lys- } \\
\text { osomes }\end{array}$ & {$[337]$} \\
\hline $\operatorname{Tg}(X \mid a . E e f 1 a 1: m / s E G F P)$ & $\begin{array}{l}\text { ZDB-TGCON- } \\
\text { STRCT-090309-1 }\end{array}$ & $\operatorname{Tg}(X \mid a . E e f 1 a 1: m / s E G F P)^{c m s 1}$ & ZDB-ALT-090309-2 & Mitochondria & {$[357]$} \\
\hline
\end{tabular}


$\operatorname{Tg}$ (actb2:Hsa.B4GALT1-GFP) line [336], which has been exploited to study dynamic protein secretory pathways that influence cell proliferation during ontogeny, and regeneration [337, 338].

\section{Endosome transgenic lines}

Rab proteins mediate endocytosis and vesicle trafficking in development, disease and cellular homeostasis [339]. More than $65 \mathrm{Rab}$ genes have been identified to date and are essential communicators with their effector proteins in formation, motilities and tethering of vesicles in membrane-bounded organelles [340]. To facilitate imaging of endosomes in real time and in vivo, Clark et al. generated transgenic fluorescent zebrafish lines [341]. To label early, recycling and late endosomes, they chose Rab5c (early), Rab11a (recycling), and Rab7 (late) based on localization and functions of these endosome subtypes in zebrafish and other species.

RAB5 has been studied for receptor-mediated signaling pathway in vesicle transport and fusion of membrane between clathrin coated vesicles of the plasma membrane and newly formed endosomes [342]. Among five zebrafish paralogs ( $r a b 5 a-c, r a b 5 a a$ and $r a b 5 a b$ ) of Drosophila Rab5, rab5c was selected for an early endosomal marker due to its ubiquitous expression in zebrafish embryos [343]. RAB11 protein is localized to the pericentriolar-recycling compartment, the recycling endosome [342]. Zebrafish rab11 has four paralogs: rab11a, rab11alike, rab11ba and rab11bb. Of which, Rab11a was used as a recycling endosome marker due to its highest protein sequence similarity to Drosophila Rab11a. In addition, Rab7 is localized to late endosomes and implicated in biogenesis of late endosomes and targeting trafficking vesicles to degradation [342]. Unlike Rab5c and Rab11a, the zebrafish Rab7 has no paralog. Rab5c, Rab11a and Rab7 were N-terminally fused to EGFP individually and then cloned downstream of the quasi-ubiquitous h2afx (also known as h2ax) promoter [341]. The resulting constructs were used to generate respective transgenic fluorescent zebrafish lines via Tol2 mediated transgenesis [335]: $\operatorname{Tg}(h 2 a f x: E G F P-R a b 5 c), \quad T g(h 2 a f x: E G F P-r a b 11 a)$ and $\operatorname{Tg}(h 2 a f x: E G F P-R a b 7)$. These lines were validated with co-localization between the fluorescent puncta from the EGFP-Rab lines and lipophilic dye FM4-64 at the early, recycling and late endosomes, respectively. Furthermore, these lines have been utilized to study the endocytosis, recycling endosomes of protein secretory pathway and their intracellular dynamics in development [344] and human diseases [231].

\section{Autophagy transgenic line}

Autophagy is an essential cellular degradative pathway that delivers cytoplasmic cargo to the lysosome. During autophagy, an autophagosome, a double-membrane vesicle, fuses with a lysosome, hydrolyses, and then degrades the macromolecules, which in turn recycles back into the cytosol for use as cellular nutrients. Autophagy plays an important role in host immune defense, tumor suppression, cardiovascular disease, gastrointestinal disorders, neurodegeneration and longevity [345-348]. The real-time monitoring of autophagy is an essential tool to reveal the process of autophagosome formation and to determine clearance of aggregate-prone proteins in in vivo small molecule screens for the autophagy regulators. To this end, $\mathrm{He}$ et al. generated two transgenic fluorescent zebrafish lines expressing a GFP fused to Lc3 [ $T g(C M V: E G F P-m a p 1 l c 3 b)]$ or to Gabarap N-terminally [Tg(CMV:EGFP-gabarapa)] under the control of the constitutive CMV promoter [349]. Gabarap is gammaaminobutyric acid type A receptor-associated protein. When they treated $3 \mathrm{dpf} T g(c m v: G F P-L c 3)$ embryos with rapamycin and lysosomal inhibitors, they observed that GFP puncta were formed and translocated to lysosomes. These lines have been adopted to monitor autophagic activity during embryogenesis in real time and in vivo $[348,350]$. In addition, expression of GFP-Lc3 in a tissue specific manner [liver: $\operatorname{Tg}(f a b p 10$ :EGFP-Lc3); photoreceptor: $\operatorname{Tg}(T \alpha C P: G F P-L c 3)]$ has made it feasible to study tissue-specific autophagy [337, 351].

To measure autophagic activity in real time and in vivo, the Mizushima group generated the $T g$ (Xla.Eef1 $\alpha 1$ :GFP$L C 3-R F P-L C 3 \Delta G)$ construct. Once translated, this gene product is cleaved by ATG4 protease into GFP-LC3 and RFP-LC3 $\Delta$ G. The former is conjugated with phosphatidylethanolamine (PE), targeted to the autophagosomes, and then degraded upon fusion of the autophagosomes with the lysosomes. However, RFP-LC3 $\Delta \mathrm{G}$ cannot be conjugated with PE due to lack of C-terminal glycine, which renders RFP-LC3 $\triangle \mathrm{G}$ stable in the cytoplasm. As such, the GFP/RFP signal ratio can act as readout of autophagic activity. Using this construct, they generated a $T g(X l a$. Eef1 1 1:GFP-LC3-RFP-LC3 $\triangle G$ ) line via Tol2 mediated transgenesis [352]. This line has been employed to assess effect of 1-phenyl 2-thiourea (PTU) on autophagic flux in zebrafish embryos [353] and to demonstrate requirement of autophagy for maturation of surfactant-containing lamellar bodies in the zebrafish swim bladder [354].

\section{Mitochondria transgenic line}

Mitochondria are double-membrane bound organelles and play an important role in energy production, metabolism, apoptosis, calcium storage and cellular signaling [355]. As such, mitochondria research has been a hot field and thus a need arose to image mitochondria in zebrafish. The Choi group cloned the mitochondrial localization sequence (MLS) of zebrafish cytochrome $c$ 
oxidase subunit VIIIA (cox8a) (NCBI accession number NM_001303053.1) to the $5^{\prime}$ end of EGFP gene on a mini-Tol2 vector $[356,357]$. Its expression was driven by a Xenopus EF-1 $\alpha$ promoter, a ubiquitous promoter. The resulting construct $T g(X l a$.Eefl $\alpha 1: m l s E G F P)$ was used to generate a zebrafish line expressing mitochondrially targeted GFP via Tol2 transposon-mediated transgenesis [164]. As expected, mitochondria in almost all types of cells in this line were labeled with GFP and mitochondrial fragmentation in chemically induced apoptosis was able to be imaged in real time and in vivo [357]. This line has been employed to visualize mitochondria in motor neurons [358], erythroid cells [359], photoreceptor cells [360] and skeletal muscles [361], and to study degradation of mitochondrial GFP [362] and effect of polycyclic aromatic hydrocarbon and hypoxia on mitochondrial content [363]. In addition, MLS-EGFP derived from the construct $\mathrm{Tg}($ Xla.Eef1 1 1:mlsEGFP) was used to image dopaminergic neurons [364, 365], Mauthner cells [366], mitophagy [367] and sensory neurons [368].

\section{Conclusion and perspectives}

This review summarized the transgenic fluorescent zebrafish lines that have been broadly used in biomedical research. As our understanding of promoters and enhancers widens, CRISPR/Cas9 mediated knock-in technology makes translational fusion easier than ever, and super resolution microscopes become commercially available, transgenic fluorescent zebrafish would make it feasible to image and track each and every protein in real time and in vivo in the near future. In addition, spatiotemporal regulation of fluorescent protein expression could be achieved by combining the transgenic fluorescent zebrafish lines with chemical or physical induction of fluorescent protein expression, which may become an invaluable tool in biomedical research.

\footnotetext{
Abbreviations

AKI: Acute kidney injury; AP: Anterior posterior; BAC: Bacterial artificial chromosome; BMP: Bone morphogenetic protein; BRE: BMP response element; Cas9: CRISPR-associated protein 9; CFP: Cyan fluorescent protein; CHT: Caudal hematopoietic tissue; CMV: Cytomegalovirus; CNC: Cranial neural crest; CNS: Central nervous system; COVID-19: Coronavirus disease-19; CRISPR: Clustered regularly interspaced short palindromic repeats; DA: Dopamine; dat: Dopamine transporter; dn-fgfr1: Dominant negative Fgf receptor; DNA: Deoxyribonucleic acid; dpf: Days post fertilization; DsRed: Discosoma sp. red; E. coli: Escherichia coli; EF-1 a: Elongation factor-1a; EGFP: Enhanced green fluorescent protein; ENS: Enteric nervous system; EPV.TP1: Epstein-Barr virus terminal protein 1; ER: Endoplasmic reticulum; FACS: Fluorescence-activated cell sorting; FGF: Fibroblast growth factor; FOXP2: Forkhead box protein P2; GalT: Galactotransferase; GFAP: Glial fibrillary acidic protein; GFP: Green fluorescent protein; Gl: Gastrointestinal; HDAC: Histone deacetylase; hpf: Hours post fertilization; HSC: Hematopoietic stem cells; HSP: Heat shock protein; I-FABP: Intestine fatty acid-binding protein; ICM: Intermediate cell mass; IPN: Interpeduncular nucleus; LEF: Lymphoid enhancer-binding factor; LFABP: Liver fatty acid binding protein; LPS: Lipopolysaccharide; MBP: Myelin basic protein; MH: Midbrain-hindbrain; MLS: Mitochondrial localization sequence; MN:
}

Motor neurons; MPEG: Macrophage Expressed Gene 1; MPX: Myeloperoxidase; MS: Multiple Sclerosis; MTZ: Metronidazole; NC: Neural crest; NCBI: National Center for Biotechnology Information; NLS: Nuclear localization sequence or signal; NSC: Neural stem cell; NTR: Nitroreductase; OL: Oligodendrocyte; PAC: P1-derived artificial chromosome; PD: Parkinson's disease; PGC: Primordial germ cell; PLM: Posterior lateral mesoderm; PNS: Peripheral nervous system; PTU: 1-Phenyl 2-thiourea; RBC: Red blood cell; RG: Radial glia; RNA: Ribonucleic acid; RUNX2: Runt-related transcription factor 2; SARS-CoV-2: Severe acute respiratory syndrome coronavirus 2; SOX9: SRY-Box transcription factor 9 ; TCF: T cell factor proteins; Tg: Transgenic; TGF- $\beta$ : Transforming growth factor beta; TOR: Target of rapamycin; TSS: Transcription start site; UAS: Upstream Activation Sequence; WISH: Whole mount in situ hybridization; ZFIN: Zebrafish information network.

\section{Acknowledgements}

We thank Gopalakrishnan Chandrasekaran and Ting Liang for their meticulous editing of our manuscript.

\section{Authors' contributions}

All authors conceived the project, drafted the manuscript and approved the final manuscript.

\section{Funding}

None declared.

Availability of data and materials

Not applicable.

\section{Declarations}

Competing interests

The authors declare that they have no competing interests.

\section{Author details}

${ }^{1}$ Division of Life Science, Gyeongsang National University, Jinju 52828, Republic of Korea. ${ }^{2}$ Division of Applied Life Science, Plant Molecular Biology and Biotechnology Research Center, Gyeongsang National University, Jinju 52828, Republic of Korea. ${ }^{3}$ Department of Biomedical Sciences, Chonnam National University Medical School, Hwasun 58128, Republic of Korea. ${ }^{4}$ Division of Biomedical Convergence, College of Biomedical Science, Kangwon National University, Chuncheon 24341, Republic of Korea. ${ }^{5}$ Department of Biological Sciences, Sookmyung Women's University, Seoul 04310, Republic of Korea. ${ }^{6}$ Department of Marine Life Sciences and Fish Vaccine Research Center, Jeju National University, Jeju 63243, Republic of Korea. ${ }^{7}$ Center for Genomic Integrity, Institute for Basic Science (IBS), Ulsan 44919, Republic of Korea. ${ }^{8}$ Department of Biomedical Sciences, College of Medicine, Korea University, Ansan 15355, Republic of Korea. ${ }^{9}$ Department of Biological Sciences, College of Bioscience and Biotechnology, Chungnam National University, Daejeon 34134, Republic of Korea.

Received: 2 June 2021 Accepted: 26 Auqust 2021

Published online: 08 September 2021

\section{References}

1. Hamilton F. An account of the fishes found in the river Ganges and its branches. London: Constable \& Co.; 1822.

2. Streisinger G, Walker C, Dower N, Knauber D, Singer F. Production of clones of homozygous diploid zebra fish (Brachydanio rerio). Nature. 1981;291(5813):293-6.

3. Stuart GW, McMurray JV, Westerfield M. Replication, integration and stable germ-line transmission of foreign sequences injected into early zebrafish embryos. Development. 1988;103(2):403-12.

4. Komori T, Yagi H, Nomura S, Yamaguchi A, Sasaki K, Deguchi K, et al. Targeted disruption of Cbfa1 results in a complete lack of bone formation owing to maturational arrest of osteoblasts. Cell. 1997;89(5):755-64.

5. Ruzicka L, Howe DG, Ramachandran S, Toro S, Van Slyke CE, Bradford YM, et al. The Zebrafish information network: new support for 
non-coding genes, richer gene ontology annotations and the alliance of genome resources. Nucleic Acids Res. 2019:47(D1):D867-73.

6. Schier AF, Talbot WS. Molecular genetics of axis formation in zebrafish. Annu Rev Genet. 2005;39:561-613.

7. Fuentes R, Tajer B, Kobayashi M, Pelliccia JL, Langdon Y, Abrams EW, et al. The maternal coordinate system: Molecular-genetics of embryonic axis formation and patterning in the zebrafish. Curr Top Dev Biol. 2020;140:341-89.

8. Sidi S, Goutel C, Peyriéras N, Rosa FM. Maternal induction of ventral fate by zebrafish radar. Proc Natl Acad Sci U S A. 2003;100(6):3315-20.

9. Kondo M. Bone morphogenetic proteins in the early development of zebrafish. FEBS J. 2007:274(12):2960-7.

10. Ro H, Dawid IB. Organizer restriction through modulation of Bozozok stability by the E3 ubiquitin ligase Lnx-like. Nat Cell Biol. 2009;11(9):1121-7.

11. Pyati UJ, Webb AE, Kimelman D. Transgenic zebrafish reveal stagespecific roles for Bmp signaling in ventral and posterior mesoderm development. Development. 2005;132(10):2333-43.

12. Korchynskyi O, ten Dijke P. Identification and functional characterization of distinct critically important bone morphogenetic protein-specific response elements in the Id1 promoter. J Biol Chem. 2002;277(7):4883-91.

13. Wu MY, Ramel MC, Howell M, Hill CS. SNW1 is a critical regulator of spatial BMP activity, neural plate border formation, and neural crest specification in vertebrate embryos. PLoS Biol. 2011;9(2):e1000593.

14. Ramel MC, Hill CS. The ventral to dorsal BMP activity gradient in the early zebrafish embryo is determined by graded expression of BMP ligands. Dev Biol. 2013;378(2):170-82.

15. Collery RF, Link BA. Dynamic smad-mediated BMP signaling revealed through transgenic zebrafish. Dev Dyn. 2011;240(3):712-22.

16. Dubrulle J, Jordan BM, Akhmetova L, Farrell JA, Kim SH, Solnica-Krezel $L$, et al. Response to Nodal morphogen gradient is determined by the kinetics of target gene induction. Elife. 2015;4:e05042.

17. Dorsky RI, Sheldahl LC, Moon RT. A transgenic Lef1/beta-catenindependent reporter is expressed in spatially restricted domains throughout zebrafish development. Dev Biol. 2002;241(2):229-37.

18. Barolo S. Transgenic Wnt/TCF pathway reporters: all you need is Lef? Oncogene. 2006;25(57):7505-11.

19. Moro E, Ozhan-Kizil G, Mongera A, Beis D, Wierzbicki C, Young RM, et al. In vivo Wnt signaling tracing through a transgenic biosensor fish reveals novel activity domains. Dev Biol. 2012;366(2):327-40.

20. Molina GA, Watkins SC, Tsang M. Generation of FGF reporter transgenic zebrafish and their utility in chemical screens. BMC Dev Biol. 2007;7:62.

21. Lee Y, Grill S, Sanchez A, Murphy-Ryan M, Poss KD. Fgf signaling instructs position-dependent growth rate during zebrafish fin regeneration. Development. 2005;132(23):5173-83.

22. Tsai SM, Liu DW, Wang WP. Fibroblast growth factor (Fgf) signaling pathway regulates liver homeostasis in zebrafish. Transgenic Res. 2013;22(2):301-14.

23. Lawson ND, Weinstein BM. In vivo imaging of embryonic vascular development using transgenic zebrafish. Dev Biol. 2002;248(2):307-18.

24. Baroffio A, Dupin E, Le Douarin NM. Common precursors for neural and mesectodermal derivatives in the cephalic neural crest. Development. 1991;112(1):301-5.

25. Schilling TF, Kimmel CB. Segment and cell type lineage restrictions during pharyngeal arch development in the zebrafish embryo. Development. 1994;120(3):483-94.

26. Wada N, Javidan Y, Nelson S, Carney TJ, Kelsh RN, Schilling TF. Hedgehog signaling is required for cranial neural crest morphogenesis and chondrogenesis at the midline in the zebrafish skull. Development. 2005;132(17):3977-88.

27. Crump JG, Maves L, Lawson ND, Weinstein BM, Kimmel CB. An essential role for Fgfs in endodermal pouch formation influences later craniofacial skeletal patterning. Development. 2004;131(22):5703-16.

28. Piotrowski T, Ahn DG, Schilling TF, Nair S, Ruvinsky I, Geisler R, et al. The zebrafish van gogh mutation disrupts tbx 1 , which is involved in the DiGeorge deletion syndrome in humans. Development 2003;130(20):5043-52.

29. Schwend T, Ahlgren SC. Zebrafish con/disp1 reveals multiple spatiotemporal requirements for Hedgehog-signaling in craniofacial development. BMC Dev Biol. 2009;9:59.
30. Piotrowski T, Nusslein-Volhard C. The endoderm plays an important role in patterning the segmented pharyngeal region in zebrafish (Danio rerio). Dev Biol. 2000;225(2):339-56.

31. Brown LA, Rodaway AR, Schilling TF, Jowett T, Ingham PW, Patient RK, et al. Insights into early vasculogenesis revealed by expression of the ETS-domain transcription factor Fli-1 in wild-type and mutant zebrafish embryos. Mech Dev. 2000;90(2):237-52.

32. Thompson MA, Ransom DG, Pratt SJ, MacLennan H, Kieran MW, Detrich HW, et al. The cloche and spadetail genes differentially affect hematopoiesis and vasculogenesis. Dev Biol. 1998;197(2):248-69.

33. Cox SG, Kim H, Garnett AT, Medeiros DM, An W, Crump JG. An essential role of variant histone $\mathrm{H} 33$ for ectomesenchyme potential of the cranial neural crest. PLoS Genet. 2012;8(9):e1002938.

34. Das A, Crump JG. Bmps and id2a act upstream of Twist1 to restrict ectomesenchyme potential of the cranial neural crest. PLoS Genet. 2012;8(5):e1002710.

35. Crump JG, Swartz ME, Kimmel CB. An integrin-dependent role of pouch endoderm in hyoid cartilage development. PLoS Biol. 2004;2(9):E244.

36. Sims NA, Martin TJ. The osteoblast lineage: its actions and communication mechanisms. In: Principles of bone biology. Elsevier; 2020. p. 89-110.

37. Nakashima K, Zhou X, Kunkel G, Zhang Z, Deng JM, Behringer RR, et al. The novel zinc finger-containing transcription factor osterix is required for osteoblast differentiation and bone formation. Cell. 2002;108(1):17-29.

38. Spoorendonk KM, Peterson-Maduro J, Renn J, Trowe T, Kranenbarg S, Winkler C, et al. Retinoic acid and Cyp26b1 are critical regulators of osteogenesis in the axial skeleton. Development. 2008;135(22):3765-74.

39. DeLaurier A, Eames BF, Blanco-Sanchez B, Peng G, He X, Swartz ME, et al. Zebrafish sp7:EGFP: a transgenic for studying otic vesicle formation, skeletogenesis, and bone regeneration. Genesis. 2010:48(8):505-11.

40. Hammond CL, Schulte-Merker S. Two populations of endochondral osteoblasts with differential sensitivity to Hedgehog signalling. Development. 2009;136(23):3991-4000.

41. Yang Z, Jiang H, Chaichanasakul T, Gong S, Yang XW, Heintz N, et al. Modified bacterial artificial chromosomes for zebrafish transgenesis. Methods. 2006;39(3):183-8.

42. Paul S, Schindler S, Giovannone D, de Millo TA, Mariani FV, Crump JG. Ihha induces hybrid cartilage-bone cells during zebrafish jawbone regeneration. Development. 2016;143(12):2066-76.

43. Lee HJ, Hou Y, Chen Y, Dailey ZZ, Riddihough A, Jang HS, et al. Regenerating zebrafish fin epigenome is characterized by stable lineage-specific DNA methylation and dynamic chromatin accessibility. Genome Biol. 2020;21(1):52.

44. Flores MV, Lam EY, Crosier P, Crosier K. A hierarchy of Runx transcription factors modulate the onset of chondrogenesis in craniofacial endochondral bones in zebrafish. Dev Dyn. 2006;235(11):3166-76.

45. Li N, Felber K, Elks P, Croucher P, Roehl HH. Tracking gene expression during zebrafish osteoblast differentiation. Dev Dyn. 2009;238(2):459-66

46. Knopf F, Hammond C, Chekuru A, Kurth T, Hans S, Weber CW, et al. Bone regenerates via dedifferentiation of osteoblasts in the zebrafish fin. Dev Cell. 2011;20(5):713-24.

47. Geurtzen K, Knopf F, Wehner D, Huitema LF, Schulte-Merker S, Weidinger $\mathrm{G}$. Mature osteoblasts dedifferentiate in response to traumatic bone injury in the zebrafish fin and skull. Development. 2014;141(11):2225-34.

48. Mishra R, Sehring I, Cederlund M, Mulaw M, Weidinger G. NF-kappaB signaling negatively regulates osteoblast dedifferentiation during zebrafish bone regeneration. Dev Cell. 2020;52(2):167-82.e7.

49. Kague E, Roy P, Asselin G, Hu G, Simonet J, Stanley A, et al. Osterix/ Sp7 limits cranial bone initiation sites and is required for formation of sutures. Dev Biol. 2016;413(2):160-72.

50. Grabher C, Joly JS, Wittbrodt J. Highly efficient zebrafish transgenesis mediated by the meganuclease I-Scel. Methods Cell Biol. 2004:77:381-401.

51. Exposito JY, Valcourt U, Cluzel C, Lethias C. The fibrillar collagen family. Int J Mol Sci. 2010;1 1(2):407-26.

52. Prockop DJ, Kivirikko KI. Collagens: molecular biology, diseases, and potentials for therapy. Annu Rev Biochem. 1995;64:403-34. 
53. Zhou G, Garofalo S, Mukhopadhyay K, Lefebvre V, Smith CN, Eberspaecher $\mathrm{H}$, et al. A 182 bp fragment of the mouse pro alpha 1 (II) collagen gene is sufficient to direct chondrocyte expression in transgenic mice. J Cell Sci. 1995;108(Pt 12):3677-84.

54. Dale RM, Topczewski J. Identification of an evolutionarily conserved regulatory element of the zebrafish col2ala gene. Dev Biol. 2011;357(2):518-31.

55. Kawakami K, Shima A. Identification of the Tol2 transposase of the medaka fish Oryzias latipes that catalyzes excision of a nonautonomous Tol2 element in zebrafish Danio rerio. Gene. 1999;240(1):239-44.

56. Kwan KM, Fujimoto E, Grabher C, Mangum BD, Hardy ME, Campbell DS, et al. The Tol2kit: a multisite gateway-based construction kit for Tol2 transposon transgenesis constructs. Dev Dyn. 2007;236(11):3088-99.

57. Dougherty M, Kamel G, Grimaldi M, Gfrerer L, Shubinets V, Ethier R, et al. Distinct requirements for wnt9a and iff6 in extension and integration mechanisms during zebrafish palate morphogenesis. Development. 2013;140(1):76-81.

58. Askary A, Mork L, Paul S, He X, Izuhara AK, Gopalakrishnan S, et al. Iroquois proteins promote skeletal joint formation by maintaining chondrocytes in an immature state. Dev Cell. 2015;35(3):358-65.

59. Unlu G, Qi X, Gamazon ER, Melville DB, Patel N, Rushing AR, et al. Phenome-based approach identifies RIC1-linked Mendelian syndrome through zebrafish models, biobank associations and clinical studies. Nat Med. 2020;26(1):98-109.

60. Bonkowsky JL, Wang X, Fujimoto E, Lee JE, Chien CB, Dorsky RI. Domainspecific regulation of foxP2 CNS expression by lef1. BMC Dev Biol. 2008;8:103.

61. Eames BF, DeLaurier A, Ullmann B, Huycke TR, Nichols JT, Dowd J, et al. FishFace: interactive atlas of zebrafish craniofacial development at cellular resolution. BMC Dev Biol. 2013;13:23.

62. McGurk PD, Swartz ME, Chen JW, Galloway JL, Eberhart JK. In vivo zebrafish morphogenesis shows Cyp26b1 promotes tendon condensation and musculoskeletal patterning in the embryonic jaw. PLoS Genet. 2017;13(12):e1007112

63. Nichols JT, Blanco-Sanchez B, Brooks EP, Parthasarathy R, Dowd J, et al. Ligament versus bone cell identity in the zebrafish hyoid skeleton is regulated by mef2ca. Development. 2016;143(23):4430-40.

64. Nichols JT, Pan L, Moens CB, Kimmel CB. barx1 represses joints and promotes cartilage in the craniofacial skeleton. Development. 2013;140(13):2765-75

65. Tallafuss A, Bally-Cuif L. Tracing of her5 progeny in zebrafish transgenics reveals the dynamics of midbrain-hindbrain neurogenesis and maintenance. Development. 2003;130(18):4307-23.

66. Muyrers JP, Zhang Y, Testa G, Stewart AF. Rapid modification of bacterial artificial chromosomes by ET-recombination. Nucleic Acids Res. 1999;27(6):1555-7.

67. Choe CP, Collazo A, le Trinh A, Pan L, Moens CB, Crump JG. Wntdependent epithelial transitions drive pharyngeal pouch formation. Dev Cell. 2013;24(3):296-309.

68. Balczerski B, Matsutani M, Castillo P, Osborne N, Stainier DY, Crump JG. Analysis of sphingosine-1-phosphate signaling mutants reveals endodermal requirements for the growth but not dorsoventral patterning of jaw skeletal precursors. Dev Biol. 2012;362(2):230-41.

69. Choe CP, Crump JG. Eph-Pak2a signaling regulates branching of the pharyngeal endoderm by inhibiting late-stage epithelial dynamics. Development. 2015;142(6):1089-94.

70. Talbot JC, Walker MB, Carney TJ, Huycke TR, Yan YL, BreMiller RA, et al. fras 1 shapes endodermal pouch 1 and stabilizes zebrafish pharyngeal skeletal development. Development. 2012;139(15):2804-13.

71. Alexander J, Stainier DY. A molecular pathway leading to endoderm formation in zebrafish. Curr Biol. 1999;9(20):1147-57.

72. Seguin CA, Draper JS, Nagy A, Rossant J. Establishment of endoderm progenitors by SOX transcription factor expression in human embryonic stem cells. Cell Stem Cell. 2008;3(2):182-95.

73. Viotti M, Nowotschin S, Hadjantonakis AK. SOX17 links gut endoderm morphogenesis and germ layer segregation. Nat Cell Biol. 2014;16(12):1146-56.

74. Chung WS, Stainier DY. Intra-endodermal interactions are required for pancreatic beta cell induction. Dev Cell. 2008;14(4):582-93.
75. Cheng P, Andersen P, Hassel D, Kaynak BL, Limphong P, Juergensen $L$, et al. Fibronectin mediates mesendodermal cell fate decisions. Development. 2013;140(12):2587-96.

76. Larbuisson A, Dalcq J, Martial JA, Muller M. Fgf receptors Fgfr1a and Fgfr2 control the function of pharyngeal endoderm in late cranial cartilage development. Differentiation. 2013;86(4-5):192-206.

77. Sakaguchi T, Kikuchi Y, Kuroiwa A, Takeda H, Stainier DY. The yolk syncytial layer regulates myocardial migration by influencing extracellular matrix assembly in zebrafish. Development. 2006;133(20):4063-72.

78. Dalcq J, Pasque V, Ghaye A, Larbuisson A, Motte P, Martial JA, et al. RUNX3, EGR1 and SOX9B form a regulatory cascade required to modulate BMP-signaling during cranial cartilage development in zebrafish. PLoS ONE. 2012;7(11):e50140.

79. Lovely CB, Swartz ME, McCarthy N, Norrie JL, Eberhart JK. Bmp signaling mediates endoderm pouch morphogenesis by regulating Fgf signaling in zebrafish. Development. 2016;143(11):2000-11.

80. Chung WS, Shin CH, Stainier DY. Bmp2 signaling regulates the hepatic versus pancreatic fate decision. Dev Cell. 2008;15(5):738-48.

81. Klein C, Mikutta J, Krueger J, Scholz K, Brinkmann J, Liu D, et al. Neuron navigator 3a regulates liver organogenesis during zebrafish embryogenesis. Development. 2011;138(10):1935-45.

82. Lee $\mathrm{KH}, \mathrm{Xu} \mathrm{Q}$, Breitbart RE. A new tinman-related gene, $n k \times 2.7$, anticipates the expression of $n k \times 2.5$ and $n k \times 2.3$ in zebrafish heart and pharyngeal endoderm. Dev Biol. 1996;180(2):722-31.

83. Serbedzija GN, Chen JN, Fishman MC. Regulation in the heart field of zebrafish. Development. 1998;125(6):1095-101.

84. Witzel HR, Jungblut B, Choe CP, Crump JG, Braun T, Dobreva G. The LIM protein Ajuba restricts the second heart field progenitor pool by regulating Isl1 activity. Dev Cell. 2012;23(1):58-70.

85. Choe CP, Crump JG. Tbx1 controls the morphogenesis of pharyngeal pouch epithelia through mesodermal Wnt1 $1 \mathrm{r}$ and Fgf8a. Development. 2014;141(18):3583-93.

86. Traver D, Paw BH, Poss KD, Penberthy WT, Lin S, Zon LI. Transplantation and in vivo imaging of multilineage engraftment in zebrafish bloodless mutants. Nat Immunol. 2003;4(12):1238-46.

87. Traver D. Cellular dissection of zebrafish hematopoiesis. Methods Cell Biol. 2004;76:127-49.

88. Bertrand JY, Chi NC, Santoso B, Teng S, Stainier DY, Traver D. Haematopoietic stem cells derive directly from aortic endothelium during development. Nature. 2010;464(7285):108-11.

89. Gore AV, Pillay LM, Venero Galanternik M, Weinstein BM. The zebrafish: a fintastic model for hematopoietic development and disease. Wiley Interdiscip Rev Dev Biol. 2018;7(3):e312.

90. Detrich HW 3rd, Kieran MW, Chan FY, Barone LM, Yee K, Rundstadler $J A$, et al. Intraembryonic hematopoietic cell migration during vertebrate development. Proc Natl Acad Sci U S A. 1995;92(23):10713-7.

91. Avagyan S, Zon LI. Fish to learn: insights into blood development and blood disorders from zebrafish hematopoiesis. Hum Gene Ther. 2016;27(4):287-94.

92. Long Q, Meng A, Wang H, Jessen JR, Farrell MJ, Lin S. GATA-1 expression pattern can be recapitulated in living transgenic zebrafish using GFP reporter gene. Development. 1997;124(20):4105-11.

93. Jagadeeswaran $\mathrm{P}$, Lin S, Weinstein B, Hutson A, Kim S. Loss of GATA1 and gain of FLI1 expression during thrombocyte maturation. Blood Cells Mol Dis. 2010;44(3):175-80.

94. Payne EM, Bolli N, Rhodes J, Abdel-Wahab OI, Levine R, Hedvat $\mathrm{CV}$, et al. Ddx18 is essential for cell-cycle progression in zebrafish hematopoietic cells and is mutated in human AML. Blood. 2011;118(4):903-15.

95. Forouhar AS, Liebling M, Hickerson A, Nasiraei-Moghaddam A, Tsai HJ, Hove JR, et al. The embryonic vertebrate heart tube is a dynamic suction pump. Science. 2006;312(5774):751-3.

96. Bennett CM, Kanki JP, Rhodes J, Liu TX, Paw BH, Kieran MW, et al. Myelopoiesis in the zebrafish. Danio rerio Blood. 2001;98(3):643-51.

97. Mathias JR, Perrin BJ, Liu TX, Kanki J, Look AT, Huttenlocher A. Resolution of inflammation by retrograde chemotaxis of neutrophils in transgenic zebrafish. J Leukoc Biol. 2006;80(6):1281-8.

98. Ellett F, Pase L, Hayman JW, Andrianopoulos A, Lieschke GJ. mpeg1 promoter transgenes direct macrophage-lineage expression in zebrafish. Blood. 2011;117(4):e49-56. 
99. Niethammer P, Grabher C, Look AT, Mitchison TJ. A tissue-scale gradient of hydrogen peroxide mediates rapid wound detection in zebrafish. Nature. 2009:459(7249):996-9.

100. Yoo SK, Deng Q, Cavnar PJ, WU YI, Hahn KM, Huttenlocher A. Differential regulation of protrusion and polarity by PI3K during neutrophil motility in live zebrafish. Dev Cell. 2010;18(2):226-36.

101. Balla KM, Lugo-Villarino G, Spitsbergen JM, Stachura DL, Hu Y, Banuelos K, et al. Eosinophils in the zebrafish: prospective isolation, characterization, and eosinophilia induction by helminth determinants. Blood. 2010;116(19):3944-54.

102. Pei W, Tanaka K, Huang SC, Xu L, Liu B, Sinclair J, et al. Extracellular HSP60 triggers tissue regeneration and wound healing by regulating inflammation and cell proliferation. NPJ Regen Med. 2016;1:16013.

103. Goldshmit Y, Sztal TE, Jusuf PR, Hall TE, Nguyen-Chi M, Currie PD. Fgf-dependent glial cell bridges facilitate spinal cord regeneration in zebrafish. J Neurosci. 2012;32(22):7477-92.

104. Evans MA, Smart N, Dube KN, Bollini S, Clark JE, Evans HG, et al. Thymosin beta4-sulfoxide attenuates inflammatory cell infiltration and promotes cardiac wound healing. Nat Commun. 2013;4:2081.

105. Misselbeck K, Parolo S, Lorenzini F, Savoca V, Leonardelli L, Bora P, et al. A network-based approach to identify deregulated pathways and drug effects in metabolic syndrome. Nat Commun. 2019;10(1):5215.

106. Ferrero $G$, Mahony CB, Dupuis E, Yvernogeau L, Di Ruggiero $E$, Miserocchi M, et al. Embryonic microglia derive from primitive macrophages and are replaced by cmyb-dependent definitive microglia in zebrafish. Cell Rep. 2018;24(1):130-41.

107. Pope HM, Voigt MM. Peripheral glia have a pivotal role in the initial response to axon degeneration of peripheral sensory neurons in zebrafish. PLoS ONE. 2014;9(7):e103283.

108. Li D, Xue W, Li M, Dong M, Wang J, Wang X, et al. VCAM-1(+) macrophages guide the homing of HSPCs to a vascular niche. Nature. 2018;564(7734):119-24.

109. Orkin SH, Zon LI. Hematopoiesis: an evolving paradigm for stem cell biology. Cell. 2008;132(4):631-44.

110. Tamplin OJ, Durand EM, Carr LA, Childs SJ, Hagedorn EJ, Li P, et al. Hematopoietic stem cell arrival triggers dynamic remodeling of the perivascular niche. Cell. 2015;160(1-2):241-52.

111. Mahony CB, Bertrand JY. How HSC s colonize and expand in the fetal niche of the vertebrate embryo: an evolutionary perspective. Front Cell Dev Biol. 2019;7:34.

112. North TE, Goessling W, Walkley CR, Lengerke C, Kopani KR, Lord AM, et al. Prostaglandin E2 regulates vertebrate haematopoietic stem cell homeostasis. Nature. 2007:447(7147):1007-11.

113. Nottingham WT, Jarratt A, Burgess M, Speck CL, Cheng JF, Prabhakar S, et al. Runx1-mediated hematopoietic stem-cell emergence is controlled by a Gata/Ets/SCL-regulated enhancer. Blood. 2007;110(13):4188-97.

114. Espin-Palazon R, Stachura DL, Campbell CA, Garcia-Moreno D, Del Cid $\mathrm{N}$, Kim AD, et al. Proinflammatory signaling regulates hematopoietic stem cell emergence. Cell. 2014;159(5):1070-85.

115. Lee Y, Manegold JE, Kim AD, Pouget C, Stachura DL, Clements WK, et al. FGF signalling specifies haematopoietic stem cells through its regulation of somitic Notch signalling. Nat Commun. 2014;5:5583.

116. Espanola SG, Song H, Ryu E, Saxena A, Kim ES, Manegold JE, et al. Haematopoietic stem cell-dependent Notch transcription is mediated by p53 through the Histone chaperone Supt16h. Nat Cell Biol. 2020;22(12):1411-22

117. Lin HF, Traver D, Zhu H, Dooley K, Paw BH, Zon LI, et al. Analysis of thrombocyte development in CD41-GFP transgenic zebrafish. Blood. 2005;106(12):3803-10.

118. North TE, Goessling W, Peeters M, Li P, Ceol C, Lord AM, et al. Hematopoietic stem cell development is dependent on blood flow. Cell. 2009:137(4):736-48.

119. Damm EW, Clements WK. Pdgf signalling guides neural crest contribution to the haematopoietic stem cell specification niche. Nat Cell Biol. 2017;19(5):457-67.

120. Gu A, Ji G, Yan L, Zhou Y. The 8-oxoguanine DNA glycosylase 1 (ogg1) decreases the vulnerability of the developing brain to DNA damage. DNA Repair (Amst). 2013;12(12):1094-104.
121. Liu W, Wu M, Huang Z, Lian J, Chen J, Wang T, et al. c-myb hyperactivity leads to myeloid and lymphoid malignancies in zebrafish. Leukemia. 2017;31(1):222-33.

122. Beis D, Bartman T, Jin SW, Scott IC, D'Amico LA, Ober EA, et al. Genetic and cellular analyses of zebrafish atrioventricular cushion and valve development. Development. 2005;132(18):4193-204.

123. Kawakami K, Takeda H, Kawakami N, Kobayashi M, Matsuda N, Mishina M. A transposon-mediated gene trap approach identifies developmentally regulated genes in zebrafish. Dev Cell. 2004;7(1):133-44.

124. Zhang R, Han P, Yang H, Ouyang K, Lee D, Lin YF, et al. In vivo cardiac reprogramming contributes to zebrafish heart regeneration. Nature. 2013;498(7455):497-501.

125. Butko E, Distel M, Pouget C, Weijts B, Kobayashi I, Ng K, et al. Gata2b is a restricted early regulator of hemogenic endothelium in the zebrafish embryo. Development. 2015;142(6):1050-61.

126. Distel M, Wullimann MF, Koster RW. Optimized Gal4 genetics for permanent gene expression mapping in zebrafish. Proc Natl Acad Sci U S A. 2009;106(32):13365-70.

127. Bussmann J, Schulte-Merker S. Rapid BAC selection for tol2-mediated transgenesis in zebrafish. Development. 2011;138(19):4327-32.

128. Sood R, Liu P. Novel insights into the genetic controls of primitive and definitive hematopoiesis from zebrafish models. Adv Hematol. 2012;2012:830703.

129. Willett CE, Cherry JJ, Steiner LA. Characterization and expression of the recombination activating genes (rag 1 and rag2) of zebrafish. Immunogenetics. 1997:45(6):394-404.

130. Willett CE, Zapata AG, Hopkins N, Steiner LA. Expression of zebrafish rag genes during early development identifies the thymus. Dev Biol. 1997;182(2):331-41.

131. Jessen JR, Willett CE, Lin S. Artificial chromosome transgenesis reveals long-distance negative regulation of rag1 in zebrafish. Nat Genet. 1999;23(1):15-6.

132. Jessen JR, Jessen TN, Vogel SS, Lin S. Concurrent expression of recombination activating genes 1 and 2 in zebrafish olfactory sensory neurons. Genesis. 2001;29(4):156-62.

133. Jessen JR, Meng A, McFarlane RJ, Paw BH, Zon LI, Smith GR, et al. Modification of bacterial artificial chromosomes through chi-stimulated homologous recombination and its application in zebrafish transgenesis. Proc Natl Acad Sci U S A. 1998;95(9):5121-6.

134. Langenau DM, Traver D, Ferrando AA, Kutok JL, Aster JC, Kanki JP, et al. Myc-induced T cell leukemia in transgenic zebrafish. Science. 2003;299(5608):887-90.

135. Chen J, Jette C, Kanki JP, Aster JC, Look AT, Griffin JD. NOTCH1-induced T-cell leukemia in transgenic zebrafish. Leukemia. 2007;21(3):462-71.

136. Okamoto H, Agetsuma M, Aizawa H. Genetic dissection of the zebrafish habenula, a possible switching board for selection of behavioral strategy to cope with fear and anxiety. Dev Neurobiol. 2012;72(3):386-94.

137. Hikosaka O. The habenula: from stress evasion to value-based decisionmaking. Nat Rev Neurosci. 2010;11(7):503-13.

138. Bianco IH, Wilson SW. The habenular nuclei: a conserved asymmetric relay station in the vertebrate brain. Philos Trans R Soc Lond B Biol Sci. 2009;364(1519):1005-20.

139. Amo R, Aizawa H, Takahoko M, Kobayashi M, Takahashi R, Aoki T, et al. Identification of the zebrafish ventral habenula as a homolog of the mammalian lateral habenula. J Neurosci. 2010;30(4):1566-74.

140. Aizawa H, Bianco IH, Hamaoka T, Miyashita T, Uemura O, Concha ML, et al. Laterotopic representation of left-right information onto the dorso-ventral axis of a zebrafish midbrain target nucleus. Curr Biol. 2005;15(3):238-43.

141. Higashijima S, Okamoto H, Ueno N, Hotta Y, Eguchi G. High-frequency generation of transgenic zebrafish which reliably express GFP in whole muscles or the whole body by using promoters of zebrafish origin. Dev Biol. 1997;192(2):289-99.

142. Chou MY, Amo R, Kinoshita M, Cherng BW, Shimazaki H, Agetsuma $\mathrm{M}$, et al. Social conflict resolution regulated by two dorsal habenular subregions in zebrafish. Science. 2016;352(6281):87-90.

143. Kim E, Jeong I, Chung AY, Kim S, Kwon SH, Seong JY, et al. Distribution and neuronal circuit of spexin $1 / 2$ neurons in the zebrafish CNS. Sci Rep. 2019;9(1):5025.

144. Kimura Y, Okamura Y, Higashijima S. alx, a zebrafish homolog of Chx10, marks ipsilateral descending excitatory interneurons that 
participate in the regulation of spinal locomotor circuits. J Neurosci. 2006;26(21):5684-97.

145. Amo R, Fredes F, Kinoshita M, Aoki R, Aizawa H, Agetsuma M, et al. The habenulo-raphe serotonergic circuit encodes an aversive expectation value essential for adaptive active avoidance of danger. Neuron. 2014;84(5):1034-48.

146. Suster ML, Sumiyama K, Kawakami K. Transposon-mediated BAC transgenesis in zebrafish and mice. BMC Genomics. 2009;10:477.

147. Andalman AS, Burns VM, Lovett-Barron M, Broxton M, Poole B, Yang SJ, et al. Neuronal dynamics regulating brain and behavioral state transitions. Cell. 2019;177(4):970-85.e20.

148. Shin J, Park HC, Topczewska JM, Mawdsley DJ, Appel B. Neural cell fate analysis in zebrafish using olig2 BAC transgenics. Methods Cell Sci. 2003;25(1-2):7-14.

149. Yu D, Ellis HM, Lee EC, Jenkins NA, Copeland NG, Court DL. An efficient recombination system for chromosome engineering in Escherichia coli. Proc Natl Acad Sci U S A. 2000;97(1 1):5978-83.

150. Shin J, Poling J, Park HC, Appel B. Notch signaling regulates neural precursor allocation and binary neuronal fate decisions in zebrafish. Development. 2007;134(10):1911-20.

151. Park HC, Shin J, Roberts RK, Appel B. An olig2 reporter gene marks oligodendrocyte precursors in the postembryonic spinal cord of zebrafish. Dev Dyn. 2007;236(12):3402-7.

152. Reimer MM, Sorensen I, Kuscha V, Frank RE, Liu C, Becker CG, et al. Motor neuron regeneration in adult zebrafish. J Neurosci. 2008;28(34):8510-6.

153. Ohnmacht J, Yang Y, Maurer GW, Barreiro-Iglesias A, Tsarouchas TM, Wehner D, et al. Spinal motor neurons are regenerated after mechanical lesion and genetic ablation in larval zebrafish. Development. 2016;143(9):1464-74.

154. Sidik $\mathrm{H}$, Talbot WS. A zinc finger protein that regulates oligodendrocyte specification, migration and myelination in zebrafish. Development. 2015;142(23):4119-28

155. Djenoune L, Khabou H, Joubert F, Quan FB, Nunes Figueiredo $S$, Bodineau $L$, et al. Investigation of spinal cerebrospinal fluid-contacting neurons expressing PKD2L1: evidence for a conserved system from fish to primates. Front Neuroanat. 2014;8:26.

156. Kani S, Bae YK, Shimizu T, Tanabe K, Satou C, Parsons MJ, et al. Proneural gene-linked neurogenesis in zebrafish cerebellum. Dev Biol. 2010;343(1-2):1-17.

157. Kim CH, Ueshima E, Muraoka O, Tanaka H, Yeo SY, Huh TL, et al. Zebrafish elav/HuC homologue as a very early neuronal marker. Neurosci Lett. 1996;216(2):109-12

158. Chen CY, Shyu AB. AU-rich elements: characterization and importance in mRNA degradation. Trends Biochem Sci. 1995;20(11):465-70.

159. Park HC, Kim CH, Bae YK, Yeo SY, Kim SH, Hong SK, et al. Analysis of upstream elements in the HuC promoter leads to the establishment of transgenic zebrafish with fluorescent neurons. Dev Biol. 2000;227(2):279-93.

160. Sato T, Takahoko M, Okamoto H. HuC:Kaede, a useful tool to label neural morphologies in networks in vivo. Genesis. 2006;44(3):136-42.

161. Faucherre A, Lopez-Schier H. Delaying Gal4-driven gene expression in the zebrafish with morpholinos and Gal80. PLoS ONE. 2011;6(1):e16587.

162. Panier T, Romano SA, Olive R, Pietri T, Sumbre G, Candelier R, et al. Fast functional imaging of multiple brain regions in intact zebrafish larvae using selective plane illumination microscopy. Front Neural Circuits. 2013;7:65.

163. Jung SH, Kim S, Chung AY, Kim HT, So JH, Ryu J, et al. Visualization of myelination in GFP-transgenic zebrafish. Dev Dyn. 2010;239(2):592-7.

164. Fisher S, Grice EA, Vinton RM, Bessling SL, Urasaki A, Kawakami K, et al. Evaluating the biological relevance of putative enhancers using Tol2 transposon-mediated transgenesis in zebrafish. Nat Protoc. 2006;1 (3):1297-305

165. Chung AY, Kim S, Kim E, Kim D, Jeong I, Cha YR, et al. Indian hedgehog B function is required for the specification of oligodendrocyte progenitor cells in the zebrafish CNS. J Neurosci. 2013;3(4):1728-33.

166. Early JJ, Cole KL, Williamson JM, Swire M, Kamadurai H, Muskavitch $M$, et al. An automated high-resolution in vivo screen in zebrafish to identify chemical regulators of myelination. Elife. 2018;7:e35136.

167. Almeida RG, Czopka T, Ffrench-Constant C, Lyons DA. Individual axons regulate the myelinating potential of single oligodendrocytes in vivo. Development. 2011;138(20):4443-50.
168. Chung AY, Kim PS, Kim S, Kim E, Kim D, Jeong I, et al. Generation of demyelination models by targeted ablation of oligodendrocytes in the zebrafish CNS. Mol Cells. 2013;36(1):82-7.

169. Curado S, Stainier DY, Anderson RM. Nitroreductase-mediated cell/tissue ablation in zebrafish: a spatially and temporally controlled ablation method with applications in developmental and regeneration studies. Nat Protoc. 2008;3(6):948-54.

170. Jacob C. Transcriptional control of neural crest specification into peripheral glia. Glia. 2015;63(11):1883-96.

171. Kelsh RN. Sorting out Sox10 functions in neural crest development. BioEssays. 2006;28(8):788-98.

172. Herbarth B, Pingault V, Bondurand N, Kuhlbrodt K, Hermans-Borgmeyer I, Puliti A, et al. Mutation of the Sry-related Sox10 gene in Dominant megacolon, a mouse model for human Hirschsprung disease. Proc Natl Acad Sci U S A. 1998;95(9):5161-5.

173. Inoue K, Tanabe Y, Lupski JR. Myelin deficiencies in both the central and the peripheral nervous systems associated with a SOX10 mutation. Ann Neurol. 1999:46(3):313-8.

174. Kapur RP. Early death of neural crest cells is responsible for total enteric aganglionosis in Sox10(Dom)/Sox 10(Dom) mouse embryos. Pediatr Dev Pathol. 1999;2(6):559-69.

175. Carney TJ, Dutton KA, Greenhill E, Delfino-Machin M, Dufourcq P, Blader $P$, et al. A direct role for Sox 10 in specification of neural crest-derived sensory neurons. Development. 2006;133(23):4619-30.

176. Tobin JL, Di Franco M, Eichers E, May-Simera H, Garcia M, Yan J, et al. Inhibition of neural crest migration underlies craniofacial dysmorphology and Hirschsprung's disease in Bardet-Biedl syndrome. Proc Natl Acad Sci U S A. 2008;105(18):6714-9.

177. Shellard A, Szabo A, Trepat X, Mayor R. Supracellular contraction at the rear of neural crest cell groups drives collective chemotaxis. Science. 2018:362(6412):339-43.

178. Stolt CC, Rehberg S, Ader M, Lommes P, Riethmacher D, Schachner $\mathrm{M}$, et al. Terminal differentiation of myelin-forming oligodendrocytes depends on the transcription factor Sox10. Genes Dev. 2002;16(2):165-70.

179. Chung AY, Kim S, Kim H, Bae YK, Park HC. Microarray screening for genes involved in oligodendrocyte differentiation in the zebrafish CNS. Exp Neurobiol. 2011;20(2):85-91.

180. Malatesta P, Gotz M. Radial glia-from boring cables to stem cell stars. Development. 2013;140(3):483-6.

181. Kriegstein A, Alvarez-Buylla A. The glial nature of embryonic and adult neural stem cells. Annu Rev Neurosci. 2009;32:149-84.

182. Bernardos RL, Raymond PA. GFAP transgenic zebrafish. Gene Expr Patterns. 2006;6(8):1007-13.

183. Lam CS, Marz M, Strahle U. gfap and nestin reporter lines reveal characteristics of neural progenitors in the adult zebrafish brain. Dev Dyn. 2009;238(2):475-86.

184. Barbosa JS, Sanchez-Gonzalez R, Di Giaimo R, Baumgart EV, Theis FJ, Gotz M, et al. Neurodevelopment. Live imaging of adult neural stem cell behavior in the intact and injured zebrafish brain. Science. 2015;348(6236):789-93.

185. Bernardos RL, Barthel LK, Meyers JR, Raymond PA. Late-stage neuronal progenitors in the retina are radial Muller glia that function as retinal stem cells. J Neurosci. 2007;27(26):7028-40.

186. Smith CJ, Johnson K, Welsh TG, Barresi MJ, Kucenas S. Radial glia inhibit peripheral glial infiltration into the spinal cord at motor exit point transition zones. Glia. 2016;64(7):1138-53.

187. Briona LK, Poulain FE, Mosimann C, Dorsky RI. Wnt/ss-catenin signaling is required for radial glial neurogenesis following spinal cord injury. Dev Biol. 2015;403(1):15-21.

188. Fuchs $E$, Tumbar T, Guasch G. Socializing with the neighbors: stem cells and their niche. Cell. 2004;116(6):769-78.

189. Lendahl U, Zimmerman LB, McKay RD. CNS stem cells express a new class of intermediate filament protein. Cell. 1990;60(4):585-95.

190. Marz M, Schmidt R, Rastegar S, Strahle U. Regenerative response following stab injury in the adult zebrafish telencephalon. Dev Dyn. 2011;240(9):2221-31.

191. Kaslin J, Ganz J, Geffarth M, Grandel H, Hans S, Brand M. Stem cells in the adult zebrafish cerebellum: initiation and maintenance of a novel stem cell niche. J Neurosci. 2009;29(19):6142-53. 
192. Drechsel DN, Hyman AA, Cobb MH, Kirschner MW. Modulation of the dynamic instability of tubulin assembly by the microtubule-associated protein tau. Mol Biol Cell. 1992;3(10):1141-54.

193. Noble W, Hanger DP, Miller CC, Lovestone S. The importance of tau phosphorylation for neurodegenerative diseases. Front Neurol. 2013;4:83.

194. Goedert M, Eisenberg DS, Crowther RA. Propagation of tau aggregates and neurodegeneration. Annu Rev Neurosci. 2017;40:189-210.

195. Paquet D, Bhat R, Sydow A, Mandelkow EM, Berg S, Hellberg S, et al. A zebrafish model of tauopathy allows in vivo imaging of neuronal cell death and drug evaluation. J Clin Invest. 2009;1 19(5):1382-95.

196. Barbereau C, Yehya A, Silhol M, Cubedo N, Verdier JM, Maurice T, et al. Neuroprotective brain-derived neurotrophic factor signaling in the TAU-P301L tauopathy zebrafish model. Pharmacol Res. 2020;158:104865

197. Hassan-Abdi R, Brenet A, Bennis M, Yanicostas C, Soussi-Yanicostas N. Neurons expressing pathological tau protein trigger dramatic changes in microglial morphology and dynamics. Front Neurosci. 2019;13:1199.

198. Giustiniani J, Chambraud B, Sardin E, Dounane O, Guillemeau K, Nakatani H, et al. Immunophilin FKBP52 induces Tau-P301L filamentous assembly in vitro and modulates its activity in a model of tauopathy. Proc Natl Acad Sci U S A. 2014;111(12):4584-9.

199. Sepulveda-Diaz JE, Alavi Naini SM, Huynh MB, Ouidja MO, Yanicostas C, Chantepie S, et al. HS3ST2 expression is critical for the abnormal phosphorylation of tau in Alzheimer's disease-related tau pathology. Brain. 2015;138(Pt 5):1339-54.

200. Bjorklund A, Dunnett SB. Dopamine neuron systems in the brain: an update. Trends Neurosci. 2007;30(5):194-202.

201. Jankovic J. Parkinson's disease: clinical features and diagnosis. J Neurol Neurosurg Psychiatry. 2008;79(4):368-76.

202. Xi Y, Yu M, Godoy R, Hatch G, Poitras L, Ekker M. Transgenic zebrafish expressing green fluorescent protein in dopaminergic neurons of the ventral diencephalon. Dev Dyn. 2011;240(11):2539-47.

203. Stednitz SJ, Freshner B, Shelton S, Shen T, Black D, Gahtan E. Selective toxicity of L-DOPA to dopamine transporter-expressing neurons and locomotor behavior in zebrafish larvae. Neurotoxicol Teratol. 2015;52(Pt A):51-6.

204. Godoy R, Noble S, Yoon K, Anisman H, Ekker M. Chemogenetic ablation of dopaminergic neurons leads to transient locomotor impairments in zebrafish larvae. J Neurochem. 2015;135(2):249-60.

205. Grunwald DJ, Eisen JS. Headwaters of the zebrafish-emergence of a new model vertebrate. Nat Rev Genet. 2002;3(9):717-24.

206. Drummond IA, Majumdar A, Hentschel H, Elger M, Solnica-Krezel L, Schier AF, et al. Early development of the zebrafish pronephros and analysis of mutations affecting pronephric function. Development. 1998;125(23):4655-67.

207. Drummond IA. The zebrafish pronephros: a genetic system for studies of kidney development. Pediatr Nephrol. 2000;14(5):428-35.

208. Tobin DM, May RC, Wheeler RT. Zebrafish: a see-through host and a fluorescent toolbox to probe host-pathogen interaction. Plos Pathog. 2012;8(1):e1002349.

209. Reimschuessel R. A fish model of renal regeneration and development. ILAR J. 2001;42(4):285-91.

210. Zhou W, Boucher RC, Bollig F, Englert C, Hildebrandt F. Characterization of mesonephric development and regeneration using transgenic zebrafish. Am J Physiol Renal Physiol. 2010;299(5):F1040-7.

211. Cianciolo Cosentino C, Roman BL, Drummond IA, Hukriede NA. Intravenous microinjections of zebrafish larvae to study acute kidney injury. J Vis Exp. 2010;42:2079.

212. Hentschel DM, Park KM, Cilenti L, Zervos AS, Drummond I, Bonventre $\mathrm{JV}$. Acute renal failure in zebrafish: a novel system to study a complex disease. Am J Physiol Renal Physiol. 2005;288(5):F923-9.

213. Johnson CS, Holzemer NF, Wingert RA. Laser ablation of the zebrafish pronephros to study renal epithelial regeneration. J Vis Exp. 2011:54:2845.

214. Perner B, Englert C. Immunofluorescence staining of Wt 1 on sections of zebrafish embryos and larvae. Methods Mol Biol. 2016;1467:129-32.

215. Perner B, Englert C, Bollig F. The Wilms tumor genes wt1a and wt $1 \mathrm{~b}$ control different steps during formation of the zebrafish pronephros. Dev Biol. 2007;309(1):87-96.
216. Bollig F, Mehringer R, Perner B, Hartung C, Schafer M, Schartl M, et al. Identification and comparative expression analysis of a second wt1 gene in zebrafish. Dev Dyn. 2006;235(2):554-61.

217. Gehrig J, Pandey G, Westhoff JH. Zebrafish as a model for drug screening in genetic kidney diseases. Front Pediatr. 2018;6:183.

218. Wingert RA, Davidson AJ. The zebrafish pronephros: a model to study nephron segmentation. Kidney Int. 2008;73(10):1120-7.

219. Westhoff JH, Giselbrecht S, Schmidts M, Schindler S, Beales PL, Tonshoff $B$, et al. Development of an automated imaging pipeline for the analysis of the zebrafish larval kidney. PLoS ONE. 2013;8(12):e82137.

220. Sanker S, Cirio MC, Vollmer LL, Goldberg ND, McDermott LA, Hukriede NA, et al. Development of high-content assays for kidney progenitor cell expansion in transgenic zebrafish. J Biomol Screen. 2013;18(10):1193-202.

221. Cirio MC, Hui Z, Haldin CE, Cosentino CC, Stuckenholz C, Chen X, et al. Lhx 1 is required for specification of the renal progenitor cell field. PLoS ONE. 2011;6(4):e18858.

222. Swanhart LM, Takahashi N, Jackson RL, Gibson GA, Watkins SC, Dawid IB, et al. Characterization of an Ihx1a transgenic reporter in zebrafish. Int J Dev Biol. 2010;54(4):731-6.

223. Diep CQ, Ma D, Deo RC, Holm TM, Naylor RW, Arora N, et al. Identification of adult nephron progenitors capable of kidney regeneration in zebrafish. Nature. 2011;470(7332):95-100.

224. Horsfield J, Ramachandran A, Reuter K, LaVallie E, Collins-Racie L, Crosier $\mathrm{K}$, et al. Cadherin-17 is required to maintain pronephric duct integrity during zebrafish development. Mech Dev. 2002;115(1-2):15-26.

225. Cianciolo Cosentino C, Skrypnyk NI, Brilli LL, Chiba T, Novitskaya T, Woods $C$, et al. Histone deacetylase inhibitor enhances recovery after AKI. J Am Soc Nephrol. 2013;24(6):943-53.

226. Wen XY, Cui LY, Morrisroe S, Maberry D, Emlet D, Watkins S, et al. A zebrafish model of infection-associated acute kidney injury. Am J Physiol Renal Physiol. 2018;315(2):F291-9.

227. Seiler C, Pack M. Transgenic labeling of the zebrafish pronephric duct and tubules using a promoter from the enpep gene. Gene Expr Patterns. 2011;11(1-2):118-21.

228. Bedell VM, Person AD, Larson JD, McLoon A, Balciunas D, Clark KJ, et al. The lineage-specific gene ponzr1 is essential for zebrafish pronephric and pharyngeal arch development. Development. 2012;139(4):793-804.

229. Ko YA, Yi H, Qiu C, Huang S, Park J, Ledo N, Kottgen A, et al. Genetic-variation-driven gene-expression changes highlight genes with important functions for kidney disease. Am J Hum Genet. 2017;100(6):940-53.

230. McCampbell KK, Springer KN, Wingert RA. Analysis of nephron composition and function in the adult zebrafish kidney. J Vis Exp. 2014;90:e51644.

231. Oltrabella F, Pietka G, Ramirez IB, Mironov A, Starborg T, Drummond IA, et al. The Lowe syndrome protein OCRL1 is required for endocytosis in the zebrafish pronephric tubule. PLoS Genet. 2015;11(4):e1005058.

232. Wang Y, Sun ZH, Zhou L, Li Z, Gui JF. Grouper tsh beta promoter-driven transgenic zebrafish marks proximal kidney tubule development. PLOS ONE. 2014;9(6):e97806.

233. Wang Z, Gu ZY, Hou Q, Chen WJ, Mu D, Zhang YX, et al. Zebrafish GSDMEb cleavage-gated pyroptosis drives septic acute kidney injury in vivo. J Immunol. 2020;204(7):1929-42.

234. He B, Ebarasi L, Hultenby K, Tryggvason K, Betsholtz C. Podocin-green fluorescence protein allows visualization and functional analysis of podocytes. J Am Soc Nephrol. 2011;22(6):1019-23.

235. Perisic L, Rodriguez PQ, Hultenby K, Sun Y, Lal M, Betsholtz C, et al. Schip1 is a novel podocyte foot process protein that mediates actin cytoskeleton rearrangements and forms a complex with Nherf2 and ezrin. PLoS ONE. 2015;10(3):e0122067.

236. Nishibori Y, Katayama K, Parikka M, Oddsson A, Nukui M, Hultenby $\mathrm{K}$, et al. Glcci1 deficiency leads to proteinuria. J Am Soc Nephrol. 2011;22(11):2037-46.

237. Carrasco-Rando M, Prieto-Sanchez S, Culi J, Tutor AS, Ruiz-Gomez M. A specific isoform of Pyd/ZO-1 mediates junctional remodeling and formation of slit diaphragms. J Cell Biol. 2019;218(7):2294-308.

238. He B, Ebarasi L, Zhao Z, Guo J, Ojala JR, Hultenby K, et al. Lm×1 b and FoxC combinatorially regulate podocin expression in podocytes. J Am Soc Nephrol. 2014;25(12):2764-77. 
239. Rodriguez PQ, Oddsson A, Ebarasi L, He B, Hultenby K, Wernerson A, et al. Knockdown of Tmem234 in zebrafish results in proteinuria. Am J Physiol Renal Physiol. 2015;309(11):F955-66.

240. Wan X, Lee MS, Zhou W. Dosage-dependent role of Rac1 in podocyte injury. Am J Physiol Renal Physiol. 2016;310(8):F777-84.

241. Zhou W, Hildebrandt F. Inducible podocyte injury and proteinuria in transgenic zebrafish. J Am Soc Nephrol. 2012;23(6):1039-47.

242. Gustafson EA, Wessel GM. Vasa genes: emerging roles in the germ line and in multipotent cells. BioEssays. 2010;32(7):626-37.

243. Krovel AV, Olsen LC. Expression of a vas::EGFP transgene in primordial germ cells of the zebrafish. Mech Dev. 2002;116(1-2):141-50.

244. Krovel AV, Olsen LC. Sexual dimorphic expression pattern of a splice variant of zebrafish vasa during gonadal development. Dev Biol. 2004;271(1):190-7.

245. Leu DH, Draper BW. The ziwi promoter drives germline-specific gene expression in zebrafish. Dev Dyn. 2010;239(10):2714-21.

246. Sreenivasan R, Jiang J, Wang X, Bartfai R, Kwan HY, Christoffels A, et al. Gonad differentiation in zebrafish is regulated by the canonical Wnt signaling pathway. Biol Reprod. 2014;90(2):45.

247. Qin M, Zhang Z, Song W, Wong QW, Chen W, Shirgaonkar N, et al. Roles of Figla/figla in juvenile ovary development and follicle formation during zebrafish gonadogenesis. Endocrinology. 2018;159(11):3699-722.

248. Houwing S, Berezikov E, Ketting RF. Zili is required for germ cell differentiation and meiosis in zebrafish. EMBO J. 2008:27(20):2702-11.

249. Huang HY, Houwing S, Kaaij LJ, Meppelink A, Redl S, Gauci S, et al. Tdrd1 acts as a molecular scaffold for Piwi proteins and piRNA targets in zebrafish. EMBO J. 2011:30(16):3298-308.

250. Crespo D, Lemos MS, Zhang YT, Safian D, Norberg B, Bogerd J, et al. PGE2 inhibits spermatogonia differentiation in zebrafish: interaction with Fsh and an androgen. J Endocrinol. 2020;244(1):163-75.

251. Nobrega RH, Morais RD, Crespo D, de Waal PP, de Franca LR, Schulz RW, et al. Fsh stimulates spermatogonial proliferation and differentiation in zebrafish via Igf3. Endocrinology. 2015;156(10):3804-17.

252. Kawasaki T, Saito K, Sakai C, Shinya M, Sakai N. Production of zebrafish offspring from cultured spermatogonial stem cells. Genes Cells. 2012;17(4):316-25.

253. Kawasaki T, Saito K, Shinya M, Olsen LC, Sakai N. Regeneration of spermatogenesis and production of functional sperm by grafting of testicular cell aggregates in Zebrafish (Danio rerio). Biol Reprod. 2010;83(4):533-9.

254. Presslauer C, Bizuayehu TT, Razmi K, Fernandes JM, Babiak I. SeeThru-Gonad zebrafish line: developmental and functional validation. Reproduction. 2016;152(5):507-17.

255. Draper BW, McCallum CM, Moens CB. nanos1 is required to maintain oocyte production in adult zebrafish. Dev Biol. 2007;305(2):589-98.

256. Houwing S, Kamminga LM, Berezikov E, Cronembold D, Girard A, van den Elst $\mathrm{H}$, et al. A role for Piwi and piRNAs in germ cell maintenance and transposon silencing in Zebrafish. Cell. 2007;129(1):69-82.

257. Beer RL, Draper BW. nanos 3 maintains germline stem cells and expression of the conserved germline stem cell gene nanos 2 in the zebrafish ovary. Dev Biol. 2013;374(2):308-18.

258. Dranow DB, Hu K, Bird AM, Lawry ST, Adams MT, Sanchez A, et al. Bmp15 is an oocyte-produced signal required for maintenance of the adult female sexual phenotype in zebrafish. PLoS Genet. 2016;12(9):e1006323.

259. Kaufman OH, Lee K, Martin M, Rothhamel S, Marlow FL. rbpms2 functions in Balbiani body architecture and ovary fate. PLoS Genet. 2018;14(7):e1007489.

260. Leerberg DM, Sano K, Draper BW. Fibroblast growth factor signaling is required for early somatic gonad development in zebrafish. PLoS Genet. 2017;13(9):e1006993.

261. Ye D, Zhu L, Zhang Q, Xiong F, Wang H, Wang X, et al. Abundance of early embryonic primordial germ cells promotes zebrafish female differentiation as revealed by lifetime labeling of germline. Mar Biotechnol (NY). 2019;21(2):217-28.

262. Feng $K$, Cui $X$, Song Y, Tao B, Chen J, Wang J, et al. Gnrh3 regulates PGC proliferation and sex differentiation in developing zebrafish. Endocrinology. 2020;161(1):bqz024

263. Zhang Q, Ye D, Wang H, Wang Y, Hu W, Sun Y. Zebrafish cyp11c1 Knockout Reveals the Roles of 11-ketotestosterone and Cortisol in Sexual Development and Reproduction. Endocrinology. 2020;161 (6):bqaa048.
264. Gautier A, Sohm F, Joly JS, Le Gac F, Lareyre JJ. The proximal promoter region of the zebrafish gsdf gene is sufficient to mimic the spatiotemporal expression pattern of the endogenous gene in Sertoli and granulosa cells. Biol Reprod. 2011;85(6):1240-51.

265. Fretaud M, Riviere L, Job E, Gay S, Lareyre JJ, Joly JS, et al. High-resolution 3D imaging of whole organ after clearing: taking a new look at the zebrafish testis. Sci Rep. 2017;7:43012.

266. Lickwar CR, Camp JG, Weiser M, Cocchiaro JL, Kingsley DM, Furey TS, et al. Genomic dissection of conserved transcriptional regulation in intestinal epithelial cells. PLoS Biol. 2017;15(8):e2002054.

267. Wallace AS, Burns AJ. Development of the enteric nervous system, smooth muscle and interstitial cells of Cajal in the human gastrointestinal tract. Cell Tissue Res. 2005;319(3):367-82.

268. Kuil LE, Chauhan RK, Cheng WW, Hofstra RMW, Alves MM. Zebrafish: a model organism for studying enteric nervous system development and disease. Front Cell Dev Biol. 2020;8:629073.

269. Her GM, Chiang CC, Wu JL. Zebrafish intestinal fatty acid binding protein (I-FABP) gene promoter drives gut-specific expression in stable transgenic fish. Genesis. 2004;38(1):26-31.

270. Her GM, Yeh YH, Wu JL. Functional conserved elements mediate intestinal-type fatty acid binding protein (I-FABP) expression in the gut epithelia of zebrafish larvae. Dev Dyn. 2004;230(4):734-42.

271. Okuda KS, Misa JP, Oehlers SH, Hall CJ, Ellett F, Alasmari S, et al. A zebrafish model of inflammatory lymphangiogenesis. Biol Open. 2015:4(10):1270-80.

272. Oehlers SH, Flores MV, Hall CJ, Crosier KE, Crosier PS. Retinoic acid suppresses intestinal mucus production and exacerbates experimental enterocolitis. Dis Model Mech. 2012;5(4):457-67.

273. Oehlers SH, Flores MV, Okuda KS, Hall CJ, Crosier KE, Crosier PS. A chemical enterocolitis model in zebrafish larvae that is dependent on microbiota and responsive to pharmacological agents. Dev Dyn. 2011;240(1):288-98.

274. Wang Z, Du J, Lam SH, Mathavan S, Matsudaira P, Gong Z. Morphological and molecular evidence for functional organization along the rostrocaudal axis of the adult zebrafish intestine. BMC Genomics. 2010;11:392.

275. Alvers AL, Ryan S, Scherz PJ, Huisken J, Bagnat M. Single continuous lumen formation in the zebrafish gut is mediated by smootheneddependent tissue remodeling. Development. 2014;141(5):1110-9.

276. Rodriguez-Fraticelli AE, Bagwell J, Bosch-Fortea M, Boncompain G, Reglero-Real N, Garcia-Leon MJ, et al. Developmental regulation of apical endocytosis controls epithelial patterning in vertebrate tubular organs. Nat Cell Biol. 2015;17(3):241-50.

277. Marjoram L, Alvers A, Deerhake ME, Bagwell J, Mankiewicz J, Cocchiaro $\mathrm{JL}$, et al. Epigenetic control of intestinal barrier function and inflammation in zebrafish. Proc Natl Acad Sci U S A. 2015;112(9):2770-5.

278. Solis CJ, Hamilton MK, Caruffo M, Garcia-Lopez JP, Navarrete P, Guillemin K, et al. Intestinal inflammation induced by soybean meal ingestion increases intestinal permeability and neutrophil turnover independently of microbiota in zebrafish. Front Immunol. 2020;11:1330.

279. Ye L, Mueller O, Bagwell J, Bagnat M, Liddle RA, Rawls JF. High fat diet induces microbiota-dependent silencing of enteroendocrine cells. Elife. 2019:8:e48479.

280. Harrison C, Wabbersen T, Shepherd IT. In vivo visualization of the development of the enteric nervous system using a $\mathrm{Tg}(-8.3 \mathrm{bphox} 2 \mathrm{~b}: K a e d e)$ transgenic zebrafish. Genesis. 2014;52(12):985-90.

281. El-Nachef WN, Bronner ME. De novo enteric neurogenesis in postembryonic zebrafish from Schwann cell precursors rather than resident cell types. Development. 2020;147(13):dev186619.

282. Uribe RA, Hong SS, Bronner ME. Retinoic acid temporally orchestrates colonization of the gut by vagal neural crest cells. Dev Biol. 2018:433(1):17-32.

283. Gui H, Schriemer D, Cheng WW, Chauhan RK, Antinolo G, Berrios C, et al. Whole exome sequencing coupled with unbiased functional analysis reveals new Hirschsprung disease genes. Genome Biol. 2017;18(1):48.

284. Sribudiani Y, Chauhan RK, Alves MM, Petrova L, Brosens E, Harrison C, et al. Identification of variants in RET and IHH pathway members in a large family with history of hirschsprung disease. Gastroenterology. 2018;155(1):118-29.e6. 
285. Holtta-Vuori M, Salo VT, Nyberg L, Brackmann C, Enejder A, Panula $P$, et al. Zebrafish: gaining popularity in lipid research. Biochem J. 2010;429(2):235-42.

286. Passeri MJ, Cinaroglu A, Gao C, Sadler KC. Hepatic steatosis in response to acute alcohol exposure in zebrafish requires sterol regulatory element binding protein activation. Hepatology. 2009;49(2):443-52.

287. Goldsmith JR, Jobin C. Think small: zebrafish as a model system of human pathology. J Biomed Biotechnol. 2012;2012:817341.

288. Tran S, Nowicki M, Chatterjee D, Gerlai R. Acute and chronic ethanol exposure differentially alters alcohol dehydrogenase and aldehyde dehydrogenase activity in the zebrafish liver. Prog Neuropsychopharmacol Biol Psychiatry. 2015;56:221-6.

289. Chu J, Sadler KC. New school in liver development: lessons from zebrafish. Hepatology. 2009;50(5):1656-63.

290. Ober EA, Field HA, Stainier DY. From endoderm formation to liver and pancreas development in zebrafish. Mech Dev. 2003;120(1):5-18.

291. Tao T, Peng J. Liver development in zebrafish (Danio rerio). J Genet Genomics. 2009;36(6):325-34.

292. Goessling W, Sadler KC. Zebrafish: an important tool for liver disease research. Gastroenterology. 2015;149(6):1361-77.

293. Vliegenthart AD, Tucker CS, Del Pozo J, Dear JW. Zebrafish as model organisms for studying drug-induced liver injury. Br J Clin Pharmacol. 2014;78(6):1217-27.

294. Kim SH, Wu SY, Baek Jl, Choi SY, Su Y, Flynn CR, et al. A post-developmental genetic screen for zebrafish models of inherited liver disease. PLOS ONE. 2015;10(5):e0125980.

295. Park KH, Kim SH. Low dose of chronic ethanol exposure in adult zebrafish induces hepatic steatosis and injury. Biomed Pharmacother. 2019;117:109179.

296. Park KH, Ye ZW, Zhang J, Kim SH. Palmitic acid-enriched diet induces hepatic steatosis and injury in adult zebrafish. Zebrafish. 2019;16(6):497-504.

297. Her GM, Chiang CC, Chen WY, Wu JL. In vivo studies of liver-type fatty acid binding protein (L-FABP) gene expression in liver of transgenic zebrafish (Danio rerio). FEBS Lett. 2003:538(1-3):125-33.

298. Goessling W, North TE, Lord AM, Ceol C, Lee S, Weidinger G, et al. APC mutant zebrafish uncover a changing temporal requirement for wht signaling in liver development. Dev Biol. 2008;320(1):161-74.

299. Li YH, Chen MH, Gong HY, Hu SY, Li YW, Lin GH, et al. Progranulin A-mediated MET signaling is essential for liver morphogenesis in zebrafish. J Biol Chem. 2010;285(52):41001-9.

300. Amali AA, Rekha RD, Lin CJ, Wang WL, Gong HY, Her GM, et al. Thioacetamide induced liver damage in zebrafish embryo as a disease model for steatohepatitis. J Biomed Sci. 2006;13(2):225-32.

301. Zhang Y, Liu K, Hassan HM, Guo H, Ding P, Han L, et al. Liver fatty acid binding protein deficiency provokes oxidative stress, inflammation, and apoptosis-mediated hepatotoxicity induced by pyrazinamide in zebrafish larvae. Antimicrob Agents Chemother. 2016;60(12):7347-56.

302. Huo J, Yu Q, Zhang Y, Liu K, Hsiao CD, Jiang Z, et al. Triptolide-induced hepatotoxicity via apoptosis and autophagy in zebrafish. J Appl Toxicol. 2019;39(11):1532-40.

303. Dong PD, Munson CA, Norton W, Crosnier C, Pan X, Gong Z, et al. Fgf10 regulates hepatopancreatic ductal system patterning and differentiation. Nat Genet. 2007;39(3):397-402.

304. Parsons MJ, Pisharath H, Yusuff S, Moore JC, Siekmann AF, Lawson N, et al. Notch-responsive cells initiate the secondary transition in larval zebrafish pancreas. Mech Dev. 2009;126(10):898-912.

305. Zhang D, Gates KP, Barske L, Wang G, Lancman JJ, Zeng XI, et al. Endoderm jagged induces liver and pancreas duct lineage in zebrafish. Nat Commun. 2017:8(1):769.

306. Liu LY, Alexa K, Cortes M, Schatzman-Bone S, Kim AJ, Mukhopadhyay B, et al. Cannabinoid receptor signaling regulates liver development and metabolism. Development. 2016;143(4):609-22.

307. Khaliq M, Choi TY, So J, Shin D. Id2a is required for hepatic outgrowth during liver development in zebrafish. Mech Dev. 2015;38(Pt 3):399-414.

308. Wilkins BJ, Gong W, Pack M. A novel keratin 18 promoter that drives reporter gene expression in the intrahepatic and extrahepatic biliary system allows isolation of cell-type specific transcripts from zebrafish liver. Gene Expr Patterns. 2014;14(2):62-8.
309. Tsedensodnom O, Vacaru AM, Howarth DL, Yin C, Sadler KC. Ethanol metabolism and oxidative stress are required for unfolded protein response activation and steatosis in zebrafish with alcoholic liver disease. Dis Model Mech. 2013;6(5):1213-26.

310. Howarth DL, Yin C, Yeh K, Sadler KC. Defining hepatic dysfunction parameters in two models of fatty liver disease in zebrafish larvae. Zebrafish. 2013;10(2):199-210.

311. Huang M, Chang A, Choi M, Zhou D, Anania FA, Shin CH. Antagonistic interaction between Wnt and Notch activity modulates the regenerative capacity of a zebrafish fibrotic liver model. Hepatology. 2014;60(5):1753-66.

312. Zhang C, Ellis JL, Yin C. Inhibition of vascular endothelial growth factor signaling facilitates liver repair from acute ethanol-induced injury in zebrafish. Dis Model Mech. 2016;9(11):1383-96.

313. Wan H, Korzh S, Li Z, Mudumana SP, Korzh V, Jiang YJ, et al. Analyses of pancreas development by generation of gfp transgenic zebrafish using an exocrine pancreas-specific elastaseA gene promoter. Exp Cell Res. 2006:312(9):1526-39.

314. Zecchin E, Filippi A, Biemar F, Tiso N, Pauls S, Ellertsdottir E, et al. Distinct delta and jagged genes control sequential segregation of pancreatic cell types from precursor pools in zebrafish. Dev Biol. 2007;301(1):192-204.

315. Flanagan-Steet H, Fox MA, Meyer D, Sanes JR. Neuromuscular synapses can form in vivo by incorporation of initially aneural postsynaptic specializations. Development. 2005;132(20):4471-81.

316. Arkhipova V, Wendik B, Devos N, Ek O, Peers B, Meyer D. Characterization and regulation of the $\mathrm{hb} / \mathrm{mn \times} \times 1$ beta-cell progenitor specific enhancer in zebrafish. Dev Biol. 2012;365(1):290-302.

317. Anderson RM, Bosch JA, Goll MG, Hesselson D, Dong PD, Shin D, et al. Loss of Dnmt1 catalytic activity reveals multiple roles for DNA methylation during pancreas development and regeneration. Dev Biol. 2009;334(1):213-23.

318. Andersson O, Adams BA, Yoo D, Ellis GC, Gut P, Anderson RM, et al. Adenosine signaling promotes regeneration of pancreatic beta cells in vivo. Cell Metab. 2012;15(6):885-94.

319. Chung WS, Andersson O, Row R, Kimelman D, Stainier DY. Suppression of Alk8-mediated Bmp signaling cell-autonomously induces pancreatic beta-cells in zebrafish. Proc Natl Acad Sci U S A. 2010;107(3):1142-7.

320. Field HA, Ober EA, Roeser T, Stainier DY. Formation of the digestive system in zebrafish I. Liver morphogenesis. Dev Biol. 2003;253(2):279-90.

321. Field HA, Dong PS, Beis D, Stainier DY. Formation of the digestive system in zebrafish. Il pancreas morphogenesis Dev Biol. 2003;261(1):197-208.

322. Ng AN, de Jong-Curtain TA, Mawdsley DJ, White SJ, Shin J, Appel B, et al. Formation of the digestive system in zebrafish: III. Intestinal epithelium morphogenesis. Dev Biol. 2005;286(1):114-35.

323. Dong PDS, Provost E, Leach SD, Stainier DY. Graded levels of Ptf1a differentially regulate endocrine and exocrine fates in the developing pancreas. Genes Dev. 2008;22(11):1445-50.

324. Makky K, Tekiela J, Mayer AN. Target of rapamycin (TOR) signaling controls epithelial morphogenesis in the vertebrate intestine. Dev Biol. 2007:303(2):501-13.

325. Yin C, Evason KJ, Maher JJ, Stainier DY. The basic helix-loop-helix transcription factor, heart and neural crest derivatives expressed transcript 2, marks hepatic stellate cells in zebrafish: analysis of stellate cell entry into the developing liver. Hepatology. 2012;56(5):1958-70.

326. Scholpp S. Introduction: in vivo cell biology in zebrafish. Histochem Cell Biol. 2020;154(5):457-61.

327. Cox NJ, Unlu G, Bisnett BJ, Meister TR, Condon BM, Luo PM, et al. Dynamic glycosylation governs the vertebrate COPII protein trafficking pathway. Biochemistry. 2018;57(1):91-107.

328. Unlu G, Levic DS, Melville DB, Knapik EW. Trafficking mechanisms of extracellular matrix macromolecules: insights from vertebrate development and human diseases. Int J Biochem Cell Biol. 2014;47:57-67.

329. Schapira AH. Mitochondrial disease. Lancet. 2006;368(9529):70-82.

330. De Matteis MA, Luini A. Mendelian disorders of membrane trafficking. N Engl J Med. 2011;365(10):927-38.

331. Wu S-Y, Zou P, Fuller AW, Mishra S, Wang Z, Schey KL, et al. Expression of cataract-linked $\gamma$-crystallin variants in zebrafish reveals a proteostasis network that senses protein stability. J Biol Chem. 2016;291(49):25387-97. 
332. Kobayashi I, Kondo M, Yamamori S, Kobayashi-Sun J, Taniguchi M, Kanemaru K, et al. Enrichment of hematopoietic stem/progenitor cells in the zebrafish kidney. Sci Rep. 2019;9(1):14205.

333. Zhang W, Roy S. The zebrafish fast myosin light chain mylpfa:H2B-GFP transgene is a useful tool for in vivo imaging of myocyte fusion in the vertebrate embryo. Gene Expr Patterns. 2016;20(2):106-10.

334. Isabella AJ, Barsh GR, Stonick JA, Dubrulle J, Moens CB. Retinoic acid organizes the Zebrafish Vagus motor topographic map via spatiotemporal coordination of Hgf/met signaling. Dev Cell. 2020;53(3):344-57.e5.

335. Kawakami K. Transposon tools and methods in zebrafish. Dev Dyn. 2005;234(2):244-54.

336. Gerhart SV, Eble DM, Burger RM, Oline SN, Vacaru A, Sadler KC, et al. The Cx43-like connexin protein Cx40.8 is differentially localized during fin ontogeny and fin regeneration. PLoS ONE. 2012;7(2):e31364.

337. George AA, Hayden S, Holzhausen LC, Ma EY, Suzuki SC, Brockerhoff SE. Synaptojanin 1 is required for endolysosomal trafficking of synaptic proteins in cone photoreceptor inner segments. PLoS ONE. 2014;9(1):e84394.

338. George AA, Hayden S, Stanton GR, Brockerhoff SE. Arf6 and the 5' phosphatase of synaptojanin 1 regulate autophagy in cone photoreceptors. BioEssays. 2016;38(Suppl 1):S119-35.

339. Mitra S, Cheng KW, Mills GB. Rab GTPases implicated in inherited and acquired disorders. Semin Cell Dev Biol. 2011;22(1):57-68.

340. Zhang J, Schulze KL, Hiesinger PR, Suyama K, Wang S, Fish M, et al. Thirty-one flavors of Drosophila rab proteins. Genetics. 2007;176(2):1307-22.

341. Clark BS, Winter M, Cohen AR, Link BA. Generation of Rab-based transgenic lines for in vivo studies of endosome biology in zebrafish. Dev Dyn. 2011;240(11):2452-65.

342. Chavrier P, Vingron M, Sander C, Simons K, Zerial M. Molecular cloning of YPT1/SEC4-related cDNAs from an epithelial cell line. Mol Cell Biol. 1990;10(12):6578-85.

343. Thisse B, Heyer V, Lux A, Alunni V, Degrave A, Seiliez I, et al. Spatial and temporal expression of the zebrafish genome by large-scale in situ hybridization screening. Methods Cell Biol. 2004;77:505-19.

344. Hagemann Al, Kurz J, Kauffeld S, Chen Q, Reeves PM, Weber S, et al. In vivo analysis of formation and endocytosis of the Wnt/beta-catenin signaling complex in zebrafish embryos. J Cell Sci. 2014;127(Pt 18):3970-82.

345. Huang J, Klionsky DJ. Autophagy and human disease. Cell Cycle. 2007:6(15):1837-49.

346. Martinet W, Knaapen MW, Kockx MM, De Meyer GR. Autophagy in cardiovascular disease. Trends Mol Med. 2007;13(11):482-91.

347. Mizushima N, Levine B, Cuervo AM, Klionsky DJ. Autophagy fights disease through cellular self-digestion. Nature. 2008;451(7182):1069-75.

348. Sasaki T, Lian S, Qi J, Bayliss PE, Carr CE, Johnson JL, et al. Aberrant autolysosomal regulation is linked to the induction of embryonic senescence: differential roles of Beclin 1 and p53 in vertebrate Spns1 deficiency. PLoS Genet. 2014;10(6):e1004409.

349. He C, Bartholomew CR, Zhou W, Klionsky DJ. Assaying autophagic activity in transgenic GFP-Lc3 and GFP-Gabarap zebrafish embryos. Autophagy. 2009;5(4):520-6.

350. Lee $E$, Koo Y, Ng A, Wei Y, Luby-Phelps K, Juraszek A, et al. Autophagy is essential for cardiac morphogenesis during vertebrate development. Autophagy. 2014;10(4):572-87.

351. Cui J, Sim TH, Gong Z, Shen HM. Generation of transgenic zebrafish with liver-specific expression of EGFP-LC3: a new in vivo model for investigation of liver autophagy. Biochem Biophys Res Commun. 2012;422(2):268-73
352. Kaizuka T, Morishita H, Hama Y, Tsukamoto S, Matsui T, Toyota Y, et al. An autophagic flux probe that releases an internal control. Mol Cell. 2016;64(4):835-49.

353. Chen XK, Kwan JS, Chang RC, Ma AC. 1-phenyl 2-thiourea (PTU) activates autophagy in zebrafish embryos. Autophagy. 2021;17(5):1222-31.

354. Morishita H, Kanda Y, Kaizuka T, Chino H, Nakao K, Miki Y, et al. Autophagy is required for maturation of surfactant-containing lamellar bodies in the lung and swim bladder. Cell Rep. 2020;33(10):108477.

355. Bock FJ, Tait SWG. Mitochondria as multifaceted regulators of cell death. Nat Rev Mol Cell Biol. 2020;21(2):85-100.

356. Urasaki A, Morvan G, Kawakami K. Functional dissection of the Tol2 transposable element identified the minimal cis-sequence and a highly repetitive sequence in the subterminal region essential for transposition. Genetics. 2006;174(2):639-49.

357. Kim MJ, Kang KH, Kim CH, Choi SY. Real-time imaging of mitochondria in transgenic zebrafish expressing mitochondrially targeted GFP. Biotechniques. 2008;45(3):331-4.

358. Sakowski SA, Lunn JS, Busta AS, Palmer M, Dowling JJ, Feldman EL. A novel approach to study motor neurons from zebrafish embryos and larvae in culture. J Neurosci Methods. 2012;205(2):277-82.

359. Kramer AC, Weber J, Zhang Y, Tolar J, Gibbens YY, Shevik M, et al. TP53 modulates oxidative stress in gata1(+) erythroid cells. Stem Cell Rep. 2017;8(2):360-72.

360. Crespo C, Knust E. Characterisation of maturation of photoreceptor cell subtypes during zebrafish retinal development. Biol Open. 2018;7(11):bio036632.

361. Sokol AM, Uszczynska-Ratajczak B, Collins MM, Bazala M, Topf U, Lundegaard PR, et al. Loss of the Mia40a oxidoreductase leads to hepatopancreatic insufficiency in zebrafish. PLoS Genet. 2018;14(11):e1007743.

362. Daniel K, Icha J, Horenburg C, Muller D, Norden C, Mansfeld J. Conditional control of fluorescent protein degradation by an auxin-dependent nanobody. Nat Commun. 2018;9(1):3297.

363. Lindberg CD, Di Giulio RT. Polycyclic aromatic hydrocarbon and hypoxia exposures result in mitochondrial dysfunction in zebrafish. Aquat Toxicol. 2019;216:105298.

364. Dukes AA, Bai Q, Van Laar VS, Zhou Y, Ilin V, David CN, et al. Live imaging of mitochondrial dynamics in CNS dopaminergic neurons in vivo demonstrates early reversal of mitochondrial transport following MPP(+) exposure. Neurobiol Dis. 2016;95:238-49.

365. Noble S, Godoy R, Affaticati P, Ekker M. Transgenic zebrafish expressing mCherry in the mitochondria of dopaminergic neurons. Zebrafish. 2015;12(5):349-56.

366. Xu Y, Chen M, Hu B, Huang R, Hu B. In vivo imaging of mitochondrial transport in single-axon regeneration of Zebrafish Mauthner cells. Front Cell Neurosci. 2017;11:4.

367. Princely Abudu Y, Pankiv S, Mathai BJ, Hakon Lystad A, Bindesboll C, Brenne HB, et al. NIPSNAP1 and NIPSNAP2 act as "eat me" signals for mitophagy. Dev Cell. 2019;49(4):509-25.e12.

368. Tian W, Czopka T, Lopez-Schier H. Systemic loss of Sarm 1 protects Schwann cells from chemotoxicity by delaying axon degeneration. Commun Biol. 2020;3(1):49.

\section{Publisher's Note}

Springer Nature remains neutral with regard to jurisdictional claims in published maps and institutional affiliations. 